\title{
Circularity in Mixed Plastics Chemical Recycling Enabled by Variable Rates of Polydiketoenamine Hydrolysis
}

Jérémy Demarteau ${ }^{1}$, Alexander R. Epstein ${ }^{2}$, Peter R. Christensen ${ }^{l}$, Mark Abubekerov ${ }^{l}$, Hai Wang ${ }^{l}$, Simon J. Teat ${ }^{3}$, Trevor J. Seguin ${ }^{4}$, Christopher W. Chan ${ }^{1}$, Corinne D. Scown ${ }^{5,6,7,8}$, Thomas P. Russell $^{4,9,10}$, Jay D. Keasling ${ }^{5,6,11,12,13}$, Kristin A. Persson ${ }^{1,2}$, Brett A. Helms ${ }^{1,4,14 *}$

\author{
Affiliations: \\ ${ }^{1}$ The Molecular Foundry, Lawrence Berkeley National Laboratory, Berkeley, CA 94720 USA. \\ ${ }^{2}$ Materials Sciences and Engineering, University of California, Berkeley, CA 94720 USA. \\ ${ }^{3}$ Advanced Light Source, Lawrence Berkeley National Laboratory, Berkeley, CA 94720 USA. \\ ${ }^{4}$ Materials Sciences Division, Lawrence Berkeley National Laboratory, Berkeley, CA 94720 \\ USA. \\ ${ }^{5}$ Joint BioEnergy Institute, Emeryville, California 94608 USA. \\ ${ }^{6}$ Biological Systems and Engineering Division, Lawrence Berkeley National Laboratory, \\ Berkeley, California 94720 USA. \\ ${ }^{7}$ Energy Analysis and Environmental Impacts Division, Lawrence Berkeley National Laboratory, \\ Berkeley, California 94720, United States \\ ${ }^{8}$ Energy \& Biosciences Institute, University of California, Berkeley, California 94720 USA \\ ${ }^{9}$ Polymer Science and Engineering Department, University of Massachusetts, Amherst, MA \\ 01003 USA.
}

${ }^{10}$ World Premier Institute-Advanced Institute for Materials Research, Tohoku University, Sendai 980-8577, Japan

${ }^{11}$ Department of Chemical and Biomolecular Engineering \& Department of Bioengineering, University of California, Berkeley, California 94720 USA.

${ }^{12}$ Center for Synthetic Biochemistry, Institute for Synthetic Biology, Shenzhen Institutes of Advanced Technologies, Shenzhen 518055, China

${ }^{13}$ Novo Nordisk Foundation Center for Biosustainability, Technical University of Denmark, Lyngby, Denmark

${ }^{14}$ Chemical Sciences Division, Lawrence Berkeley National Laboratory, Berkeley, CA 94720 USA.

*Correspondence to: bahelms@lbl.gov. 


\begin{abstract}
:
Footwear, carpet, soft furnishings, automotive interiors, and multi-layer packaging are examples of products manufactured from several types of polymers whose inextricability poses significant challenges for recycling at end-of-life. Here, we show that chemical circularity in mixed-polymer recycling becomes possible by controlling the rates of depolymerization of polydiketoenamines (PDKs) over several orders of magnitude through molecular engineering. Stepwise deconstruction of mixed-PDK composites, laminates, and assemblies is chemospecific, allowing a prescribed subset of monomers, fillers, and additives to be recovered in pristine condition at each stage of the recycling process. We provide a theoretical framework to understand PDK depolymerization via acid-catalyzed hydrolysis and experimentally validate trends predicted for the rate-limiting step. The control achieved by PDKs in managing thermal and materials entropy points to new opportunities for pairing circular design with sustainable manufacturing.
\end{abstract}

One Sentence Summary: Circularity in mixed-polymer recycling.

Polydiketoenamine variants address the challenge of recycling products made from several polymers to reusable feedstocks for sustainable manufacturing.

\title{
Main Text:
}

Products manufactured from two or more blended or laminated polymer resins are ubiquitous and present obstacles to chemical recycling due to the difficulty in and cost of deconstructing each polymer to their respective monomers for re-use in manufacturing supply chains (1-3). Recycling efforts are further challenged when such products also include metals or glass, e.g., as complex assemblies bonded together using adhesives or fixtures (4-6). The inability to recover valuable chemical and materials resources from these products at end-of-useful-life is both wasteful and unsustainable (7-12). Furthermore, the accumulation and leakage of non-recyclable mixedpolymer and mixed-material waste in the environment continues to strain global ecosystems (1317).

Here, we show that chemospecificity in mixed-polymer recycling is achievable through molecular engineering of polydiketoenamines (PDKs) $(18,19)$ where fast- and slow-to-depolymerize PDK chemistries incorporated into either mixed-polymer or mixed-material products allow each PDK variant to be selectively deconstructed in space and time simply by varying the depolymerization temperature under acidic conditions (Fig. 1a). At each stage of a thermally-controlled recycling process, we recover specific monomers, additives, and fillers from PDK resins in either mixedPDK blends, laminates, or assemblies that are indistinguishable from the associated primary feedstocks and re-usable in closed-loop materials lifecycles (Fig. 1b,c). The predictability and control afforded by PDKs in multi-stage chemical recycling suggest a common infrastructure may be used to recycle complex products that would normally be considered non-recyclable. Because specialized plastic recycling infrastructure is capital-intensive (20), a general process that handles a variety of materials - from polymers and thermosets to composites-could offer economic advantages and even enable recycling in industries that produce durable goods. If implemented, PDKs could relax a growing number of constraints faced by supply chain managers and product designers when making materials choices for circularity to meet their sustainability goals $(21,22)$ 
to reduce the need for virgin resin. Pairing recycle-by-design chemistries with customer-focused take-back schemes is also poised to improve industrial materials efficiency.
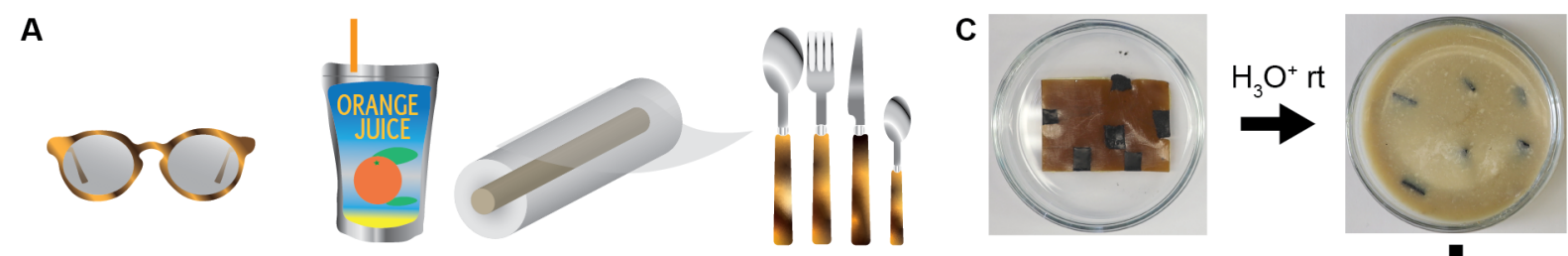

B
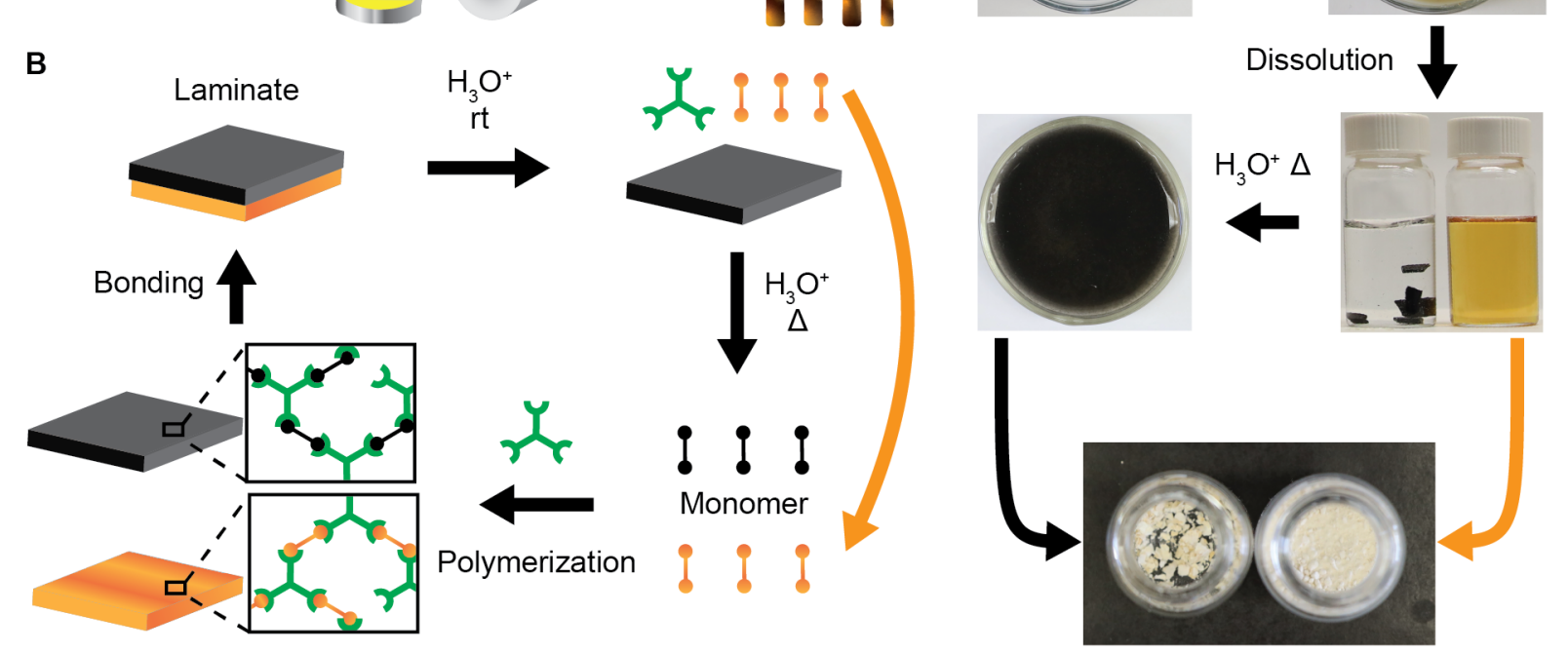

Fig. 1. Closed-Loop chemical recycling of mixed-polymer waste. (A) Examples of consumer products featuring several polymer resins whose inextricability poses challenges to recycling at end-of-life for resource recovery. (B) Mixed-Polymer recycling can be realized if each polymer were to undergo chemical depolymerization at a different temperature, allowing specific monomers to be recovered in successive stages of the recycling process. These monomers may then be used in secondary polymer resin manufacturing processes to reduce the demand for primary chemical feedstocks. (C) Realization of mixed-polymer recycling with polydiketoenamines (PDKs), where molecular engineering of diketoenamine polymer bonds enables fine-control over polymerization rates in strong acid. Each PDK variant is deconstructed in a chemospecific manner simply by varying the depolymerization temperature.

\section{Molecular-Engineering of triketone monomers yields structurally diverse PDK resins}

PDKs are synthesized from polytopic triketone and amine monomers via spontaneous "click" polycondensation reactions $(18,19)$, which proceed under ambient conditions and do not require a promoter. The properties of PDKs are similar to those of nylons and polyurethanes, yet bridge those of plastics and thermosets due to their dynamic covalent character $(18,19,23-26)$. While the formulation space for tailoring PDK properties is broad, resins formulated with structurally similar triketone monomers depolymerize at similar rates. For example, while changing the carbon chain length in triketone monomers used to synthesize PDK 1 resins changes their glass transition temperature and other characteristics (Fig. 2), it does not significantly change the rate of their chemical depolymerization to monomer, which is complete in $\sim 12 \mathrm{~h}$ at $25{ }^{\circ} \mathrm{C}$, or in $\sim 1 \mathrm{~h}$ at $90{ }^{\circ} \mathrm{C}$ in $5.0 \mathrm{M} \mathrm{H}_{2} \mathrm{SO}_{4}$ or $\mathrm{HCl}$ (18). To differentiate the rates of PDK depolymerization, we designed PDKs 2-4, which vary in number and placement of heteroatoms relative to the keto functionality 
in the ring (Fig. 2a). In doing so, we anticipated that their distinctive susceptibility for diketoenamine hydrolysis could give rise to orthogonal rates of PDK depolymerization, which would enable step-wise recovery of the embodied resources in mixed-PDK and mixed-material waste streams during chemical recycling.

In pursuit of this goal, we synthesized PDKs 1-4 from a cohesive group of ditopic triketone monomers 1-4 and tris(2-aminoethyl)amine (TREN) (Fig. 2a). As evidenced from single crystal X-ray diffraction (XRD) data (Fig. 2b), the preferred tautomer of triketone monomers 2-4 features an exocyclic enol, whereas that for triketone 1 features an endocyclic enol. Furthermore, the degree of asymmetry in hydrogen bonding highlights notable differences in electronegativity for $O$ centered hydrogen-bond acceptors and donors, with triketones $\mathbf{1}$ and $\mathbf{4}$ showing significant yet opposite asymmetries in hydrogen bonding by comparison to the more symmetric triketone $\mathbf{2}$ (Tables S1-5). Despite these differences, a common and unifying structure for the diketoenamine bond in all PDK resins is evident in XRD data of small molecule analogues (Fig. S1 and Table S6) (18). PDKs 1-4 obtained after ball-mill polymerization were micron-sized dispersible powders (Fig. S2) and therefore suitable for pelletization or molding (Fig. 2c). Differential scanning calorimetry showed glass transition temperatures $\left(T_{\mathrm{g}}\right)$ of $96,98,104$, and $136{ }^{\circ} \mathrm{C}$ for PDKs $\mathbf{1}-\mathbf{4}$ (Figs. S3-6), respectively, with only slight variations in modulus $\left(E^{\prime}\right)$ in either the glassy state $(1.8-2.1 \mathrm{GPa})$ or rubbery state $(5.3-6.9 \mathrm{MPa})$ as determined by dynamic mechanical analysis (Table S7).

A
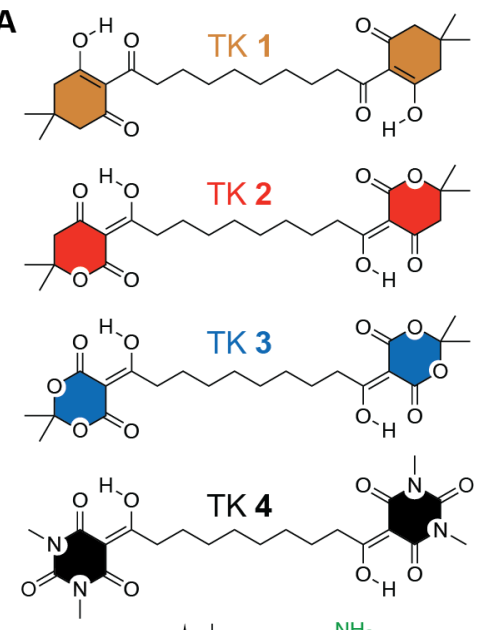

- TREN $+\mathrm{H}_{3} \mathrm{O}^{+} \uparrow \mid-\mathrm{H}_{2} \mathrm{O} \overbrace{\mathrm{H}_{2} \mathrm{~N}}^{\mathrm{NH}_{2}} \overbrace{\mathrm{NH}_{2}}^{\mathrm{N}}$

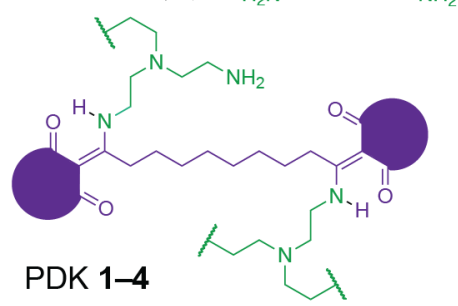

B
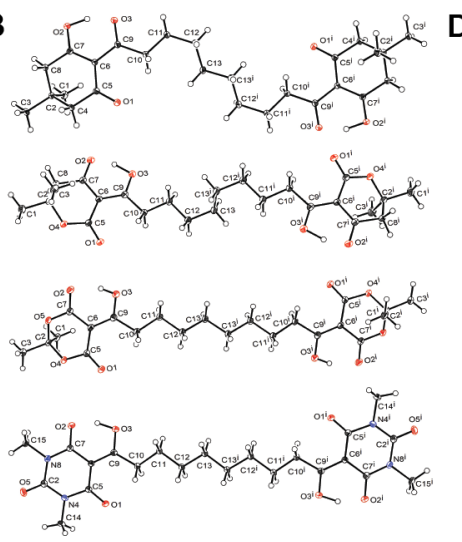

C Compression-Molded PDK

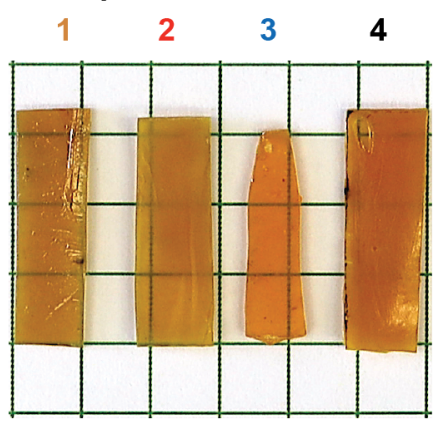

Temperature-Controlled PDK Recycling

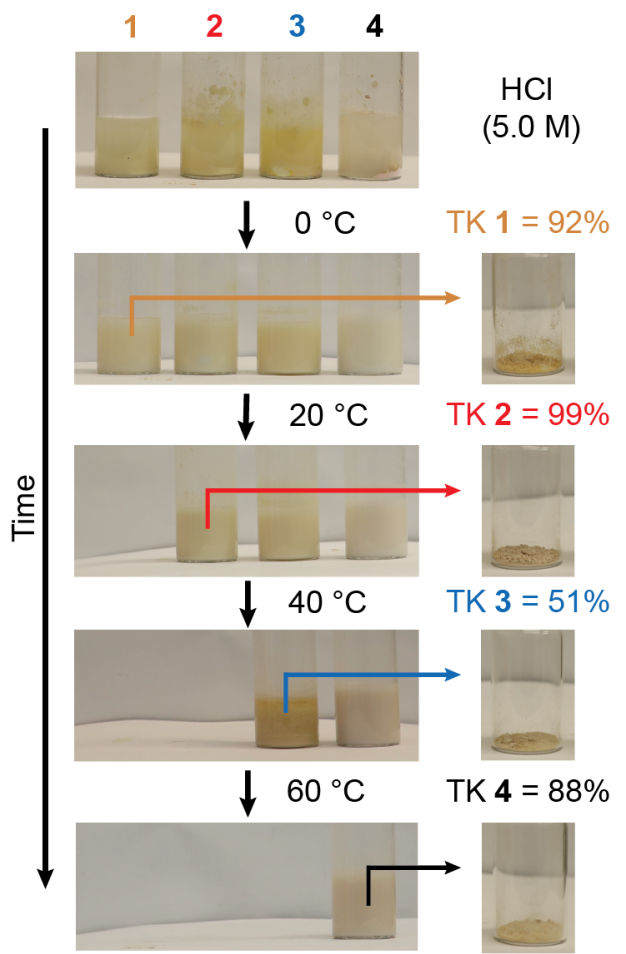

Fig. 2. Molecularly-Engineered PDKs are depolymerized selectively and iteratively at different temperatures. (A) Triketone monomers 1-4 and their use in the chemical synthesis of PDKs $\mathbf{1 - 4}$ by polycondensation with tris(2-aminoethyl)amine (TREN). (B) Single-crystal X-ray structures for triketones 1-4 show distinctive packing in the solid-state and structure-dependent 
hydrogen-bond symmetry and preferred tautomer. (C) Compression-molded samples of PDKs 14. (D) Chemospecific recycling of PDKs 1-4 to triketone and TREN monomers in $5.0 \mathrm{M} \mathrm{HCl}$ at $0,20,40$, and $60{ }^{\circ} \mathrm{C}$. Triketone monomers are recovered in pristine quality from PDKs $\mathbf{1}, \mathbf{2}$, and $\mathbf{4}$ (Figs. S7-10) and in high yield; recovery of triketone 3 was lower due to transformation of some of its chain ends to $\beta$-keto acids.

\section{PDK variants depolymerize to monomer at different temperatures}

To assess the rates of chemical depolymerization of PDKs 1-4, we dispersed the resin powders in strong acid (e.g., $5.0 \mathrm{M}$ aqueous $\mathrm{HCl}$ ) for up to $24 \mathrm{~h}$ at either $0,20,40$, or $60^{\circ} \mathrm{C}$ (Fig. 2d). PDK 1 was exclusively depolymerized at $0{ }^{\circ} \mathrm{C}$ to monomer (92\% recovery), whereas PDK 2 was depolymerized at $20{ }^{\circ} \mathrm{C}$ to monomer with $99 \%$ recovery. Elevated temperature was required to depolymerize PDK $3\left(51 \%\right.$ recovery at $\left.40{ }^{\circ} \mathrm{C}\right)$ and PDK $4\left(88 \%\right.$ recovery at $\left.60^{\circ} \mathrm{C}\right)$. Notably, while triketones 1, 2, and $\mathbf{4}$ were recovered from their corresponding PDKs in pristine condition (i.e., indistinguishable from the monomer used in primary resin production), triketone $\mathbf{3}$ showed signs of transformation to a ß-keto acid in strong acid at elevated temperature (Figs. S7-10). In all cases, TREN can recovered quantitatively from the filtrate after neutralization with a basic ion-exchange resin (18). Together, these data confirmed our hypothesis that varying the structure and electronics of the diketoenamine could enable variable rates of PDK depolymerization to monomer. The data further suggest that chemically recycling mixtures of resins is possible, permitting the recovery of two or more triketone monomers from TREN in consecutive yet fully closed-loops (Fig. 1).

\section{Torsional strain dictates activation barrier to diketoenamine hydrolysis in strong acid}

To understand the contrasting rates of PDK depolymerization to monomer, we carried out DFT simulations of the reaction coordinates for acid-catalyzed hydrolysis of small molecule diketoenamines 1-4 (Fig. 3 and Figs. S11-13), which represent the cleavable bonds in PDKs 14, respectively. Hydrolysis proceeds by an addition-elimination mechanism and features transition states corresponding to the addition of water to the acid-activated diketoenamine and the collapse of the tetrahedral hemiaminal to eliminate an alkylammonium and regenerate the triketone (Fig. 3a). We modeled all reactions in a continuum solvent from an initial state consisting of a hydronium ion and a reactive diketoenamine, whose $\mathrm{N}, \mathrm{N}$-dimethylaminoethyl moiety was protonated as it would be in strong acid. We optimized all molecular geometries using the m06$2 \mathrm{X} / 6-311++\mathrm{G}(2 \mathrm{df}, 2 \mathrm{p}) / \mathrm{SMD}$ level of theory $(27,28)$ and calculated free energies with the quasiRRHO model (Table S8) (29). We found that protonation of the diketoenamine triggers the formation of an iminium, which rotates out-of-plane in advance of the addition of water in the ratelimiting step. Notably, the calculated standard free energies of activation $\left(\Delta G^{\ddagger}\right)$ for the addition of water to the iminium vary by as much as $18 \mathrm{~kJ} \mathrm{~mol}^{-1}$ between diketoenamine variants (Fig. 3a) and trends are consistent with the observed differences in rates of depolymerization. We also found that differences in $\Delta G^{\ddagger}$ are highly dependent on the energy barrier associated with rotating the iminium into the transition state geometry. Specifically, potential energy barriers for rotation $\left(E_{\text {tor }}\right)$ of the iminium dihedral display the same trend as $\Delta G^{\ddagger}$ across diketoenamines 1-4 (Fig. 3b). 
A
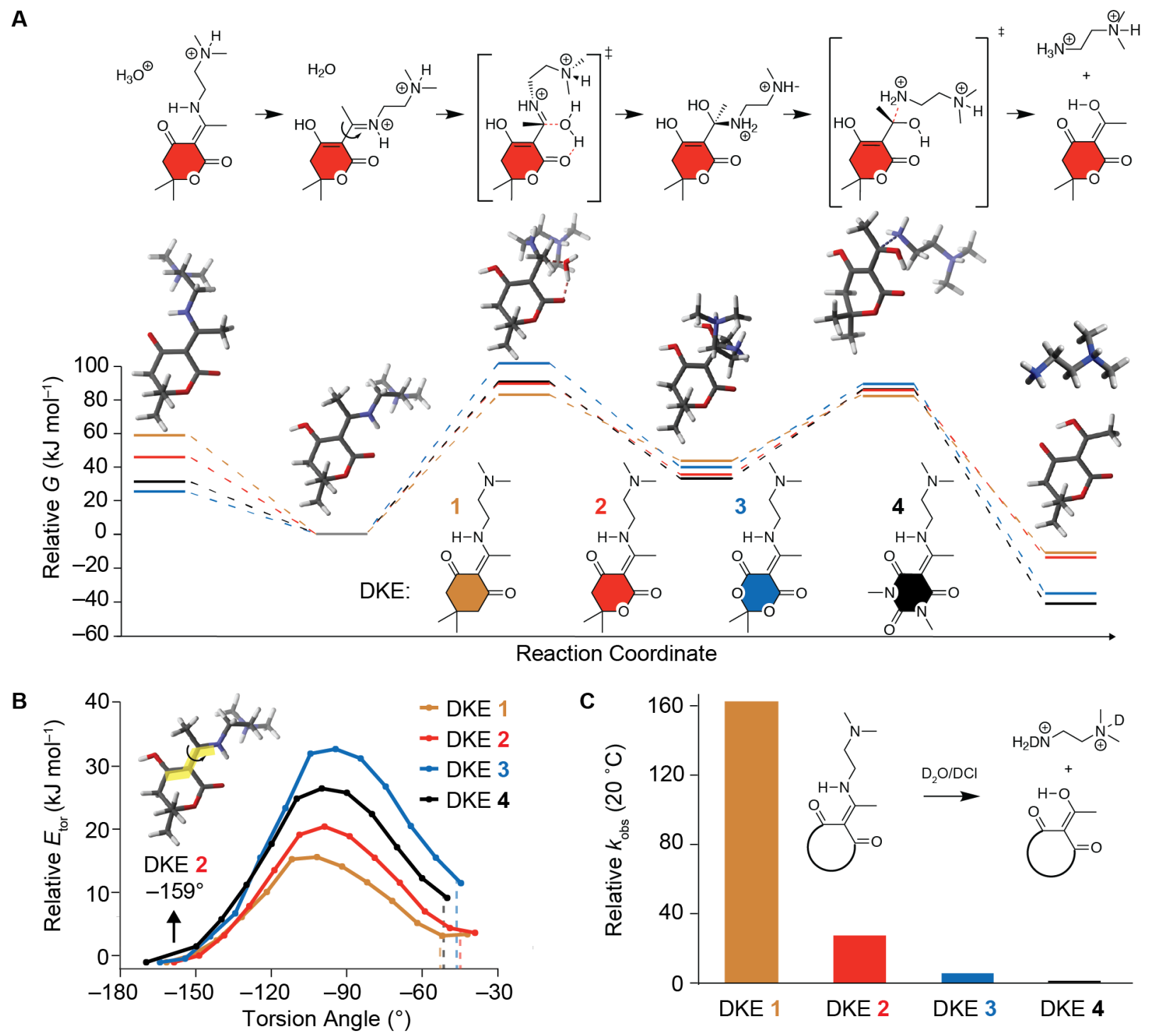

Fig. 3. Molecular basis for the rate-limiting step in PDK hydrolysis. (A) Calculated energy landscapes along reaction coordinates for hydrolysis of PDKs 1-4 via an addition-elimination mechanism. Diketoenamines 1-4 are studied as surrogates of the bonds in PDKs 1-4 undergoing hydrolysis to triketones in acid. Intermediates along the reaction coordinate are shown for diketoenamine 2; reaction coordinates for hydrolysis of diketoenamines $\mathbf{1}, \mathbf{3}$, and $\mathbf{4}$ are given in Figs. S11-13. (B) Relative potential energy barriers $\left(E_{\text {tor }}\right)$ for rotating the iminium out of plane to allow the addition of water in the transition state. (C) Experimentally determined rates of hydrolysis of diketoenamines $1-4$ in $5.0 \mathrm{M} \mathrm{DCl}$ in $\mathrm{D}_{2} \mathrm{O}$ at $T=20^{\circ} \mathrm{C}$; data are normalized to the hydrolysis rate for diketoenamine 4. Kinetic data at different temperatures and associated Eyring analyses are given in Figs. S14-S17 and Table S9.

To experimentally benchmark the theoretical studies of the rate-limiting step for diketoenamine hydrolysis, we measured $\Delta G^{\ddagger}$ for acid-catalyzed hydrolysis of small molecule diketoenamines 14, which we synthesized from the corresponding triketones and $N, N$-dimethylethylenediamine. We dissolved diketoenamines $\mathbf{1 - 4}$ in $5.0 \mathrm{DCl}$ in $\mathrm{D}_{2} \mathrm{O}$ and monitored their hydrolysis to insoluble 
triketones and soluble amine salts using variable temperature ${ }^{1} \mathrm{H}$ NMR spectroscopy (Figs. S14S17). The relative rates of diketoenamine hydrolysis at $20{ }^{\circ} \mathrm{C}$ vary by over two orders of magnitude, with diketoenamines 1 and 2 hydrolyzing $>150$-times and $>25$-times faster than diketoenamine 4, respectively (Fig. 3c). Furthermore, our calculated values for $\Delta G^{\ddagger}$ for the ratelimiting step in diketoenamine hydrolysis after Eyring analyses of the kinetics data agree well with both theoretical determinations (Table S9) and the observed temperature-dependent rates of PDK depolymerization as solid or molded resins (Figs. $1 \&$ \& $)$. We found that hydrolysis of diketoenamine $\mathbf{3}$ and ultimately depolymerization of PDK $\mathbf{3}$ were outliers in that their hydrolysis is faster than what is predicted by our DFT simulations. This discrepancy is explained by the apparent faster rate diketoenamine conversion when there is concurrent hydrolysis and degradation by decarboxylation to ß-keto acids (Fig. S18), as evidenced by ${ }^{1} \mathrm{H}$ NMR (Fig. S9). Nevertheless, the convergence of computational and experimental data provide valid and important insights into the mechanism of diketoenamine hydrolysis and the underlying foundations for varying the rate of hydrolysis by molecular engineering of the diketoenamine bond through targeted heteroatom placement. These modifications unlock orthogonal rates of PDK polymerization, which can be put to use in multi-polymer and multi-material recycling, where there are few options to do so with polymers in use today.

\section{Mixed-Polymer and mixed-material recycling enabled by chemospecific PDK deconstruction}

To showcase emerging opportunities afforded by molecularly engineered PDKs 1-4 in mixedpolymer and mixed-material chemical recycling to monomer, we considered deconstructing an intimate blend of PDKs 1 and 4, which are prepared as resin powders $\sim \mu \mathrm{m}$ in size (Fig. S2). We mechanically mixed and molded the two PDK resin powders into a solid bar. We then carried out chemospecific depolymerization of PDKs $\mathbf{1}$ and $\mathbf{4}$ in two stages: initially at $20^{\circ} \mathrm{C}$ endeavoring to depolymerize PDK 1 and then at $60^{\circ} \mathrm{C}$ to depolymerize PDK 4 (Fig. 4a). After the first stage, we used simple solid-liquid separations to isolate triketone $\mathbf{1}$ and TREN monomers from intact PDK 4. After the second stage, we isolated triketone 4 from TREN. Notably, only the prescribed set of monomers were isolated at each stage. We neither observed triketone $\mathbf{4}$ impurities in triketone $\mathbf{1}$ recovered in the first stage, nor did we observe triketone 1 impurities in triketone 4 recovered in the second stage. We found that this chemospecificity in mixed-PDK recycling extended to bilayer laminates, where pigments added to one of the resins (in this case, carbon black loaded into PDK 4) could also be dissociated from the monomers (Fig. 4b).

Based on our success in deconstructing bilayer laminates, we further considered the deconstruction of a trilayer assembly of polypropylene (PP) and polyethylene terephthalate (PET) film featuring PDK 1 as an adhesive bonding layer. This architecture is a model system for flexible packaging, where the adhesive bonding layer is typically polyethylene or nylon, which complicates the recycling of multi-layer laminates due to difficulties in debonding the layers for sorting into homogeneous waste streams. Within $24 \mathrm{~h}$ at $20^{\circ} \mathrm{C}$, we found that the PDK 1 adhesive bonding layer was completely depolymerized, despite its low contact surface area with the acidic depolymerization medium. This allowed both PP and PET films to be separated and sorted (Fig. 4c). We also recovered monomers from PDK 1 without contamination, e.g., from any oligomers or monomers that may have depolymerized from PET in acid. 
A

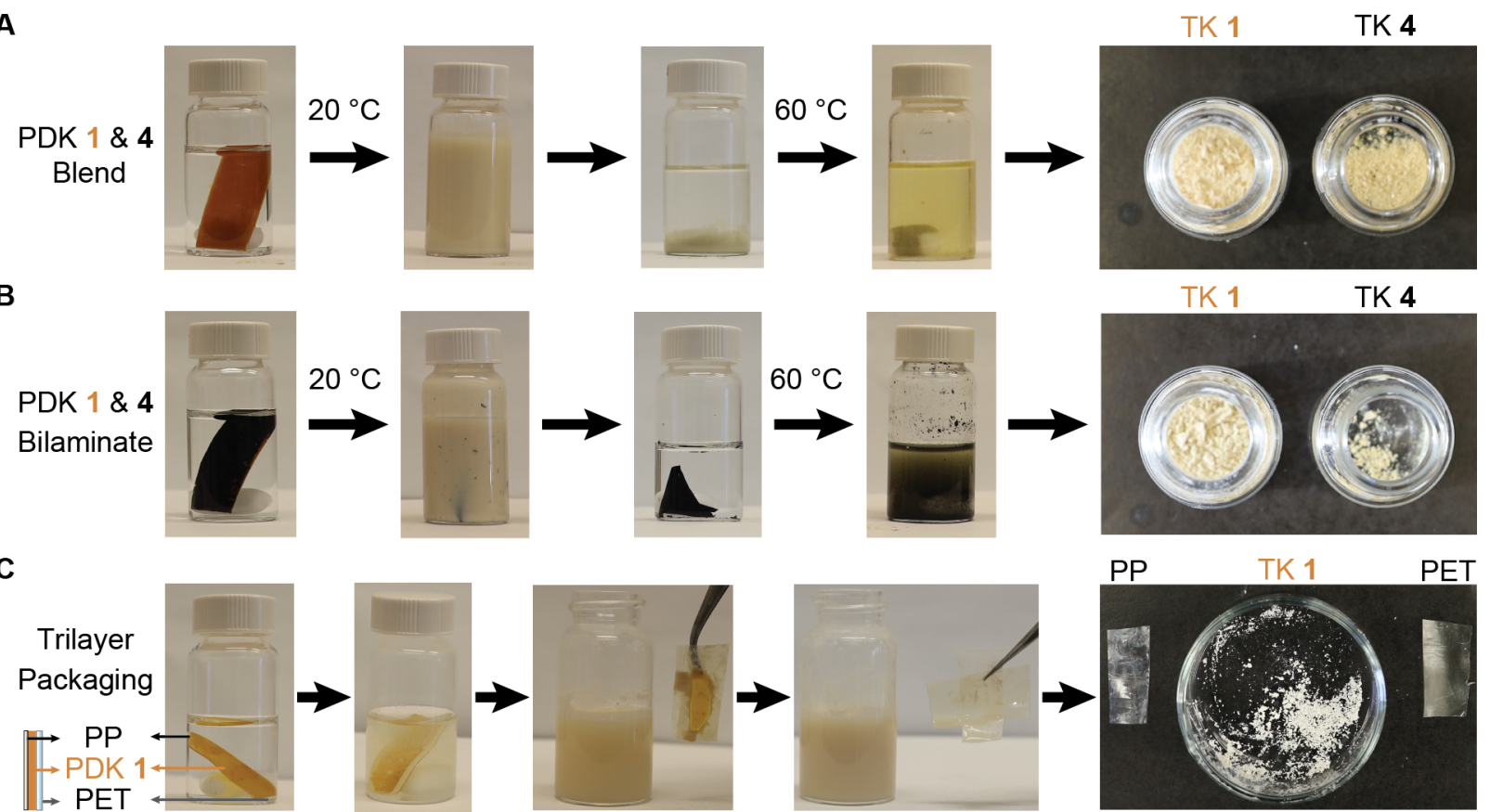

Figure 4. Chemical Circularity in Mixed-PDK and Mixed-Polymer Recycling. (A) A blend of PDK 1 and 4 resin powders was compression molded into a solid bar sample. At $20{ }^{\circ} \mathrm{C}$ in strong acid, PDK 1 was chemospecifically depolymerized into triketone monomer 1 and TREN; PDK 4 remained intact and was isolated as a solid. The isolated PDK 4 resin was then depolymerized at $60{ }^{\circ} \mathrm{C}$ to recover triketone monomer 4 and TREN. (B) A bilayer laminate of PDK 1 and carbonblack loaded PDK 4 was chemospecifically deconstructed to prescribed monomers in two stages, initially at $20^{\circ} \mathrm{C}$ and then at $60^{\circ} \mathrm{C}$. (C) A trilayer laminate consisting of polypropylene (PP) film and poly(ethylene terephthalate) (PET) film laminated by PDK 1 was deconstructed as a model for recycling mixed-polymer, multi-layer packaging. (A-C) In all cases, recovered monomers showed indistinguishable characteristics from initial monomers, demonstrating chemical circularity in mixed-PDK and mixed-polymer recycling.

The orthogonality in PDK depolymerization at different temperatures makes possible the removal or recovery of essentially an endless series of additives compounded into the various PDK resins. As proof-of-concept, we compounded a blue pigment in PDK $\mathbf{2}$ and carbon black in PDK 4 to highlight that de-coloration and additive dissociation can be conducted concurrently at each stage of the recycling process (Fig. 5a). Despite chemical differences in the two pigments and an increase in number of solid-liquid separations processes, monomer recovery was high: $90 \%$ for triketone 2, and $75 \%$ for triketone 4 . Both monomers were recovered with indistinguishable properties from those used in primary PDK resin production, thus completing the loop in chemical circularity for mixed-polymers and composites (Fig. S19 \& S20).

To extend our purview of chemical circularity in mixed-material recycling with PDKs $\mathbf{1}-\mathbf{4}$, we fabricated a bonded assembly comprising metal (stainless steel comprising mainly of Fe with $\sim 12 \% \mathrm{Cr}, \sim 0.6 \% \mathrm{C}$, and the remainder trace elements), glass, and PDKs 1 and 4; an epoxy resin was used to glue the assembly together. This assembly is a crude yet illustrative model for difficultto-recycle products, from electronics to complex parts integrated into vehicles, aircraft, and 
buildings (e.g., panels and windows). The challenge in mixed materials recycling is that the conditions used to depolymerize either PDK resin may affect the integrity of the metals and glass through corrosion or etching, respectively. Indeed, when PDK 1 was depolymerized from the bonded assembly at $20^{\circ} \mathrm{C}$ in strong acid, the reaction mixture evidenced signs of metal corrosion, even at this low temperature. Despite this, we recovered triketone $\mathbf{1}$ free from metal and other impurities, as evidenced by both ${ }^{1} \mathrm{H}$ NMR (Fig. S21) and ICP-OES analysis, which is notable, given the propensity for some triketones to coordinate metals (30). After depolymerization PDK 1 , we then deconstructed the remainder of the assembly at $60{ }^{\circ} \mathrm{C}$ in strong acid, isolating metal from glass and separating triketone 4 from TREN using solid-liquid separations. For recovered triketone 4, its ${ }^{1} \mathrm{H}$ NMR indicated high purity (Fig. S22); however, its slight coloration was tied to $2.85 \mathrm{ppm}$ Fe and $0.19 \mathrm{ppm} \mathrm{Cr}$, as quantified by ICP-OES. While metal contamination in triketone 4 remains lower by nearly two orders of magnitude by comparison to metal contamination of mechanically recycled polymers and slightly lower than virgin resins for commodity plastics (31), it can be refined to pristine metal-free quality by recrystallization.

A

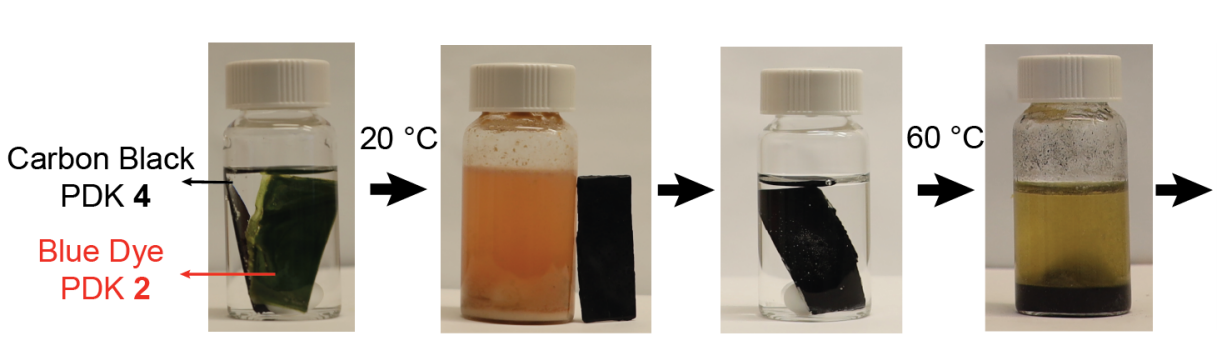

TK 4

B

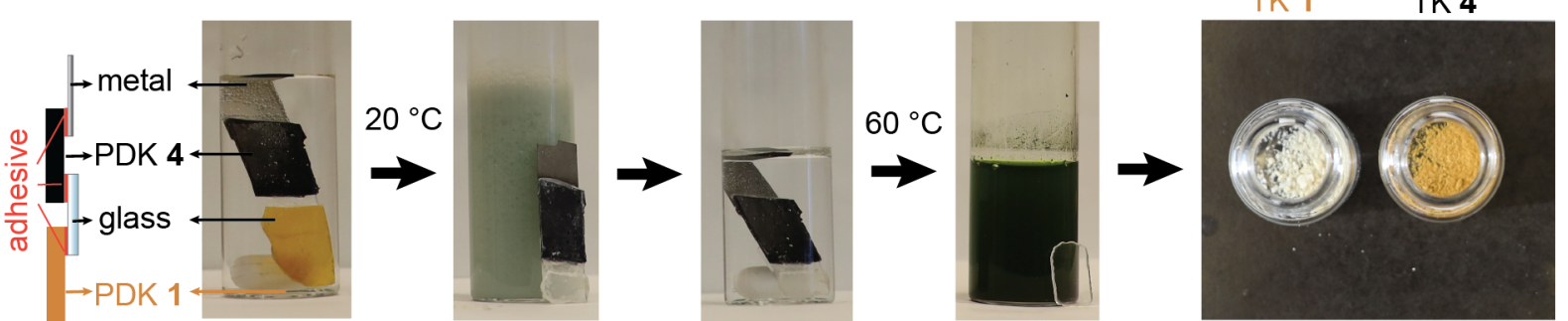

Figure 5. Chemical Circularity in Deconstructing Multi-Color Composites and Bonded Multi-Material Assemblies. (A) Mixed-PDK composite recycling with de-coloration at each step was demonstrated by first depolymerizing blue dye-loaded PDK 2 at $20{ }^{\circ} \mathrm{C}$ in strong acid into triketone 2, TREN, and a blue dye (whose hue is $\mathrm{pH}$ dependent). Carbon-Black loaded PDK 4 was then retrieved and separately depolymerized at $60{ }^{\circ} \mathrm{C}$ in strong acid to recover triketone 4 from TREN and carbon black, after filtration (filter shown). (B) Mixed-Material and Mixed-PDK recycling, where compression molded samples of PDK 1 and carbon-black loaded PDK 4 were glued to glass and metal sheets by an epoxy adhesive. PDK 1 was depolymerized at $20{ }^{\circ} \mathrm{C}$ to recover triketone $\mathbf{1}$ in pristine condition, which is notable given the contamination of the reaction mixture by metal corrosion. To deconstruct the metal-PDK 4-glass bonded assembly, the temperature of the strongly acidic solution was raised to $60^{\circ} \mathrm{C}$ to depolymerize PDK 4 and recover triketone monomer 4 . The presence of an adhesive did not appear to affect the yield or purity of recovered monomers from either PDK 1 or PDK 4. 


\section{Conclusion}

The outcomes demonstrated here address outstanding challenges in monomer-to-monomer chemical recycling for both mixed-polymer and mixed-material waste, which require additive- and impurity-tolerant chemical depolymerization and separation processes that are not universally available. Consequently, re-use strategies have instead focused on mixed-polymer upcycling, where mixtures of polymers are blended into a higher value material by compatibilization (3234). However, products made from compatibilized polymer blends are difficult to sort at materials recovery facilities and more often contaminate sorted recycling streams. Furthermore, individual components within compatibilized blends undergo degradation by various forms of chain scission, suggesting limited re-use opportunities for polymer blends beyond the initial upcycle $(35,36)$. Sequential depolymerization of several polymers in complex mixtures is an attractive alternative, allowing re-use of monomer feedstocks, which significantly lowers greenhouse gas emissions by comparison to those generated in primary resin production $(37,38)$. However, it is rare for each of the polymers in mixed-polymer waste to be depolymerized sequentially to their respective monomers in high yield and purity $(1,2,18,39,40)$, which we show here becomes possible when using PDK variants. In this way, PDKs provide an important entry point to managing thermal and materials entropy in circular manufacturing systems (41). In early applications, we expect industries that retain ownership of their assets or implement take-back programs will be most capable of using PDKs in closed-loop recycling. For example, in automotive manufacturing, where polymers and composites comprise nearly $10 \%$ of the weight an average vehicle, chemical circularity could provide a step-change in industrial materials efficiency as car-makers transition to mobility as a service $(5,6)$. Long term, we anticipate that collecting and sorting mixed-PDK waste in municipal recycling facilities will benefit from emerging digital barcoding strategies (42), which can be used to direct chemical recycling processes efficiently for resource recovery for a more sustainable and circular economy of polymers.

\section{References and Notes:}

1. P. T. Williams, E. A. Williams, Interaction of Plastics in Mixed-Plastics Pyrolysis. Energy \& Fuels 13, 188-196 (1999).

2. M. N. Siddiqui, H. H. Redhwi, Pyrolysis of mixed plastics for the recovery of useful products. Fuel Process. Technol. 90, 545-552 (2009).

3. Z. O. G. Schyns, M. P. Shaver, Mechanical Recycling of Packaging Plastics: A Review. Macromol. Rapid Commun. 42, 2000415 (2021).

4. H. S. Park, Y. S. Han, J. H. Park, Massive Recycling of Waste Mobile Phones: Pyrolysis, Physical Treatment, and Pyrometallurgical Processing of Insoluble Residue. ACS Sustain. Chem. Eng. 7, 14119-14125 (2019).

5. L. Miller, K. Soulliere, S. Sawyer-Beaulieu, S. Tseng, E. Tam, Challenges and Alternatives to Plastics Recycling in the Automotive Sector. Materials 7, 5883-5902 (2014).

6. Vermeulen, J. Van Caneghem, C. Block, J. Baeyens, C. Vandecasteele, Automotive shredder residue (ASR): Reviewing its production from end-of-life vehicles (ELVs) and its recycling, energy or chemicals' valorization. J. Hazard. Mater. 190, 8-27 (2011).

7. Rahimi, J. M. García, Chemical recycling of waste plastics for new materials production. Nat. Rev. Chem. 1, 46 (2017).

8. J.-B. Zhu, E. M. Watson, J. Tang, E. Y.-X. Chen, A synthetic polymer system with repeatable chemical recyclability. Science 360, 398-403 (2018). 
9. G. W. Coates, Y. D. Y. L. Getzler, Chemical recycling to monomer for an ideal, circular polymer economy. Nat. Rev. Mater. 5, 501-516 (2020).

10. I. Vollmer, M. J. F. Jenks, M. C. P. Roelands, R. J. White, T. van Harmelen, P. de Wild, G. P. van der Laan, F. Meirer, J. T. F. Keurentjes, B. M. Weckhuysen, Beyond Mechanical Recycling: Giving New Life to Plastic Waste. Angew. Chem. Int. Ed. 59, 15402 (2020).

11. M. Häußler, M. Eck, D. Rothauer, S. Mecking, Closed-loop recycling of polyethylene-like materials. Nature 590, 423-427 (2021).

12. H. Jeswani, C. Kruger, M. Russ, M. Horlacher, F. Antony, S. Hann, A. Azapagic, Life cycle environmental impacts of chemical recycling via pyrolysis of mixed plastic waste in comparison with mechanical recycling and energy recovery. Sci. Total Environ. 769, 144483 (2021).

13. J. R. Jambeck, R. Geyer, C. Wilcox, T. R. Siegler, M. Perryman, A. Andrady, R. Narayan, K. L. Law, Plastic waste inputs from land into the ocean. Science 347, 768-771 (2015).

14. R. Geyer, J. R. Jambeck, K. L. Law, Production, use, and fate of all plastics ever made. Sci. Adv. 3, e1700782 (2017).

15. D. E. MacArthur, Beyond plastic waste. Science 358, 843 (2017).

16. J. B. Lamb, B. L. Willis, E. A. Fiorenza, C. S. Couch, R. Howard, D. N. Rader, J. D. True, L. A. Kelly, A. Ahmad, J. Jompa, C. D. Harvell, Plastic waste associated with disease on coral reefs. Science 359, 460-462 (2018).

17. S. B. Borrelle, J. Ringma, K. L. Law, C. C. Monnahan, L. Lebreton, A. McGivern, E. Murphy, J. Jambeck, G. H. Leonard, M. A. Hilleary, M. Eriksen, H. P. Possingham, H. De Frond, L. R. Gerber, B. Polidoro, A. Tahir, M. Bernard, N. Mallos, M. Barnes, C. M. Rochman, Predicted growth in plastic waste exceeds efforts to mitigate plastic pollution. Science 369, 1515-1518 (2020).

18. P. R. Christensen, A. M. Scheuermann, K. E. Loeffler, B. A. Helms, Closed-loop recycling of plastics enabled by dynamic covalent diketoenamine bonds. Nat. Chem. 11, $442-448$ (2019).

19. C. He, P. R. Christensen, T. J. Seguin, E. A. Dailing, B. M. Wood, R. K. Walde, K. A. Persson, T. P. Russell, B. A. Helms, Conformational Entropy as a Means to Control the Behavior of Poly(diketoenamine) Vitrimers In and Out of Equilibrium. Angew. Chem. Int. Ed. 59, 735-739 (2020).

20. T. W. Walker, N. Frelka, Z. Shen, A. K. Chew, J. Banick. S. Grey, M. S. Kim, J. A. Dumesic, R. C. Van Lehn, G. W. Huber, Recycling of multilayer plastic packaging materials by solventtargeted recovery and precipitation. Sci. Adv. 6, eaba7599 (2020).

21. Ellen MacArthur Foundation. The new plastics economy: rethinking the future of plastics \& catalysing action. Ellen MacArthur (2017), (available at https://www.ellenmacarthurfoundation.org/publications/the-new-plastics-economyrethinking-the-future-of-plastics-catalysing-action).

22. S. Billiet, S. R. Trenor, 100th Anniversary of Macromolecular Science Viewpoint: Needs for Plastics Packaging Circularity. ACS Macro Lett. 9, 1376-1390 (2020).

23. S. J. Rowan, S. J. Cantrill, G. R. L. Cousins, J. K. M. Sanders, J. F. Stoddart, Dynamic covalent chemistry. Angew. Chem. Int. Ed. 41, 899-952 (2002).

24. D. Montarnal, M. Capelot, F. Tournilhac, L. Leibler, Silica-Like Malleable Materials from Permanent Organic Networks. Science 334, 965-968 (2011).

25. W. Denissen, J. M. Winne, F. E. Du Prez, Vitrimers: permanent organic networks with glasslike fluidity. Chem. Sci. 7, 30-38 (2016).

26. Y. Jin, Z. Lei, P. Taynton, S. Huang, W. Zhang, Malleable and Recyclable Thermosets: The 
Next Generation of Plastics. Matter 1, 1456-1493 (2019).

27. Y. Zhao, D. G. Truhlar, The M06 suite of density functionals for main group thermochemistry, thermochemical kinetics, noncovalent interactions, excited states, and transition elements: two new functionals and systematic testing of four M06-class functionals and 12 other function. Theor. Chem. Acc. 120, 215-241 (2008).

28. A. V. Marenich, C. J. Cramer, D. G. Truhlar, Universal solvation model based on solute electron density and on a continuum model of the solvent defined by the bulk dielectric constant and atomic surface tensions. J. Phys. Chem. B 113, 6378-6396 (2009).

29. S. Grimme, Supramolecular Binding Thermodynamics by Dispersion-Corrected Density Functional Theory. Chem. Eur. J. 18, 9955-9964 (2012).

30. V. Rusanov, A. Ahmedova, M. Mitewa, A Mössbauer study on iron(II) complex of 2-acetyl1,3-indandione - spin-crossover or structural changes. Eur. J. Chem. 5, 176-180 (2014).

31. M. K. Eriksen, K. Pivnenko, M. E. Olsson, T. F. Astrup, Contamination in plastic recycling: Influence of metals on the quality of reprocessed plastic. Waste Manag. 79, 595-606 (2018).

32. M. Xanthos, S. S. Dagli, Compatibilization of polymer blends by reactive processing. Polym. Eng. Sci. 31, 929-935 (1991).

33. C. W. Macosko, H. K. Jeon, T. R. Hoye, Reactions at polymer-polymer interfaces for blend compatibilization. Prog. Polym. Sci. 30, 939-947 (2005).

34. J. M. Eagan, J. Xu, R. Di Girolamo, C. M. Thurber, C. W. Macosko, A. M. La Pointe, F. S. Bates, G. W. Coates, Combining polyethylene and polypropylene: Enhanced performance with PE/iPP multiblock polymers. Science 355, 814-816 (2017).

35. H. Hinsken, S. Moss, J. R. Pauquet, H. Zweifel, Degradation of polyolefins during melt processing. Polym. Degrad. Stab. 34, 279-293 (1991).

36. P. Oblak, J. Gonzalez-Gutierrez, B. Zupancic, A. Aulova, I. Emri, Processability and mechanical properties of extensively recycled high density polyethylene. Polym. Degrad. Stab. 114, 133-145 (2015).

37. N. Vora, P. R. Christensen, J. Demarteau, N. R. Baral, J. D. Keasling, B. A. Helms, C. D. Scown, Leveling the cost and carbon footprint of circular polymers that are chemically recycled to monomer. Sci. Adv. 7, eabf0187 (2021).

38. S. R. Nicholson, N. A. Rorrer, A. C. Carpenter, G. T. Beckham, Manufacturing energy and greenhouse gas emissions associated with plastics consumption. Joule, in press, doi: $10.1016 /$ j.joule.2020.12.027.

39. C. Jehanno, J. Demarteau, D. Mantione, M. C. Arno, F. Ruiperez, J. L. Hedrick, A. P. Dove, H. Sardon, Selective Chemical Upcycling of Mixed Plastics Guided by a Thermally Stable Organocatalyst. Angew. Chem. Int. Ed. 60, 6710-6717 (2021).

40. J. Briceno, M. A. Lemos, F. Lemos, Kinetic analysis of the degradation of HDPE+PP polymer mixtures. Int. J. Chem. Kinet. in press, doi:10.1002/kin.21472.

41. K. Kuemmerer, J. H. Clark, V. G. Zuin, Rethinking chemistry for a circular economy. Science 367, 369-370 (2020).

42. J. Paben, https://resource-recycling.com/plastics/2020/01/03/companies-embrace-invisiblebarcode-to-aid-in-sorting/ (2020).

Acknowledgments: Portions of this work, including monomer synthesis and characterization, were carried out as a User Project at the Molecular Foundry, which is supported by the Office of Science, Office of Basic Energy Sciences, of the U.S. Department of Energy under Contract No. DE-AC02-05CH11231. Single-crystal X-ray characterization was carried out at the Advanced 
Light Source, which is a DOE Office of Science User Facility operating under the same contract. Tracy Mattox and Rafal Dziedzic are thanked for ICP-OES and SEM, respectively. Alexander Zapata are Andres Mariano are also thanked for performing preliminary studies.; Funding: The technical scope of work associated with the chemistry development was supported by the Laboratory Directed Research and Development Program of Lawrence Berkeley National Laboratory under U.S. Department of Energy Contract No. DE-AC02-05CH11231. For mixedpolymer and mixed-material recycling, we acknowledge support from the U.S. Department of Energy (DOE) Bioenergy Technologies Office award number 1916-1597. This research used the Savio computational cluster resource provided by the Berkeley Research Computing program at the University of California, Berkeley (supported by the UC Berkeley Chancellor, Vice Chancellor for Research, and Chief Information Officer). We also acknowledge Grant No. NIH S10OD023532 for additional computational resources. A.R.E. was supported by the National Science Foundation Graduate Research Fellowship under Grant No. DGE 1752814.; Author contributions: B.A.H. designed and directed the study and wrote the manuscript. J.D., P.R.C., H.W., and C.W.C. synthesized and characterized the monomers and polymers. J.D. compounded and processed the polymers, performed thermomechanical characterization, and conducted the recycling experiments. M.A.B. performed the hydrolysis kinetics experiments. S.J.T. conducted single-crystal X-ray crystallography and analyzed the results. K.A.P. directed and A.R.E. and T.J.S. designed and executed the computational studies. All co-authors participated in data analysis and interpretation.; Competing interests: $\mathrm{BAH}$ and $\mathrm{PRC}$ are inventors on US provisional patent application 62/587,148 submitted by Lawrence Berkeley National Laboratory that covers polydiketoenamines, as well as aspects of their use and recovery; and Data and materials availability: All data is available in the main text or the supplementary materials.

\section{Supplementary Materials:}

Materials and Methods

Figures S1-S22

Tables S1-S9

References (43-55) 


\section{Materials and Methods}

5,5-dimethyl-1,3-cyclohexanedione (dimedone, 95\%), 2,2-dimethyl-1,3-dioxane-4,6-dione (Meldrum's acid, 95\%), 1,3-dimethylbarbituric acid (>99\%), sebacoyl chloride ( $>95 \%)$, 4(dimethylamino)pyridine (DMAP, 99\%), N,N'-dicyclohexylcarbodiimide (DCC, 99\%), $N, N$ dimethylethylenediamine (95\%), tris(2-aminoethyl)amine (TREN, 96\%), magnesium sulfate ( $\mathrm{MgSO}_{4}$, anhydrous), potassium carbonate $\left(\mathrm{K}_{2} \mathrm{CO}_{3},>\right)$ and hydrochloric acid $(\mathrm{HCl})$ were purchased from Sigma Aldrich and used as received. Carbon black (Super P® Conductive, 99\%) was purchased from Alfa Aesar. Bio-based sebacic acid (99\%) was purchased from Arkema. Triketone 1 was synthesized as described by us previously (18). All solvents - dichloromethane (DCM) (>99.9\%), chloroform $\left(\mathrm{CHCl}_{3}\right)(>99.8 \%)$, ethyl acetate $(>99.8 \%)$, hexane $(>98.5 \%)$, acetone $(>99.5 \%)$, pyridine $(99 \%)$, acetonitrile $(>99.8 \%)$, trifluoroacetic acid $(>99.8 \%)$, formic acid (98-100\%), ethanol $(>99.5 \%)$-were purchased from VWR and used without further purification. $N, N$-dimethylacetamide $(>99 \%)$ was purchased from Sigma Aldrich and used without further purification. Dihydro-6,6-dimethyl-2 $\mathrm{H}$-pyran-2,4(3H)-dione (43), 2-acetyl-5,5dimethyl-1,3-cyclohexanedione (18), 3-acetyl-6,6-dimethyldihydro-2H-pyran-2,4(3H)-dione (44), 5-acetyl-2,2-dimethyl-1,3-dioxane-4,6-dione (45), and 5-acetyl-1,3-dimethylpyrimidine2,4,6(1H,3H,5H)-trione (46) were synthesized according to previously reported procedures. Biaxially-Oriented Poly(propylene) (BOPP) and Poly(ethylene terephthalate) (PET) foils were both purchased from Amazon. Loctite HY 4090 structural hybrid adhesive was purchased from Henkel.

${ }^{1} \mathrm{H}$ and ${ }^{13} \mathrm{C}$ Nuclear Magnetic Resonance Spectroscopy was carried out using a Bruker Avance II at $500 \mathrm{MHz}$ and $125 \mathrm{MHz}$, respectively. Chemical shifts are reported in $\delta$ (ppm) relative to the residual solvent peak: 1) $\mathrm{CDCl}_{3}$ : 7.26 for ${ }^{1} \mathrm{H}, 77.16$ for ${ }^{13} \mathrm{C}$, or 2) $\mathrm{D}_{2} \mathrm{O}: 4.8$ for the hydrolysis kinetics in $\mathrm{D}_{2} \mathrm{O} / \mathrm{DCl} 5.0 \mathrm{M}$. Splitting patterns are designated as s (singlet), $d$ (doublet), $\mathrm{t}$ (triplet), $\mathrm{q}$ (quartet), and $\mathrm{m}$ (multiplet).

Electrospray Ionization Mass Spectrometry (ESI-MS) was carried out using a Bruker microTOF-Q_using acetonitrile containing either $0.1 \%$ trifluoroacetic acid or $0.1 \%$ formic acid as the ionization medium.

Fourier Transform Infrared Spectra (FTIR). Data were acquired using a Perkin Elmer Spectrum One spectrophotometer as an average of 16 scans over an energy range of 400-4000 cm 1 .

Single Crystal XRD. Single crystals for triketones 1-4 were selected, mounted on Mitegen ${ }^{\circledR}$ loops with Paratone oil, and placed in an Oxford Cryosystems Cryostream 800 plus at $T=100 \mathrm{~K}$. Data were collected on beamline 12.2.1 at the Advanced Light Source (Berkeley, CA) with $\lambda=$ $0.7288 \AA$ using a Bruker D8 diffractometer with a Bruker PHOTONII CPAD detector. Data reduction were performed and corrected for Lorentz and polarization effects using SAINT (47) v8.40a and were corrected for absorption effects and other effects using TWINABS 2012/1 (48) for triketones 1, 3, and 4, while SADABS v2016/2 (49) was used for triketone 2. Structure solutions were performed by SHELXT (50) using the direct method and were refined by leastsquare refinement against $\mathrm{F}^{2}$ by $\operatorname{SHELXL~(51).~}$ 
Differential Scanning Calorimetry (DSC). Data were acquired using a TA Instruments Q200 Differential Scanning Calorimeter. Samples were heated over a temperature range of either 40$220^{\circ} \mathrm{C}$ (for PDKs 1, 2 \& 4) or $40-120^{\circ} \mathrm{C}$ (for PDK 3) at a rate of $5^{\circ} \mathrm{C} \mathrm{min}{ }^{-1}$ under a $\mathrm{N}_{2}$ atmosphere. For each sample, data acquisition runs consisted of a heating step, a cooling step, and a second heating step. Glass transition temperatures $\left(T_{\mathrm{g}}\right)$ were interpreted and reported from the second heating curve with the exception of PDK 3, those $T_{\mathrm{g}}$ was interpreted from the first heating curve due to decomposition.

Dynamic Mechanical Analysis (DMA). Data were acquired using a TA instruments DMA Q800 in tensile mode. All samples were fabricated as rectangular specimens with $\sim 0.5 \mathrm{~mm}(T) \times 5 \mathrm{~mm}$ $(W) \times 20 \mathrm{~mm}(L)$. Each sample was tested at a frequency of $1 \mathrm{~Hz}$ with a displacement amplitude of $15 \mu \mathrm{m}$ and a preload force of $0.01 \mathrm{~N}$. Heating ramps of $3{ }^{\circ} \mathrm{C} \mathrm{min}^{-1}$ were applied from 40-200 ${ }^{\circ} \mathrm{C}$. The softening temperature was reported as the maximum value of $\tan \delta$.

Scanning Electron Microscopy (SEM). Imaging was performed using a Zeiss Gemini Ultra-55 Analytical Field Emission Scanning Electron Microscope with a $5 \mathrm{kV}$ accelerating voltage and using the secondary detector mode. Polymer powders were deposited onto carbon tape affixed to the stainless steel stage in the microscope. Excess polymer was removed using a stream of compressed air and the sample was sputter-coated with gold (thickness $\sim 7 \mathrm{~nm}$ ) prior to analysis by SEM.

Inductively Coupled Plasma-Optical Emission Spectroscopy (ICP-OES). Concentrations of $\mathrm{Fe}$ and $\mathrm{Cr}$ in parts per million (ppm) in triketones $\mathbf{1}$ and 4, chemically recycled using strong acid from mixed-material waste containing stainless steel, were quantified by ICP-OES 720ES (Varian) equipped with an axial argon torch. For each determination, $\sim 10 \mathrm{mg}$ of triketone was oxidatively digested at ambient temperature in concentrated $\mathrm{HNO}_{3}(\sim 200 \mu \mathrm{L})$ at ambient temperature for $24 \mathrm{~h}$ and subsequently diluted with MilliQ water to $10 \mathrm{~mL}$ in a precision volumetric flask prior to analysis and comparison to a calibration curve for each element.

Theoretical Methods. All calculations were performed using Gaussian 16 (52). For the reaction pathway free energy calculations, the computational model included the small molecule and one explicit hydronium ion encased in a continuum dielectric medium using the SMD implicit solvent model (53). To identify the global minimum energy conformers for each step of the reaction pathway, we performed a random rotor conformer search for each structure. For each structure with $n$ rotors, $3^{n}$ conformers were generated by rotating each rotor twice in $120^{\circ}$ increments. We then selected 200 conformers randomly, optimized the geometry of each structure and compared the energies at the $b 97 \mathrm{~d} / 6-31 \mathrm{~g}(\mathrm{~d}, \mathrm{p})$ level of theory in vacuum. We then identified the lowest energy conformer by optimizing the geometry of the 10 lowest energy structures from the initial search and comparing the energies at the $\mathrm{m} 062 \mathrm{x} / 6-31+\mathrm{g}(\mathrm{d}, \mathrm{p}) / / \mathrm{SMD}$ level of theory. For transition state structures, the bond distance of the primary bond being broken or formed at the transition state was constrained during the conformer search. In addition, we compared the lowest-energy structures of each diketoenamine to the others and evaluated additional conformers based on substitution of those structures. We then performed a final geometry optimization and free energy calculation at the $\mathrm{m} 062 \mathrm{x} / 6-311++\mathrm{g}(2 \mathrm{df}, 2 \mathrm{p}) / / \mathrm{SMD}$ level of theory. For steps 1 and 2 in the reaction pathway, in which there were two molecules in the system, calculations were performed separately for each fragment. We also employed Grimme's Quasi-RRHO free energy model to correct for 
inaccurate vibrational entropy contributions from low-frequency modes as calculated in Gaussian 16 with a pure harmonic oscillator model (54). Free energies were calculated at 298K and corrected for the standard state of liquid water,

$$
G_{\text {sol }}=G_{\text {Quasi-RRHO }}+R T \ln \left(\left[\mathrm{H}_{2} \mathrm{O}\right]\right) .
$$

To calculate the dihedral torsion potentials, the dihedral angle was constrained in $10^{\circ}$ increments beginning with the structure in step 2 of the reaction pathway. We performed a constrained geometry optimization for each dihedral angle at the m062x/6-311++g(d,p)//SMD level of theory. 


\section{Supplementary Text}

\section{Synthesis of 3,3'-(1,10-dihydroxydecane-1,10-diyl)bis(6,6-dimethyldihydro-2H-pyran- 2,4(3H)-dione) (Triketone 2).}

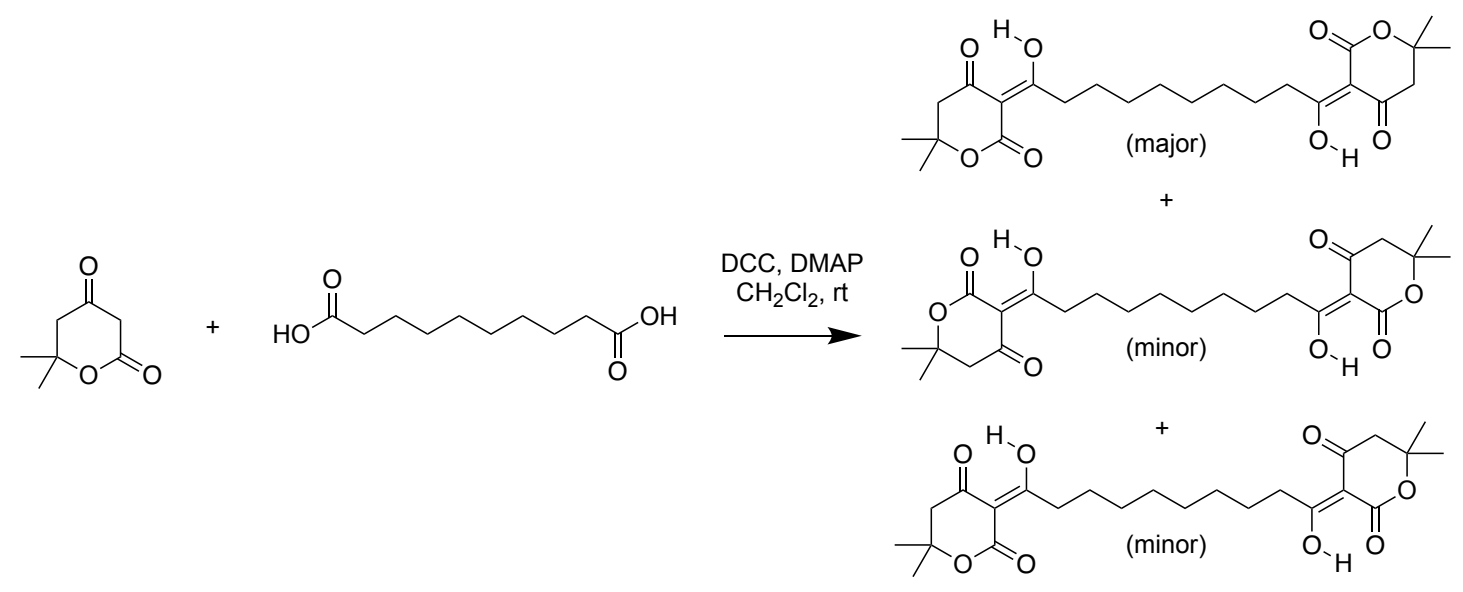

Dihydro-6,6-dimethyl-2H-pyran-2,4(3H)-dione (4.00 g, $28.2 \mathrm{mmol})$, sebacic acid (2.83 g, 14.0 mmol), and DMAP $(5.13 \mathrm{~g}, 42.0 \mathrm{mmol})$ were dissolved in dichloromethane ([dihydro-6,6dimethyl-2H-pyran-2,4(3H)-dione $]=1.0 \mathrm{M})$ with stirring. A separate solution of DCC (6.94 g, $33.6 \mathrm{mmol})$ in dichloromethane $([\mathrm{DCC}]=1.0 \mathrm{M})$ was added slowly at room temperature to the reaction mixture. The pale-yellow solution gradually turned darker yellow, which was accompanied by the formation of a white precipitate. The mixture was stirred at room temperature overnight $(16 \mathrm{~h})$, at which point the white $N, N^{\prime}$-dicyclohexylurea precipitate was filtered. The precipitate was washed with DCM until colorless. The filtrate was collected and washed with $3 \%$ $\mathrm{HCl}$ until the $\mathrm{pH}$ of the aqueous phase was $<3$. The organic phase was separated, dried over $\mathrm{MgSO}_{4}$, filtered and the solvent is removed under vacuum. The crude, pale yellow solid was solubilized in $300 \mathrm{~mL} \mathrm{~K}_{2} \mathrm{CO}_{3}(1.0 \mathrm{M})$ and the mixture stirred for $2 \mathrm{~h}$, filtered, and precipitated in $500 \mathrm{~mL} \mathrm{HCl}(1.0 \mathrm{M})$. The mixture was filtered and the colorless solid dried under vacuum overnight (84\% isolated yield). A small amount of the purified solid was recrystallized from ethanol to yield colorless needles for single crystal XRD. Characterization Data: ${ }^{1} \mathrm{H}$ NMR (500 $\left.\mathrm{MHz}, \mathrm{CDCl}_{3}\right): \delta 17.97(\mathrm{~s}, 2 \mathrm{H}), 16.28(\mathrm{~s}, 2 \mathrm{H}), 3.02-3.05\left(\mathrm{t},{ }^{3} J_{\mathrm{H}-\mathrm{H}}=7.35 \mathrm{~Hz}, 4 \mathrm{H}\right), 2.70(\mathrm{~s}, 4 \mathrm{H}), 2.63$ $(\mathrm{s}, 4 \mathrm{H}), 1.62-1.66(\mathrm{~m}, 4 \mathrm{H}), 1.47(\mathrm{~s}, 12 \mathrm{H}), 1.32-1.36(\mathrm{~m}, 10 \mathrm{H}) \mathrm{ppm} ;{ }^{13} \mathrm{C} \mathrm{NMR}\left(125 \mathrm{MHz}, \mathrm{CDCl}_{3}\right)$ : $\delta 204.00,197.06,195.09,190.09,174.48,163.60,102.74,100.05,79.51,76.60,49.45,44.18$, 38.44, 36.22, 33.52, 29.42, 29.24, 29.19, 29.12, 29.00, 27.67, 27.42, 26.05, 25.03 ppm; ESI-MS: $\mathrm{m} / \mathrm{z}$ for $\left(\mathrm{C}_{24} \mathrm{H}_{34} \mathrm{O}_{8}\right)_{2} \mathrm{Na}^{+}\left([2 \mathrm{M}+\mathrm{Na}]^{+}\right)$calculated 923.4400 , found 923.4684. FT-IR: 2975, 2939, 2869, 2856, 1691, 1549, 1467, 1454, 1415, 1402, 1385, 1371, 1318, 1287, 1265, 1228, 1212, 1175, $1126,1059,1005,988,938,907,850,837,771,721,643,603,540,506,483,433 \mathrm{~cm}^{-1}$. 

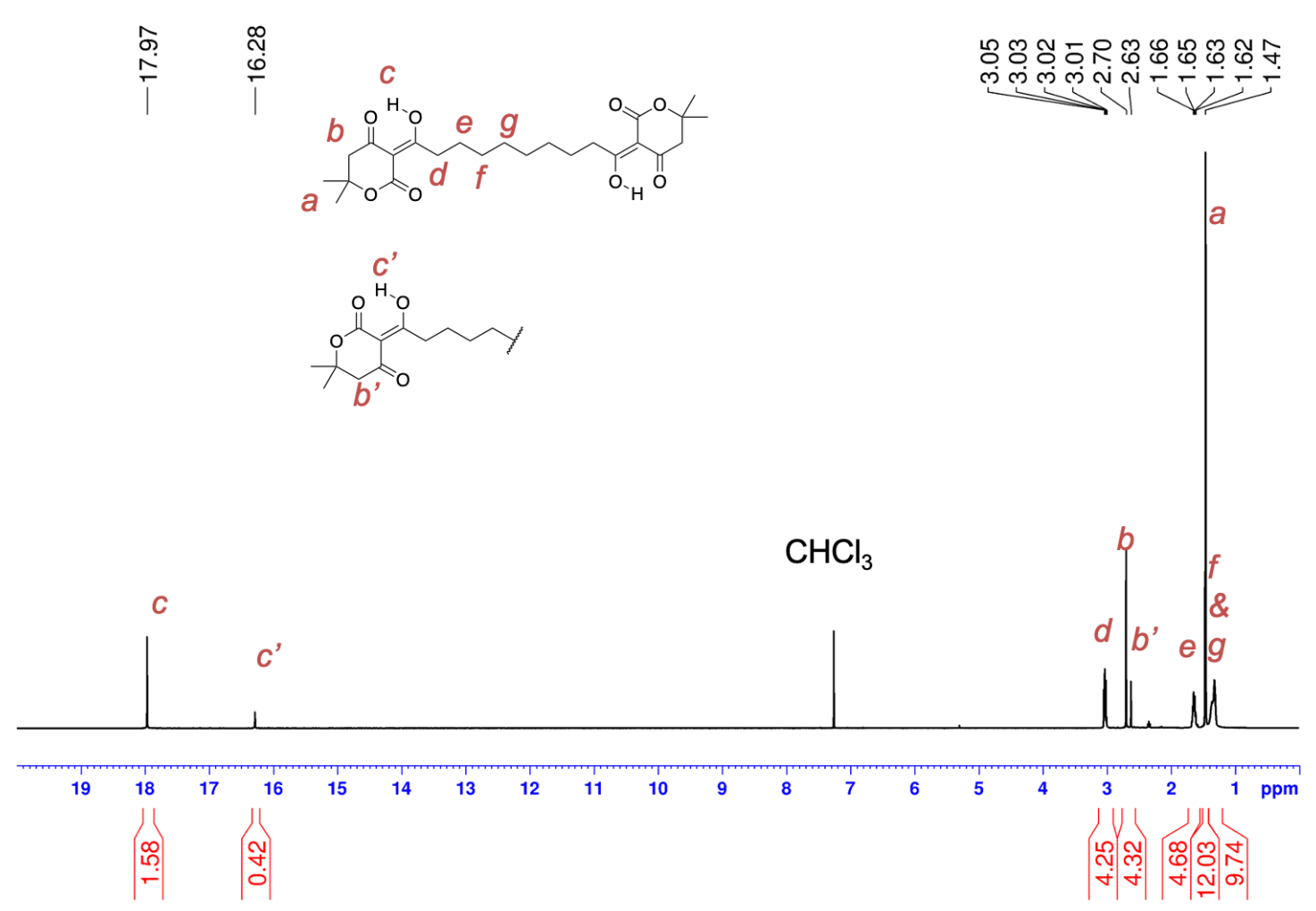

${ }^{1} \mathrm{H}$ NMR of TK 2.
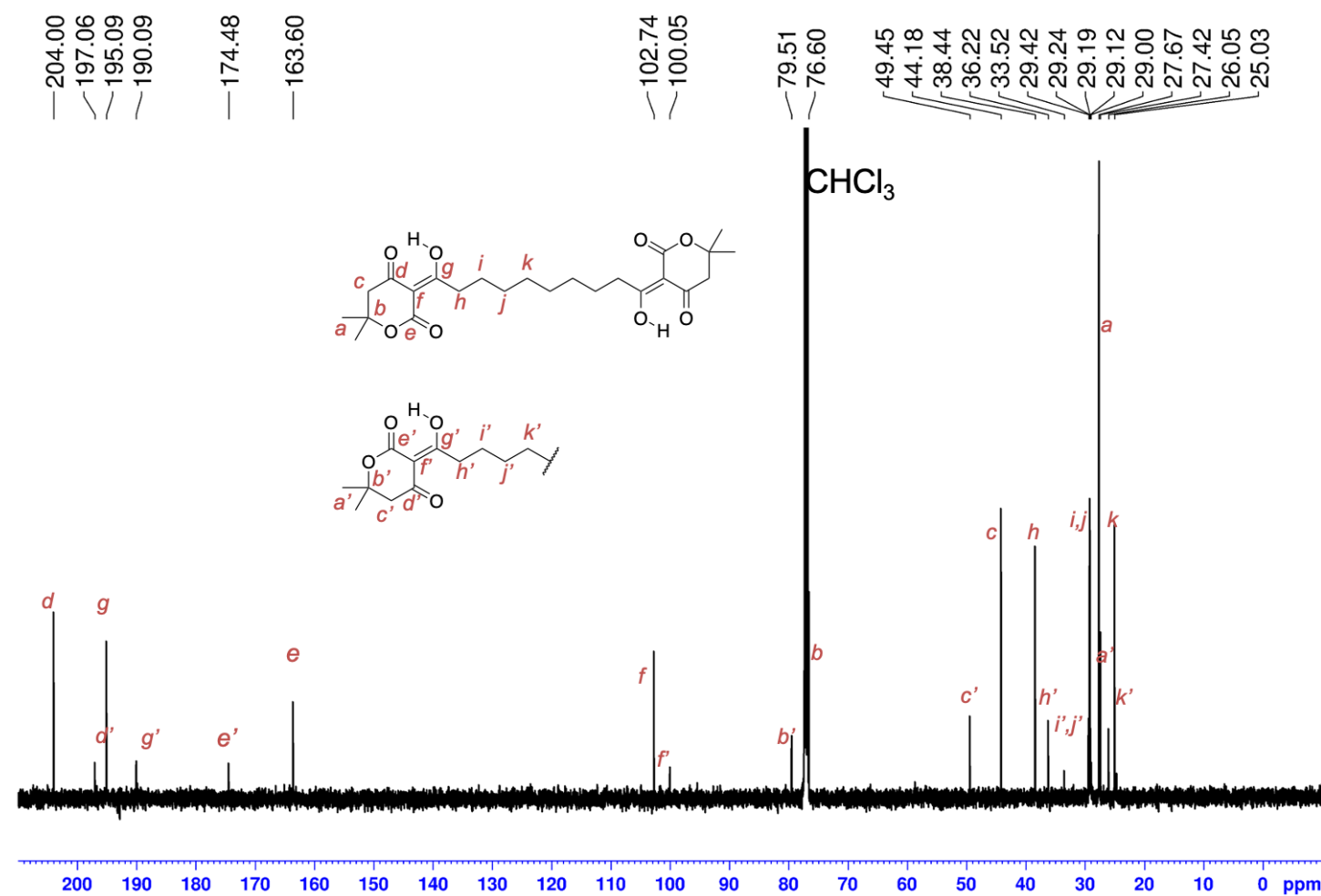

${ }^{13} \mathrm{C}$ NMR of TK 2. 


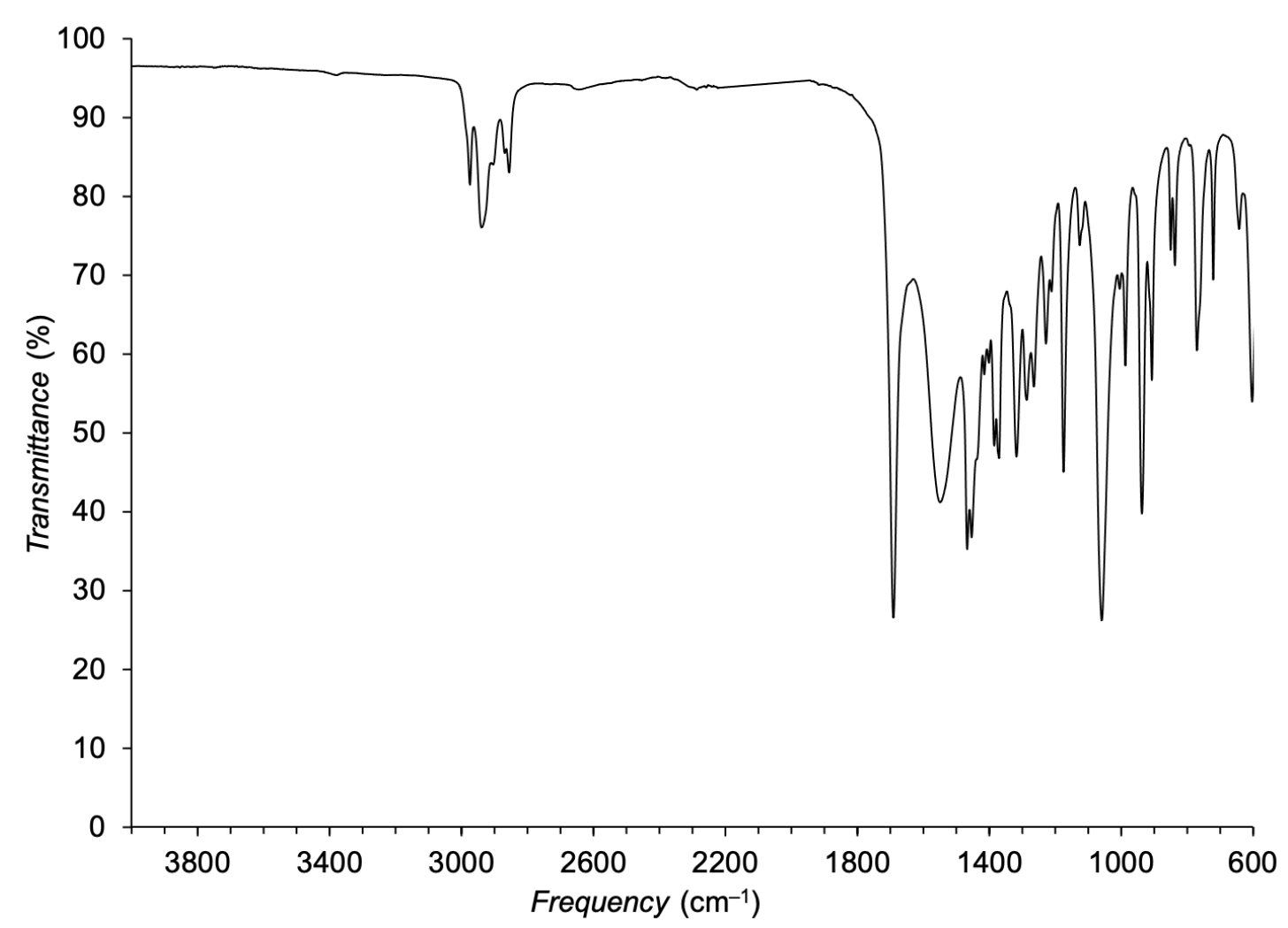

FT-IR of TK 2.

Synthesis of 5,5'-decanedioylbis(2,2-dimethyl-1,3-dioxane-4,6-dione) (Triketone 3).<smiles>CC1CC(=O)OC(C)(C)O1</smiles>

Meldrum's acid (5.00 g, $34.7 \mathrm{mmol})$ was dissolved in pyridine $(25 \mathrm{~mL})$ with stirring at room temperature to from a light-yellow homogenous solution, which was protected from light. The solution was cooled to $0{ }^{\circ} \mathrm{C}$ prior to the slow addition of sebacoyl chloride $(4.04 \mathrm{~g}, 16.9 \mathrm{mmol})$. The orange reaction mixture was stirred at $0{ }^{\circ} \mathrm{C}$ for another $1 \mathrm{~h}$, and the $\mathrm{pH}$ was then adjusted to $<$ 3 by $1.0 \mathrm{M} \mathrm{HCl}$ at $0{ }^{\circ} \mathrm{C}$. The yellow precipitate formed was collected by filtration and washed with $1.0 \mathrm{M} \mathrm{HCl}$. The precipitate was re-dissolved in DCM and further washed with $1.0 \mathrm{M} \mathrm{HCl}(1 \times 20$ $\mathrm{mL})$ and brine $(1 \times 20 \mathrm{~mL})$. The organic phase was separated, dried over $\mathrm{MgSO}_{4}$, filtered and the solvent is removed under vacuum to yield pale yellow solid as the crude product $75 \%$ isolated yield). The crude product was recrystallized in acetone/hexane to yield colorless needles. Characterization Data: ${ }^{1} \mathrm{H}$ NMR (500 MHz, $\left.\mathrm{CDCl}_{3}\right): \delta 15.29(\mathrm{~s}, 2 \mathrm{H}), 3.04-3.07\left(\mathrm{t},{ }^{3} J_{\mathrm{H}-\mathrm{H}}=7.35 \mathrm{~Hz}\right.$, $4 \mathrm{H}), 1.58-1.73(\mathrm{~m}, 16 \mathrm{H}), 1.34-1.40(\mathrm{~m}, 4 \mathrm{H}) \mathrm{ppm} ;{ }^{13} \mathrm{C} \mathrm{NMR}\left(125 \mathrm{MHz}, \mathrm{CDCl}_{3}\right): \delta$ 198.24, 170.59 , $160.24,104.82,91.24,35.73,29.27,28.99,26.82,26.06$ ppm; ESI-MS: $m / z$ for $\left(\mathrm{C}_{22} \mathrm{H}_{30} \mathrm{O}_{10}\right)_{2} \mathrm{Na}^{+}$ $\left([2 \mathrm{M}+\mathrm{Na}]^{+}\right)$calculated 931.3570 , found 931.3695. FT-IR: 3000, 2939, 2925, 2859, 1725, 1642, 1574, 1466, 1458, 1423, 1399, 1390, 1383, 1342, 1294, 1280, 1263, 1242, 1231, 1203, 1151, 1062, $1053,1035,1014,955,916,893,847,798,731,721,643,605,548,506,496,458,410 \mathrm{~cm}^{-1}$. 


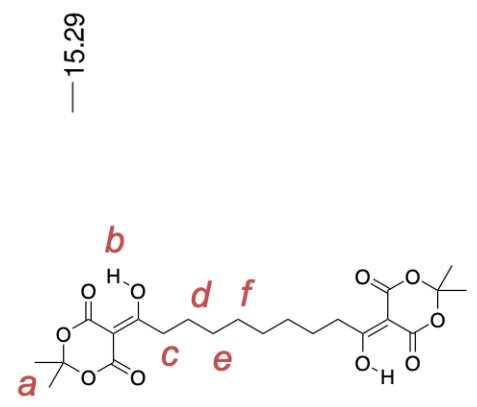

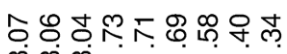

लू लं
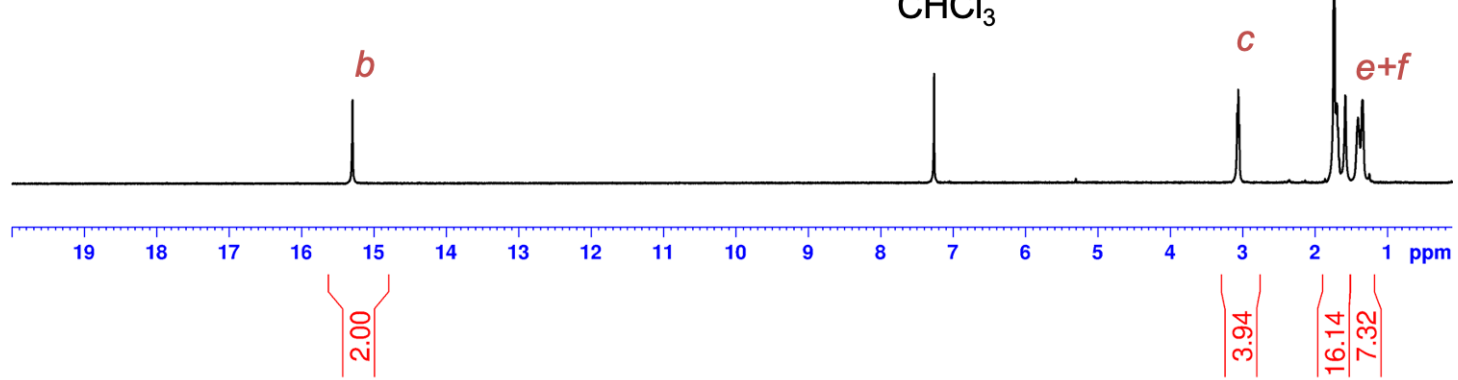

${ }^{1} \mathrm{H}$ NMR of TK 3.

i

i

กล่

นึं ํำ
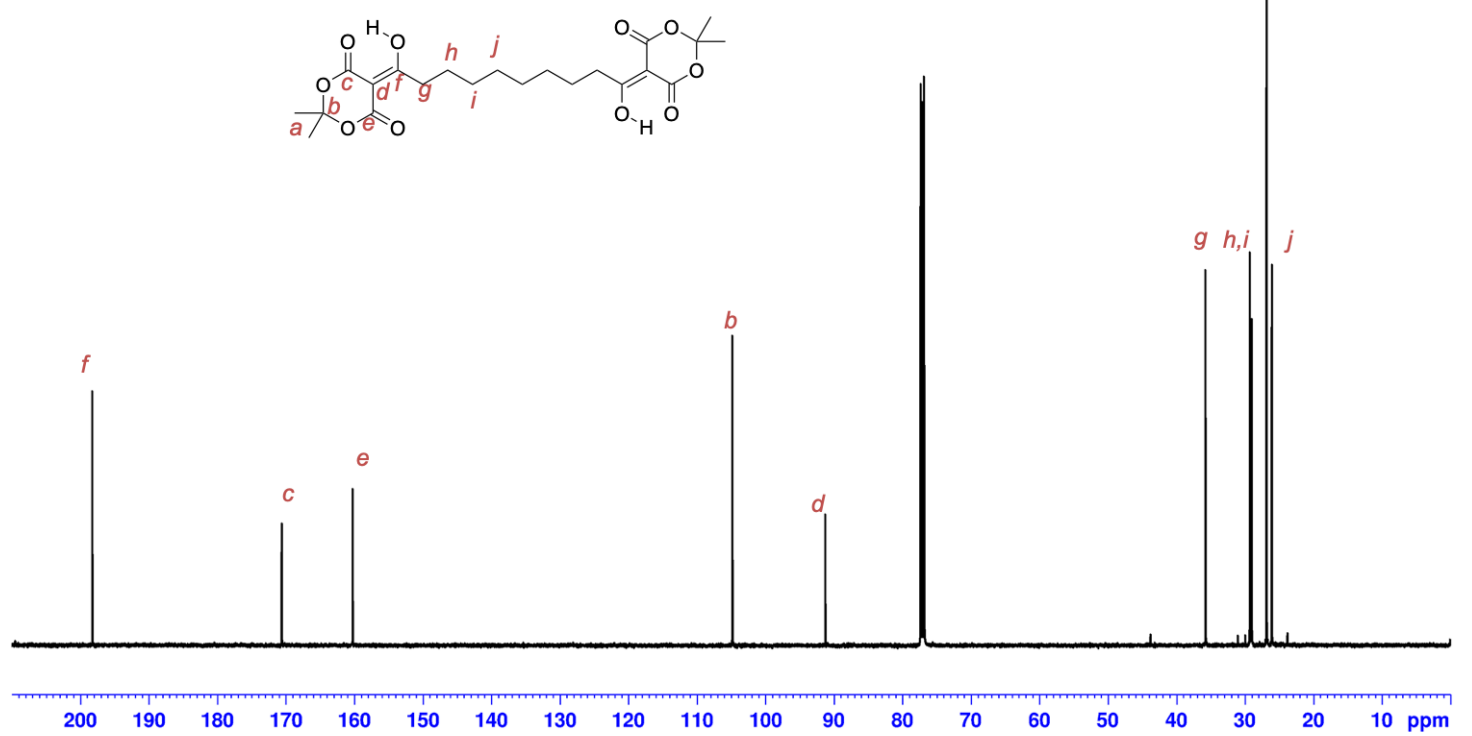

$\mathrm{CHCl}_{3}$

a

${ }^{13} \mathrm{C}$ NMR of TK 3 . 


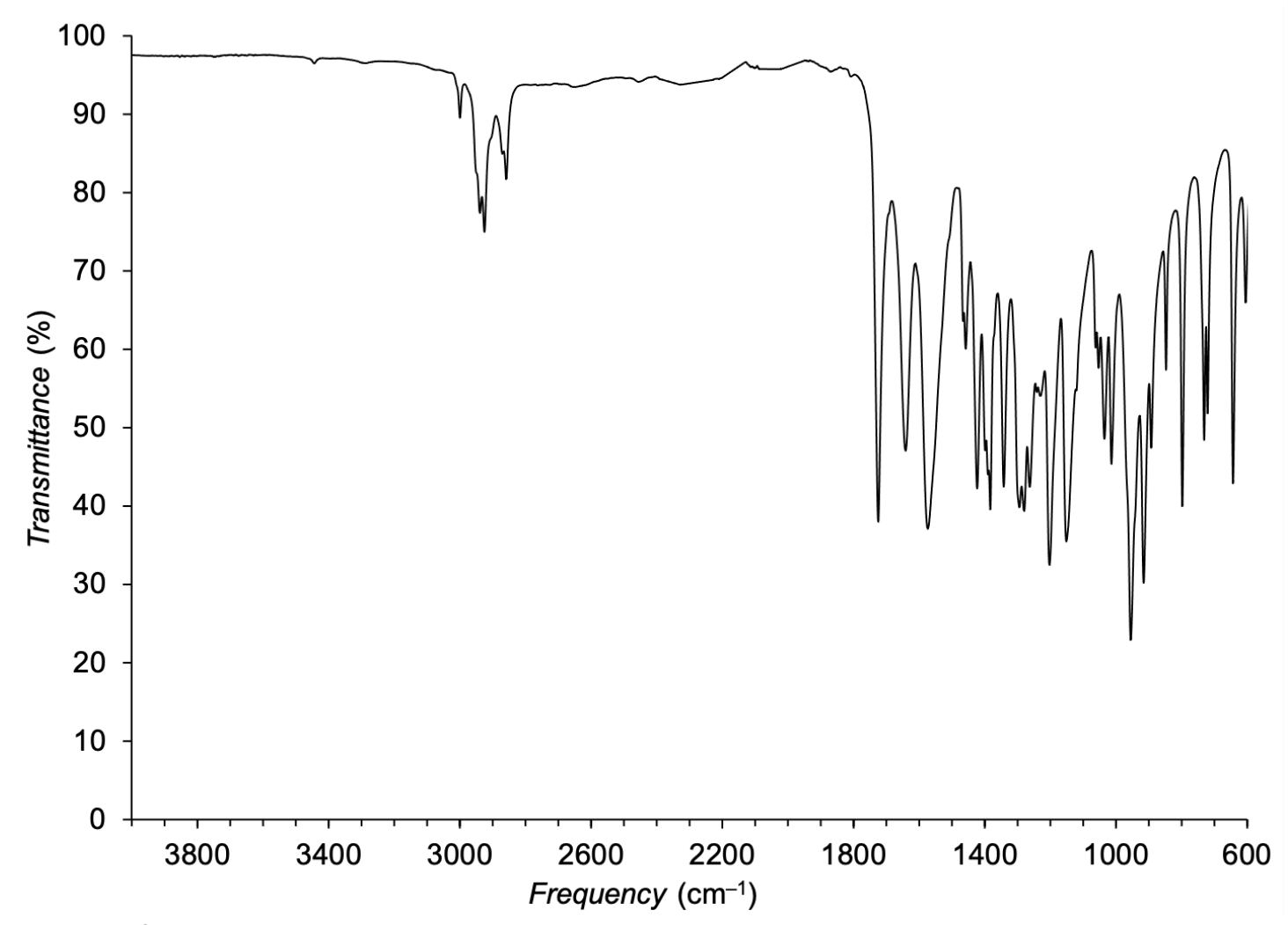

FT-IR of TK 3.

Synthesis of $\quad 5,5^{\prime}$-(1,10-dihydroxydecane-1,10-diylidene)bis(1,3-dimethylpyrimidine2,4,6(1H,3H,5H)-trione) (Triketone 4).<smiles>CN1C(=O)CC(=O)N(C)C1=O</smiles>

dimethylbarbituric acid (100 g, $640.5 \mathrm{mmol})$ was dissolved in pyridine $(220 \mathrm{~mL})$ and DMF (50 $\mathrm{mL}$ ) with stirring at room temperature to give a light-yellow homogenous solution. A solution of sebacoyl chloride $(74.7 \mathrm{~g}, 312.4 \mathrm{mmol})$ in DMF $(50 \mathrm{~mL})$ was added dropwise, which was accompanied by the formation of a precipitate. The mixture was stirred at room temperature during $4 \mathrm{~h}$, at which point the white precipitate was filtered. The precipitate was washed with DMF until colorless. The crude solid was recrystallized from $N, N$-dimethylacetamide to yield colorless needles (85\% isolated yield). Characterization Data: ${ }^{1} \mathrm{H}$ NMR $\left(500 \mathrm{MHz}, \mathrm{CDCl}_{3}\right): \delta 17.53(\mathrm{~s}, 2 \mathrm{H})$, $3.37(\mathrm{~s}, 6 \mathrm{H}) 3.33(\mathrm{~s}, 6 \mathrm{H}), 3.10-3.14\left(\mathrm{t},{ }^{3} J_{\mathrm{H}-\mathrm{H}}=7.60 \mathrm{~Hz}, 4 \mathrm{H}\right), 1.65-1.71(\mathrm{~m}, 4 \mathrm{H}), 1.33-1.42(\mathrm{~m}$, $8 \mathrm{H}) \mathrm{ppm} ;{ }^{13} \mathrm{C} \mathrm{NMR}\left(125 \mathrm{MHz}, \mathrm{CDCl}_{3}\right): \delta 199.84,169.78,160.86,150.40,95.22,36.73,29.37$, 29.10, 28.03, 27.83, 25.79 ppm; ESI-MS: $m / z$ for $\mathrm{C}_{22} \mathrm{H}_{30} \mathrm{~N}_{4} \mathrm{O}_{8} \mathrm{Na}^{+}\left([\mathrm{M}+\mathrm{Na}]^{+}\right)$calculated 501.1961, found 501.1818. FT-IR: 2935, 2868, 1719, 1664, 1552, 1492, 1473, 1446, 1360, 1269, 1225, 1201, 1044, 1005, 994, 948, 877, 841, 787, 754, 730, 713, 672, 568, 503, 483, 421, $403 \mathrm{~cm}^{-1}$. 


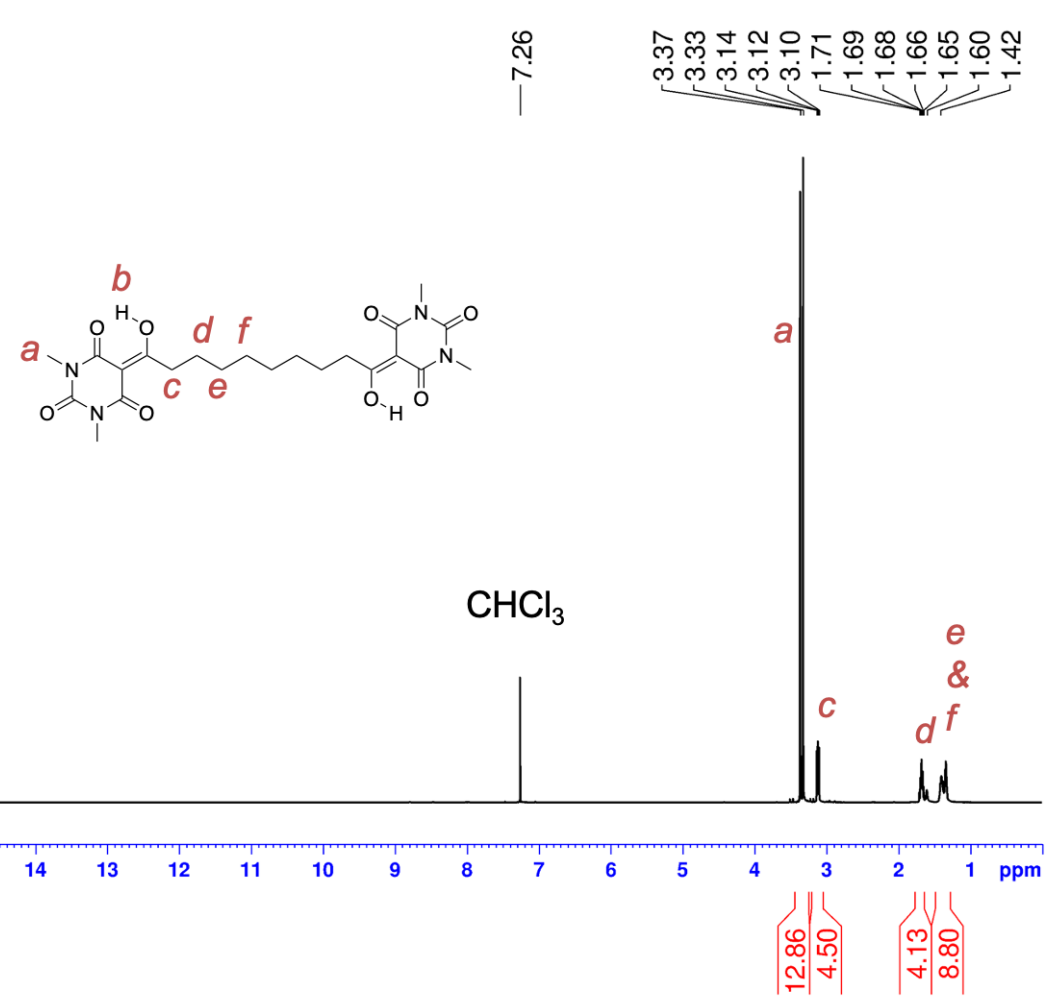

${ }^{1} \mathrm{H}$ NMR of TK 4.

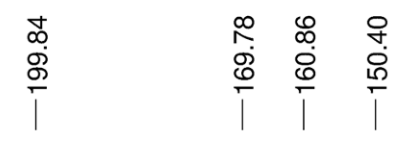

กิ

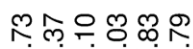

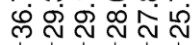

$$
\text { 1 }
$$
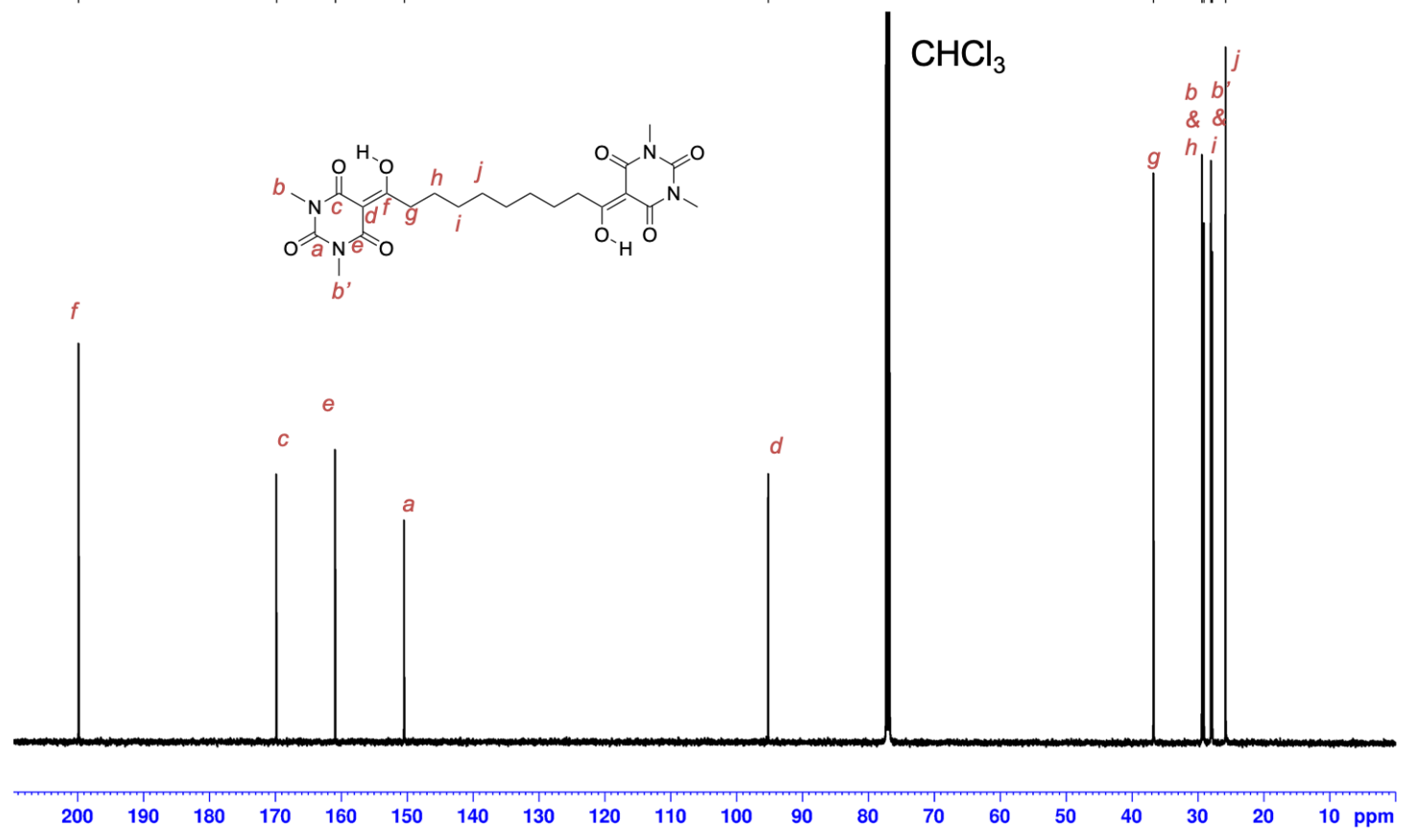

${ }^{13} \mathrm{C}$ NMR of TK 4. 


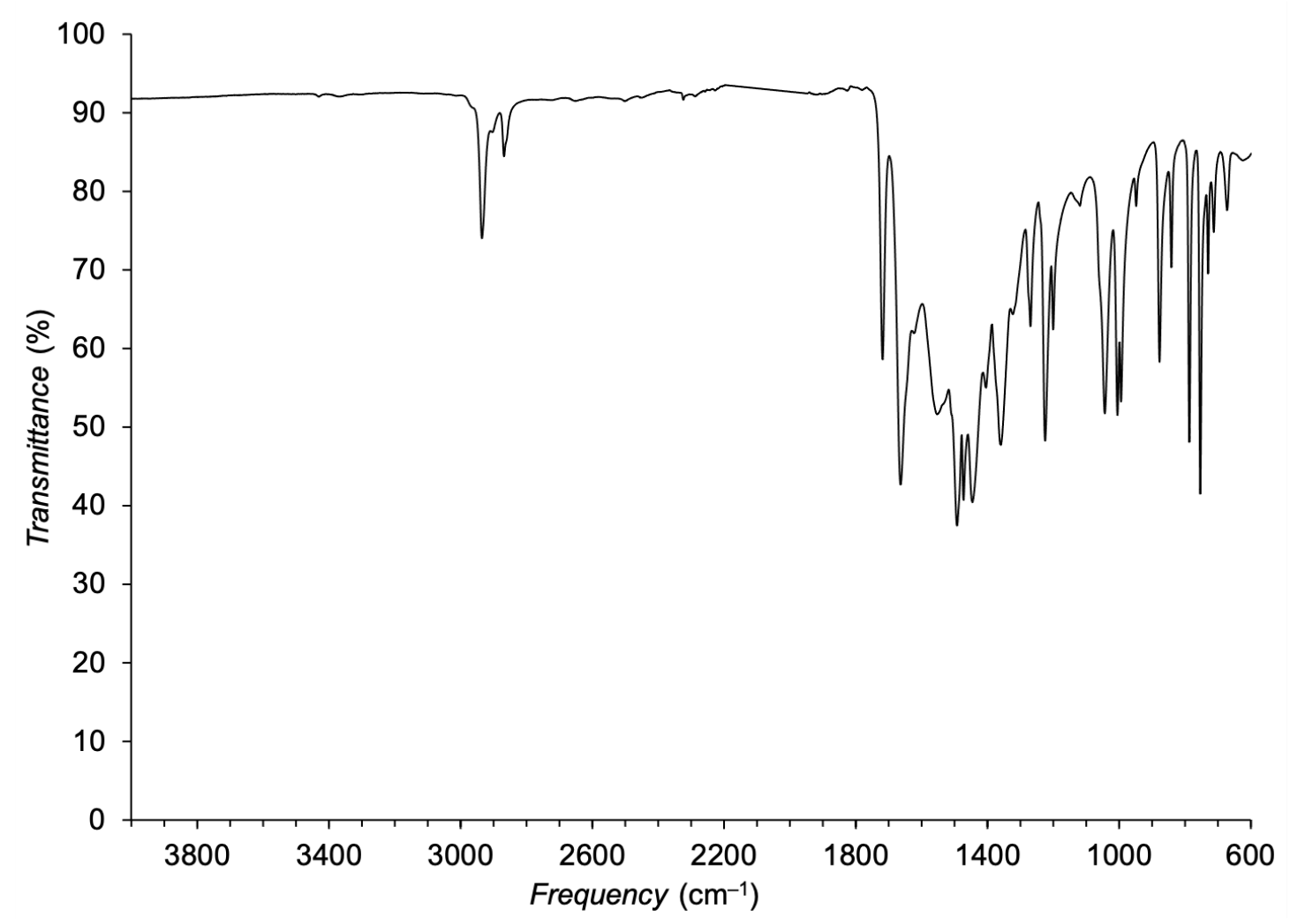

FT-IR of TK 4.

General Procedure for the Synthesis of Diketoenamines 1-4. To any of the acetyl-diones 1-4 $(1.00 \mathrm{mmol})$ in $\mathrm{CHCl}_{3}(4 \mathrm{~mL})$ was added $N, N$-dimethylethylenediamine $(1.00 \mathrm{mmol})$. The reaction mixture was stirred for $2 \mathrm{~h}$ at ambient temperature, after which the volatiles were removed under reduced pressure and the crude product was purified via a silica plug from 9:1 EtOAc:MeOH $(v / v)$ to obtain the respective diketoenamines $\mathbf{1}-\mathbf{4}$.

2-(1-((2-(dimethylamino)ethyl)amino)ethylidene)-5,5-dimethylcyclohexane-1,3-dione (DKE 1).<smiles>CC(=O)C1=C(O)CC(C)(C)CC1=O</smiles>

Isolated as brown oil (76\% yield). Characterization data: ${ }^{1} \mathrm{H} \mathrm{NMR}\left(500 \mathrm{MHz}, \mathrm{CDCl}_{3}\right): \delta 13.36$ (br $\mathrm{s}, 1 \mathrm{H}), 3.44-3.48\left(\mathrm{td},{ }^{3} J_{\mathrm{H}-\mathrm{H}}=6.20 \mathrm{~Hz}, 5.10 \mathrm{~Hz}, 2 \mathrm{H}\right), 2.56-2.59\left(\mathrm{t}, 2 \mathrm{H},{ }^{3} J_{\mathrm{H}-\mathrm{H}}=6.35 \mathrm{~Hz}\right), 2.56(\mathrm{~s}$, $3 \mathrm{H}), 2.36$ (br s, 4H), $2.30(\mathrm{~s}, 6 \mathrm{H}), 1.02(\mathrm{~s}, 6 \mathrm{H}) \mathrm{ppm} ;{ }^{13} \mathrm{C} \mathrm{NMR}\left(125 \mathrm{MHz}, \mathrm{CDCl}_{3}\right): \delta 197.35$, 173.21 , 107.95, 57.39, 52.87, 45.29, 41.40, 30.08, 28.28, $18.25 \mathrm{ppm}$; ESI-MS: $\mathrm{m} / z$ for $\left(\mathrm{C}_{14} \mathrm{H}_{24} \mathrm{~N}_{2} \mathrm{O}_{2}\right)_{2} \mathrm{H}^{+}\left([2 \mathrm{M}+\mathrm{H}]^{+}\right)$calculated 505.3748, found 505.4131. FT-IR: 3454, 2953, 2867, 2822, 2770, 1634, 1567, 1458, 1420, 1385, 1367, 1323, 1300, 1285, 1210, 1184, 1142, 1125, 1099, $1039,948,879,821,786,728,624,585,541,512,463 \mathrm{~cm}^{-1}$. 


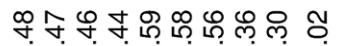

लं लं

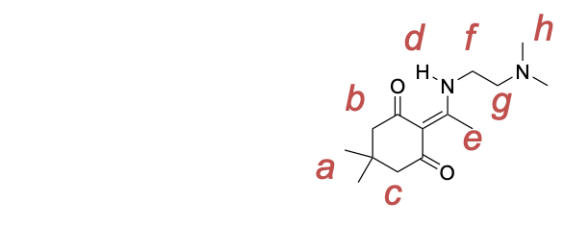

m m

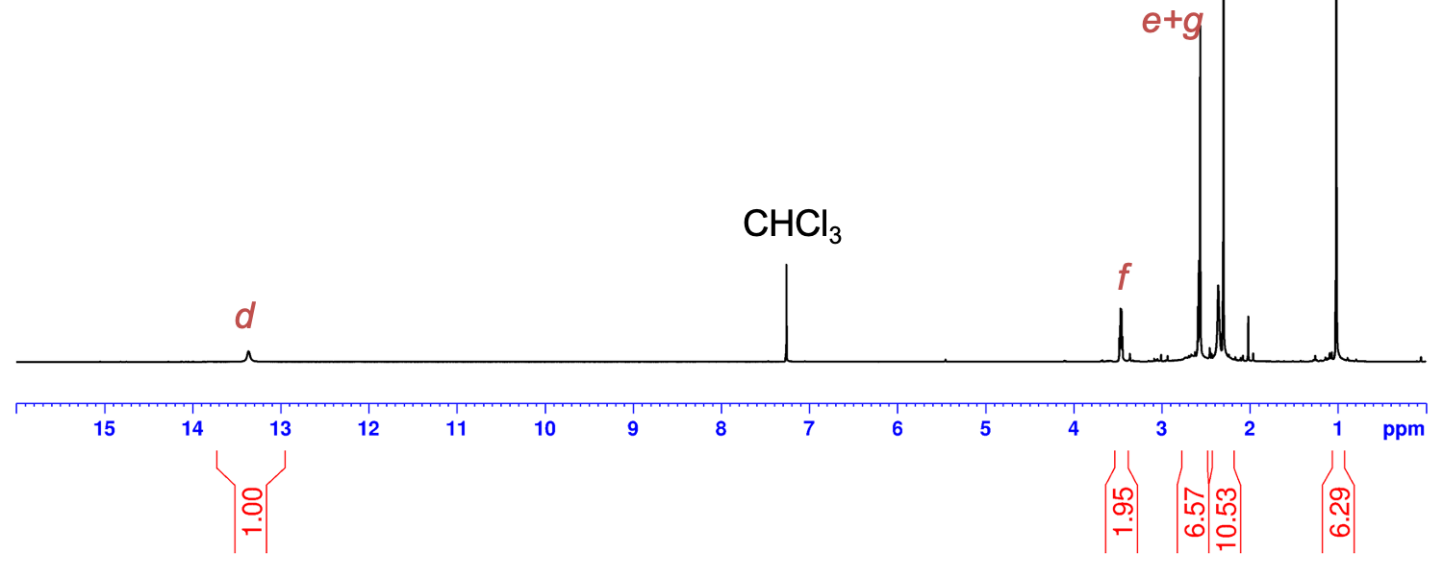

${ }^{1} \mathrm{H}$ NMR of DKE 1.
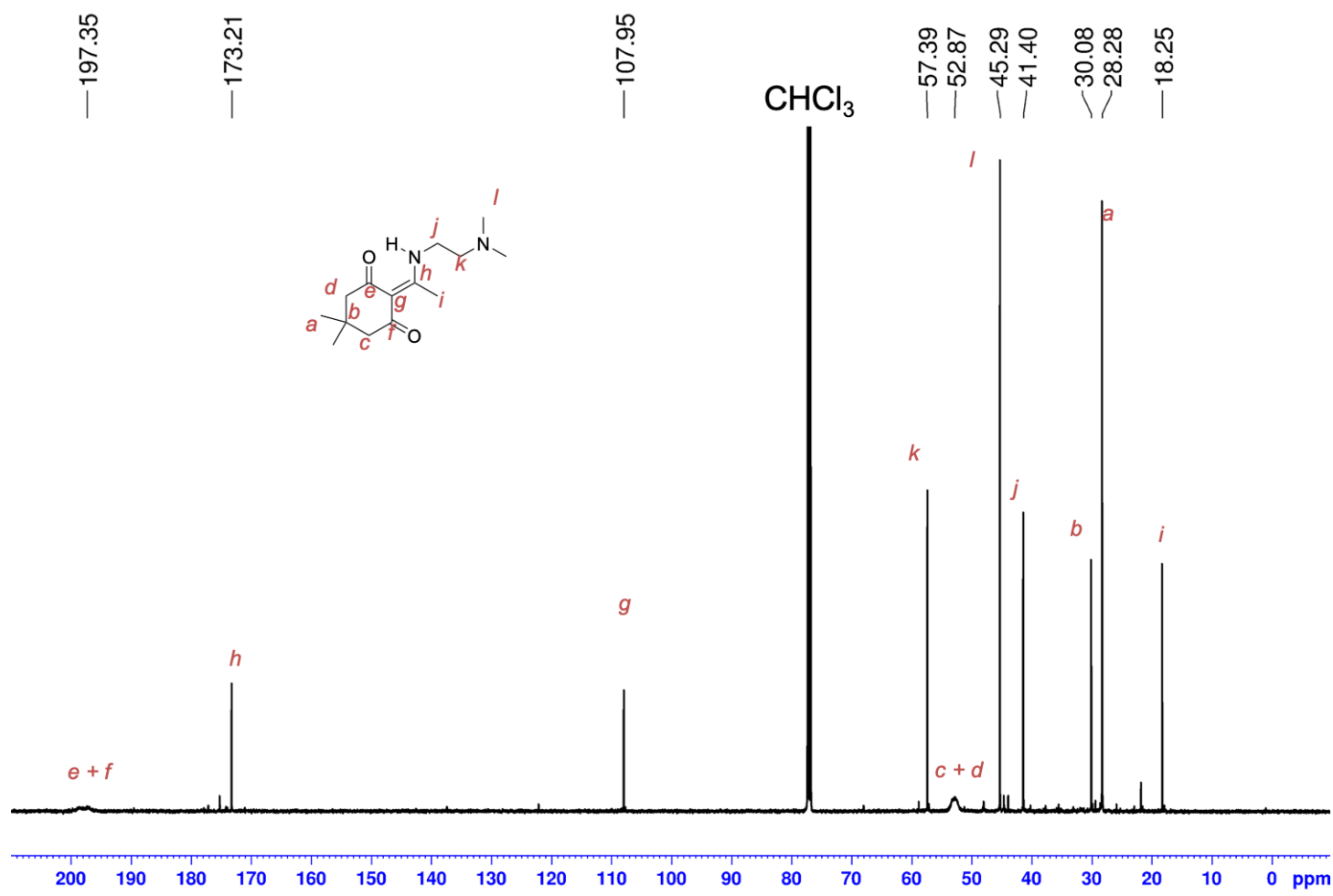

${ }^{13} \mathrm{C}$ NMR of DKE 1. 


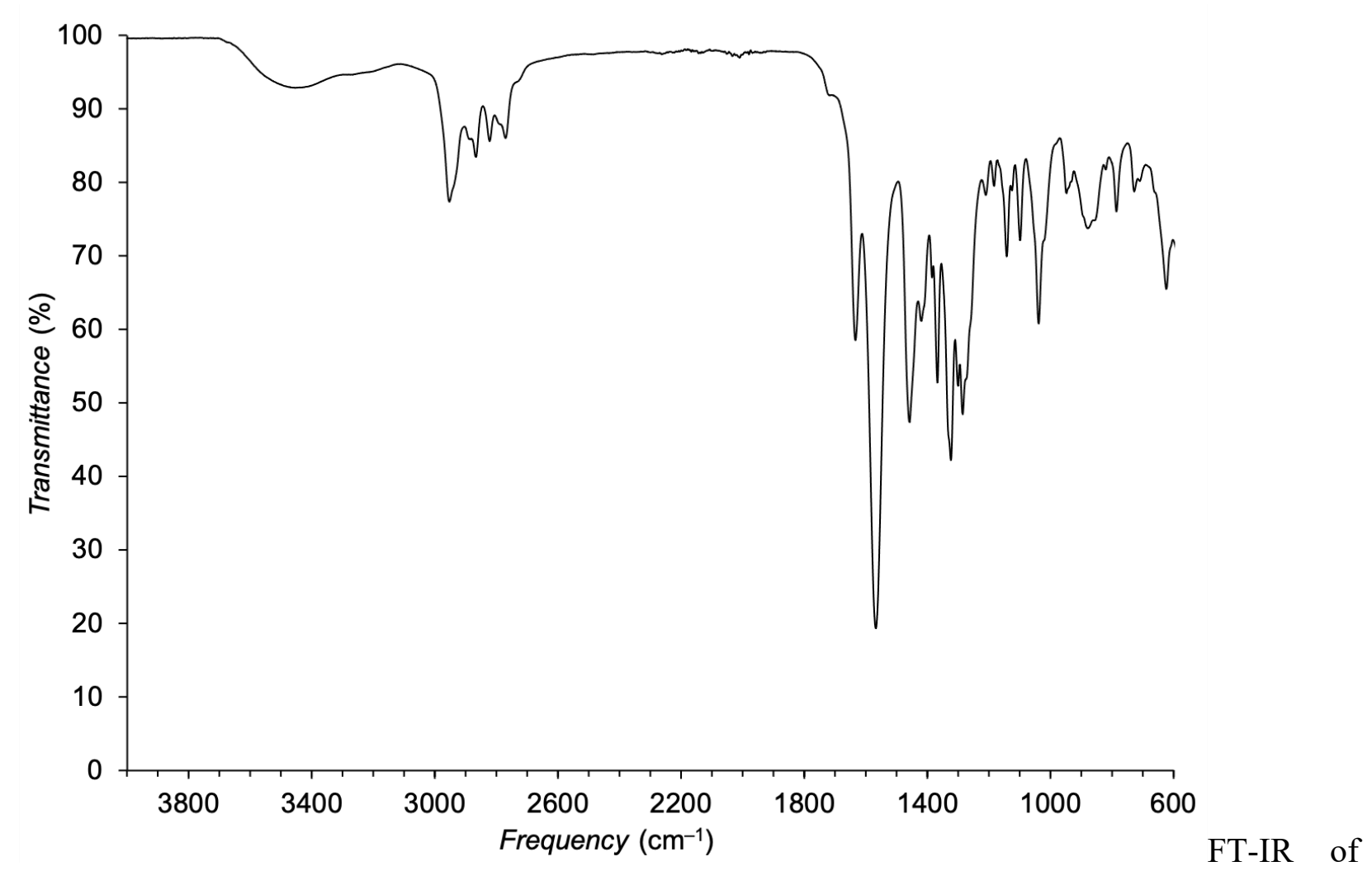

DKE 1.

3-(1-((2-(dimethylamino)ethyl)amino)ethylidene)-6,6-dimethyldihydro-2H-pyran-2,4(3H)dione (DKE 2).

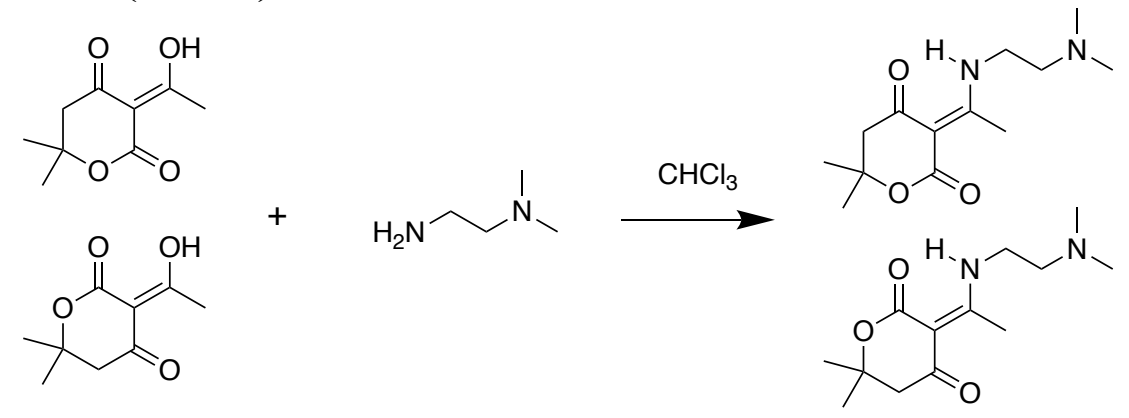

Isolated as pale yellow solid (83\% yield) consisting of two regioisomers in 1:4.5 ratio. Characterization data: ${ }^{1} \mathrm{H}$ NMR $\left(500 \mathrm{MHz}, \mathrm{CDCl}_{3}\right): \delta 12.96(\mathrm{~s}, 1 \mathrm{H}$, major), $11.82(\mathrm{~s}, 1 \mathrm{H}$, minor), $3.45-3.48\left(\mathrm{td}\right.$, major, $\left.{ }^{3} J_{\mathrm{H}-\mathrm{H}}=5.95 \mathrm{~Hz}, 5.40 \mathrm{~Hz}, 2 \mathrm{H}\right), 2.56-2.58\left(\mathrm{t}\right.$, major, $\left.{ }^{3} J_{\mathrm{H}-\mathrm{H}}=6.20 \mathrm{~Hz}, 3 \mathrm{H}\right)$, 2.55 (s, 2H, major), 2.54 (s, 2H, major), 2.31 (s, 6H, major), 1.41 (s, 6H, major) ppm; ${ }^{13} \mathrm{C} \mathrm{NMR}$ $\left(125 \mathrm{MHz}, \mathrm{CDCl}_{3}\right): \delta 193.47,191.16,173.20,172.35,170.75,166.98,97.02,95.37,75.63,57.33$, 49.64, 48.19, 41.82, 27.46, 18.07 ppm; ESI-MS: $m / z$ for $\left(\mathrm{C}_{13} \mathrm{H}_{22} \mathrm{~N}_{2} \mathrm{O}_{3}\right)_{2} \mathrm{H}^{+}\left([2 \mathrm{M}+\mathrm{H}]^{+}\right)$calculated 509.3334, found 509. FT-IR: 3250, 3066, 2974, 2947, 2859, 2818, 2765, 1679, 1652, 1617, 1594, $1563,1443,1412,1384,1375,1370,1334,1272,1235,1201$,1175, 1159, 1123 ,1098, 1071, 1055 1038, 993,951 ,928, 858, 841, 786, 772, 727, 651, 632, 595, 578, 561, 523, 481, $427 \mathrm{~cm}^{-1}$. 


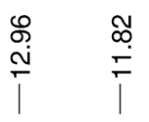
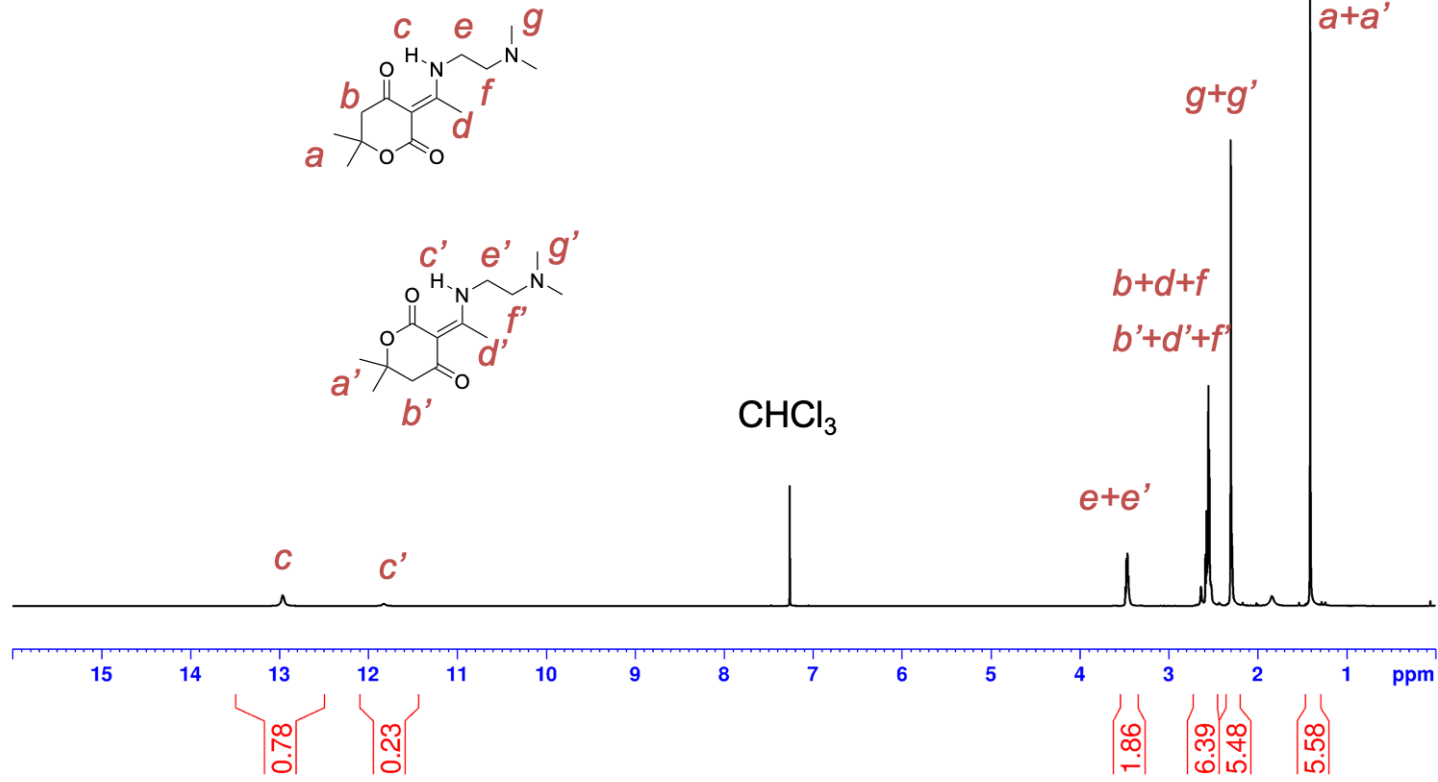

${ }^{1} \mathrm{H}$ NMR of DKE 2.

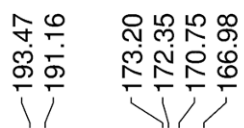

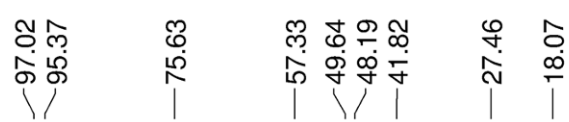

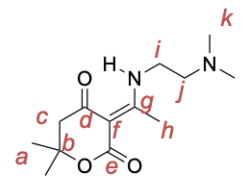

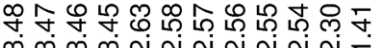
ल ल

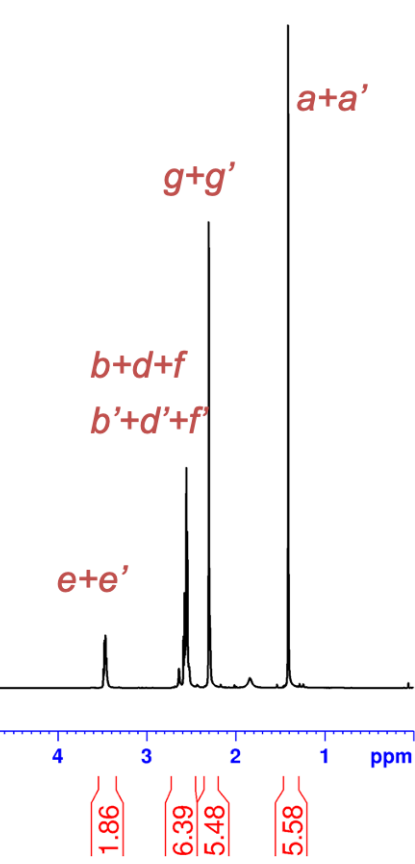




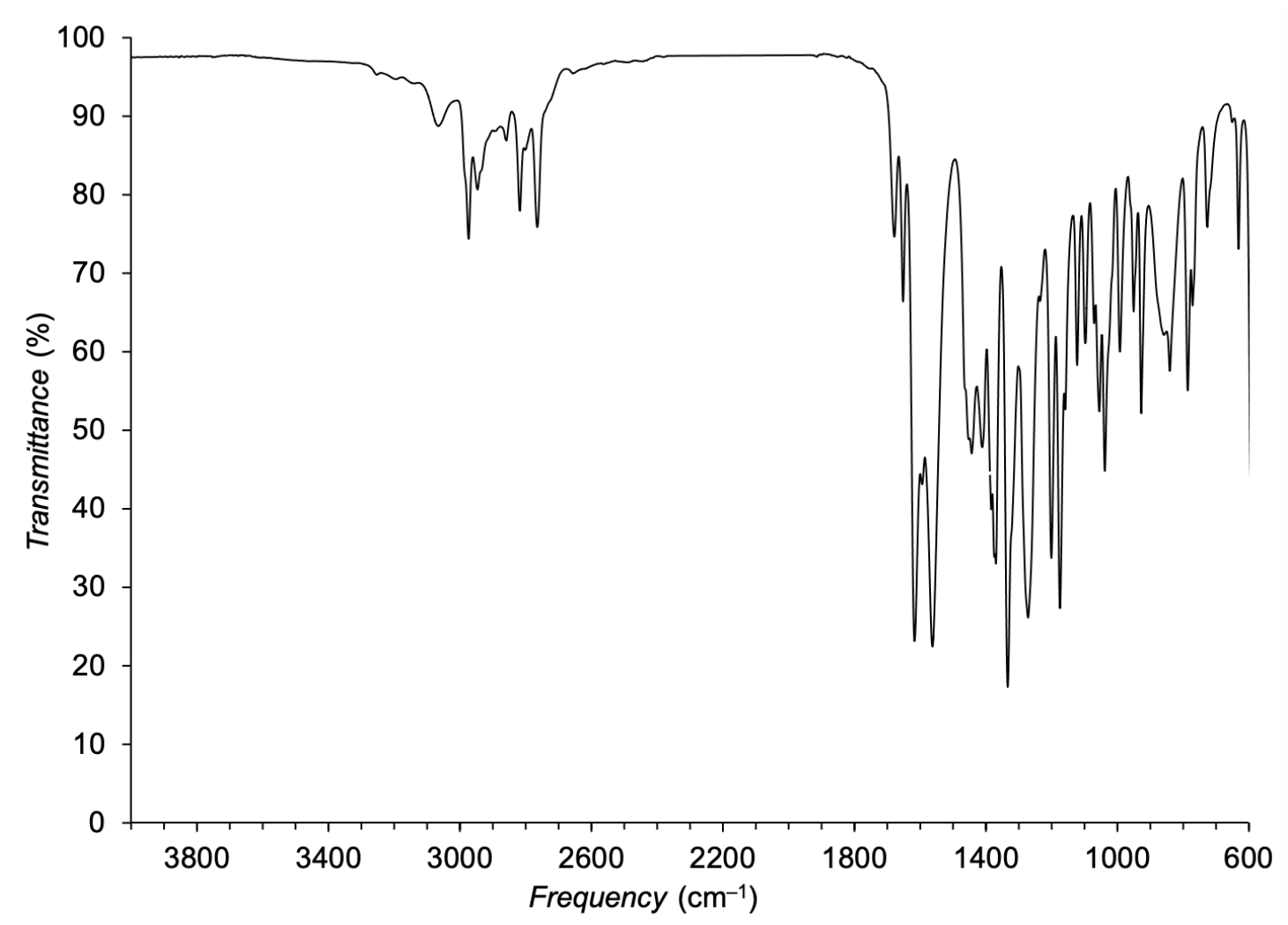

FT-IR of DKE 2.

5-(1-((2-(dimethylamino)ethyl)amino)ethylidene)-2,2-dimethyl-1,3-dioxane-4,6-dione (DKE 3).<smiles>CC(C1=C(O)OC(C)(C)OC1=C(C)C(C)(C)C)=C1C(=O)OC(C)(C)OC1=O</smiles>

Isolated as a pale yellow solid (68\% yield). Characterization data: ${ }^{1} \mathrm{H}$ NMR (500 MHz, $\left.\mathrm{CDCl}_{3}\right): \delta$ $11.46($ br s, $1 \mathrm{H}), 3.46-3.49\left(\mathrm{td},{ }^{3} J_{\mathrm{H}-\mathrm{H}}=6.20 \mathrm{~Hz}, 5.10 \mathrm{~Hz}, 2 \mathrm{H}\right), 2.62(\mathrm{~s}, 3 \mathrm{H}), 2.57-2.60\left(\mathrm{t},{ }^{3} J_{\mathrm{H}-\mathrm{H}}=\right.$ $6.25 \mathrm{~Hz}, 2 \mathrm{H}), 2.30(\mathrm{~s}, 6 \mathrm{H}), 1.67(\mathrm{~s}, 6 \mathrm{H}) \mathrm{ppm} ;{ }^{13} \mathrm{C} \mathrm{NMR}\left(125 \mathrm{MHz}, \mathrm{CDCl}_{3}\right): \delta 173.20,167.09$, 163.44, 102.30, 84.44, 57.18, 45.28, 41.95, 26.40, $18.22 \mathrm{ppm}$; ESI-MS: $m / z$ for $\left(\mathrm{C}_{12} \mathrm{H}_{20} \mathrm{~N}_{2} \mathrm{O}_{4}\right)_{2} \mathrm{H}^{+}$ $\left([2 \mathrm{M}+\mathrm{H}]^{+}\right)$calculated 513.2919, found 513.3124. FT-IR: 3100, 2998, 2983, 2943, 2859, 2820, 2793, 2766, 2728, 1712, 1698, 1652, 1576, 1459, 1422, 1394, 1387, 1375, 1322, 1296, 1267, 1204, $1166,1095,1069,1045,1039,1015,988,955,927,890,866,832,791,738,720,648,583,570$, $531,518,510,448 \mathrm{~cm}^{-1}$. 


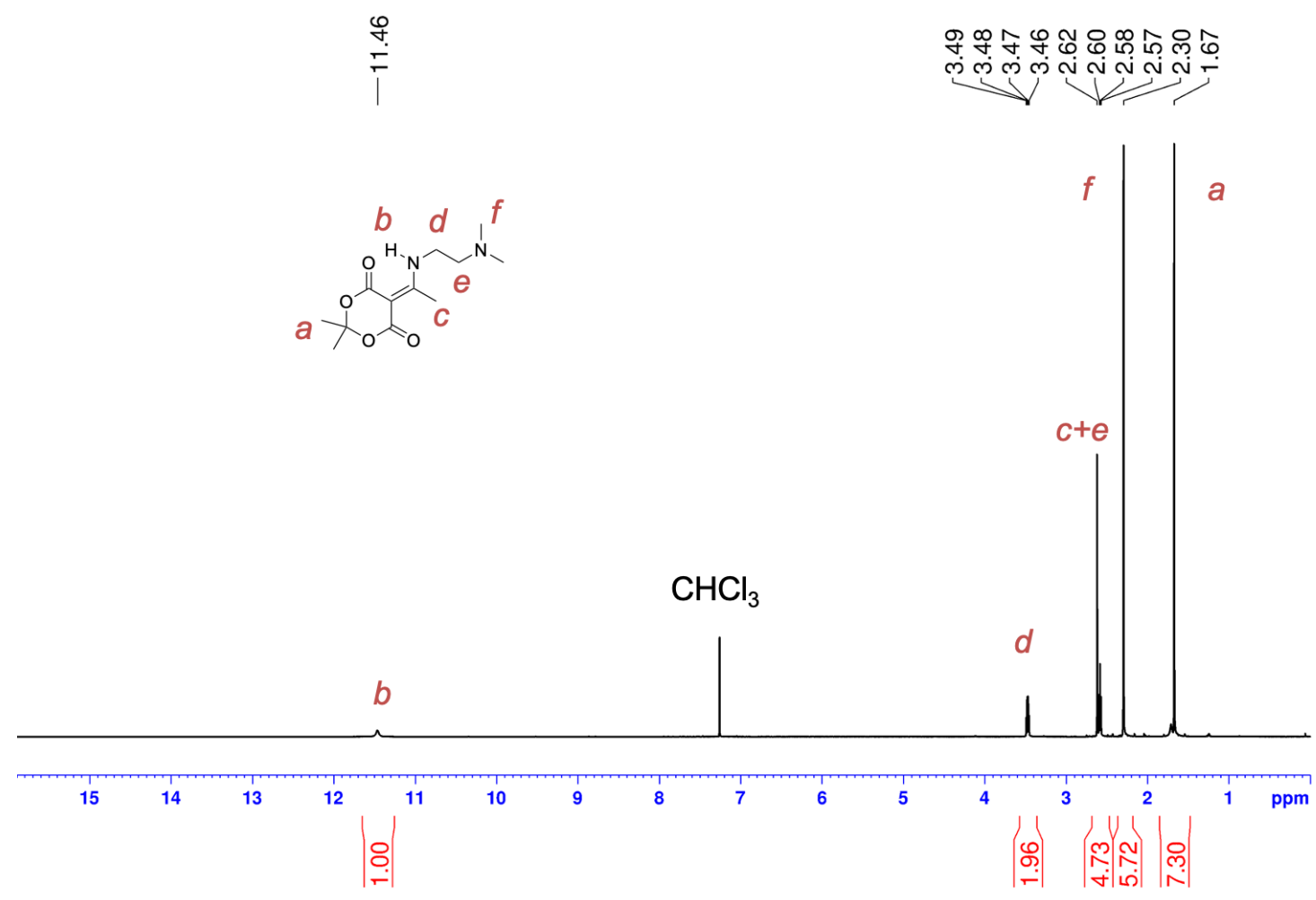

${ }^{1} \mathrm{H}$ NMR of DKE 3.

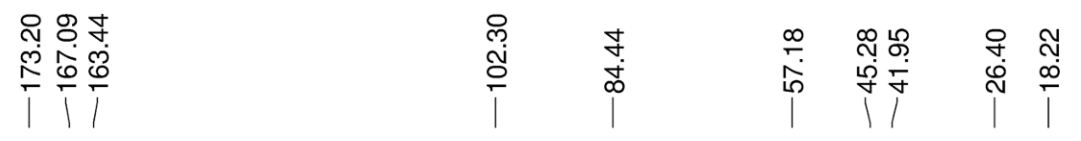

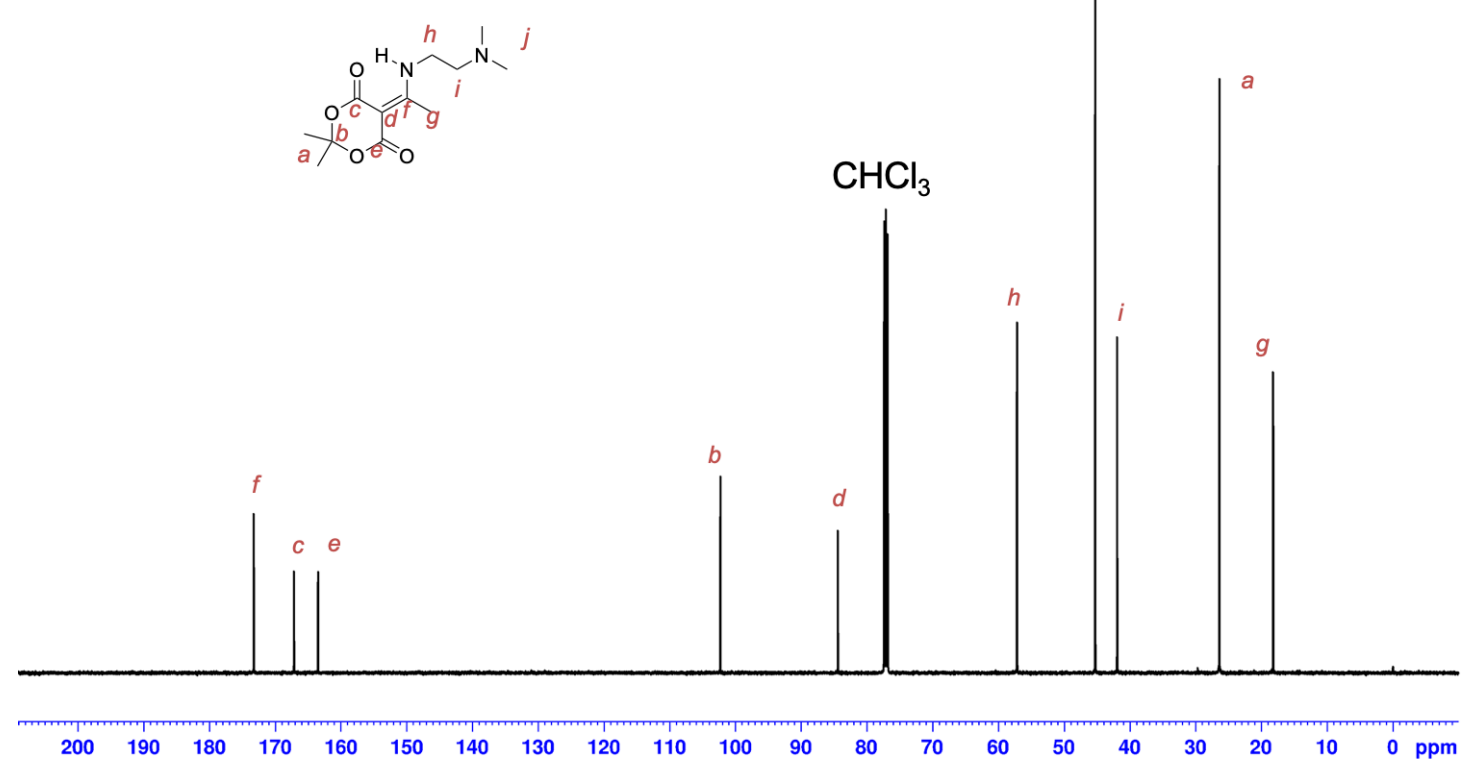

${ }^{13} \mathrm{C}$ NMR of DKE 3. 


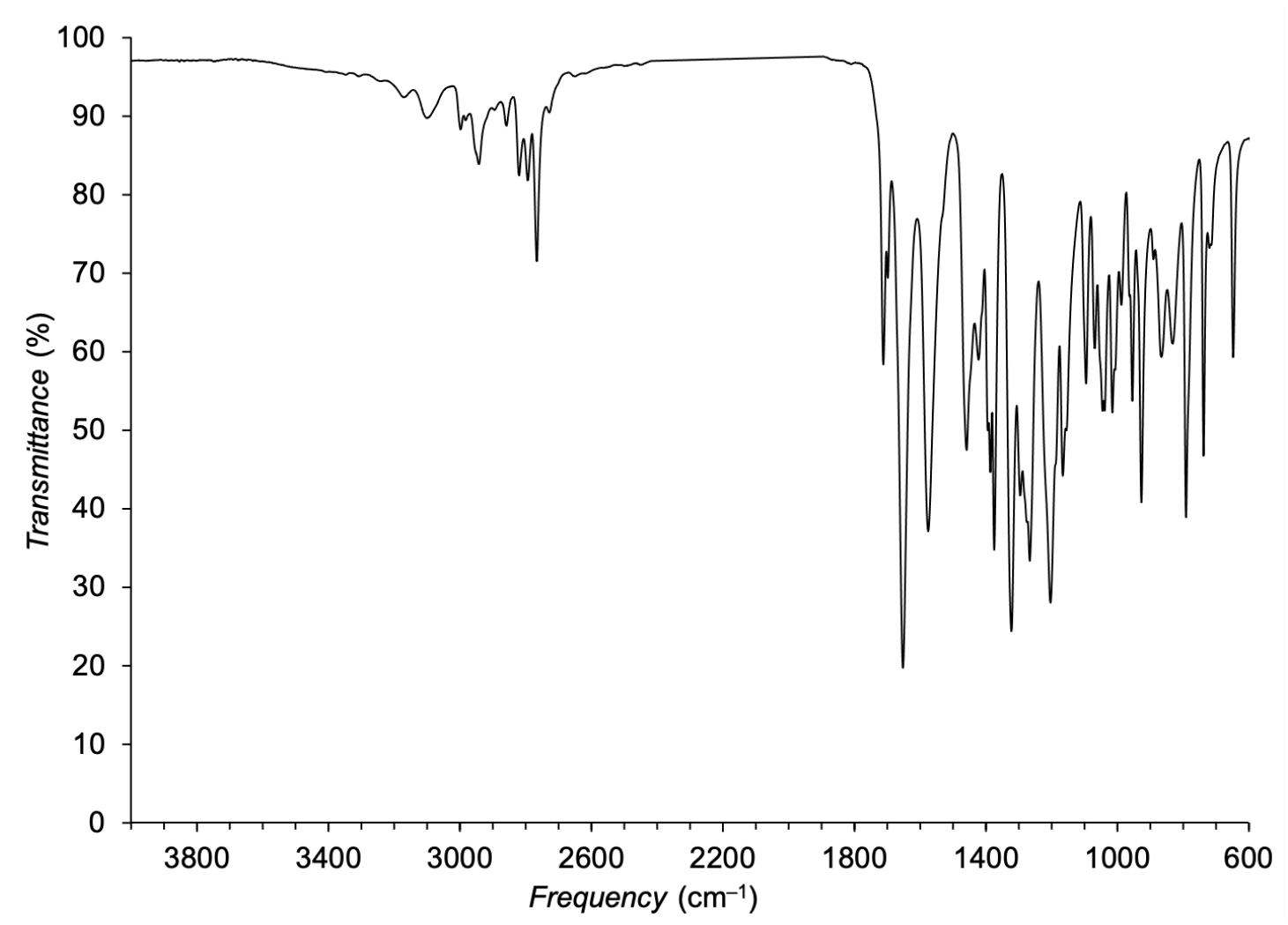

FT-IR of DKE 3.

5-(1-((2-(dimethylamino)ethyl)amino)ethylidene)-1,3-dimethylpyrimidine-2,4,6(1H,3H,5H)trione (DKE 4).<smiles>CC(=C1C(=O)N(C)C(=O)N(C)C1=O)C(C)=c1c(=O)n(C)c(=O)n(C)c1=C(C)NCCN(C)C</smiles>

Isolated as a pale pink solid (74\% yield). Characterization data: ${ }^{1} \mathrm{H} \mathrm{NMR}\left(500 \mathrm{MHz}, \mathrm{CDCl}_{3}\right): \delta$ $12.55($ br s, $1 \mathrm{H}), 3.49-3.52\left(\mathrm{td},{ }^{3} J_{\mathrm{H}-\mathrm{H}}=6.20 \mathrm{~Hz}, 5.10 \mathrm{~Hz}, 2 \mathrm{H}\right), 3.32(\mathrm{~s}, 3 \mathrm{H}), 3.30(\mathrm{~s}, 3 \mathrm{H}), 2.70(\mathrm{~s}$, $3 \mathrm{H}), 2.58-2.61\left(\mathrm{t},{ }^{3} J_{\mathrm{H}-\mathrm{H}}=6.25 \mathrm{~Hz}, 2 \mathrm{H}\right), 2.31(\mathrm{~s}, 6 \mathrm{H}) \mathrm{ppm} ;{ }^{13} \mathrm{C} \mathrm{NMR}\left(125 \mathrm{MHz}, \mathrm{CDCl}_{3}\right): \delta 173.78$, 166.20, 163.13, 151.48, 90.43, 57.51, 45.42, 41.99, 27.86, 27.65, $18.28 \mathrm{ppm}$; ESI-MS $\mathrm{m} / \mathrm{z}$ for $\left(\mathrm{C}_{12} \mathrm{H}_{20} \mathrm{~N}_{4} \mathrm{O}_{3}\right)_{2} \mathrm{H}^{+}\left([2 \mathrm{M}+\mathrm{H}]^{+}\right)$calculated 537.3144, found 537.2999. FT-IR: 3588, 3588, 2949, 2856, 2815, 2758, 1701, 1642, 1613, 1578, 1462, 1409, 1346, 1298, 1276, 1257, 1218, 1167, 1093, $1037,989,946,916,852,783,774,754,741,687,574,555,501,467 \mathrm{~cm}^{-1}$. 


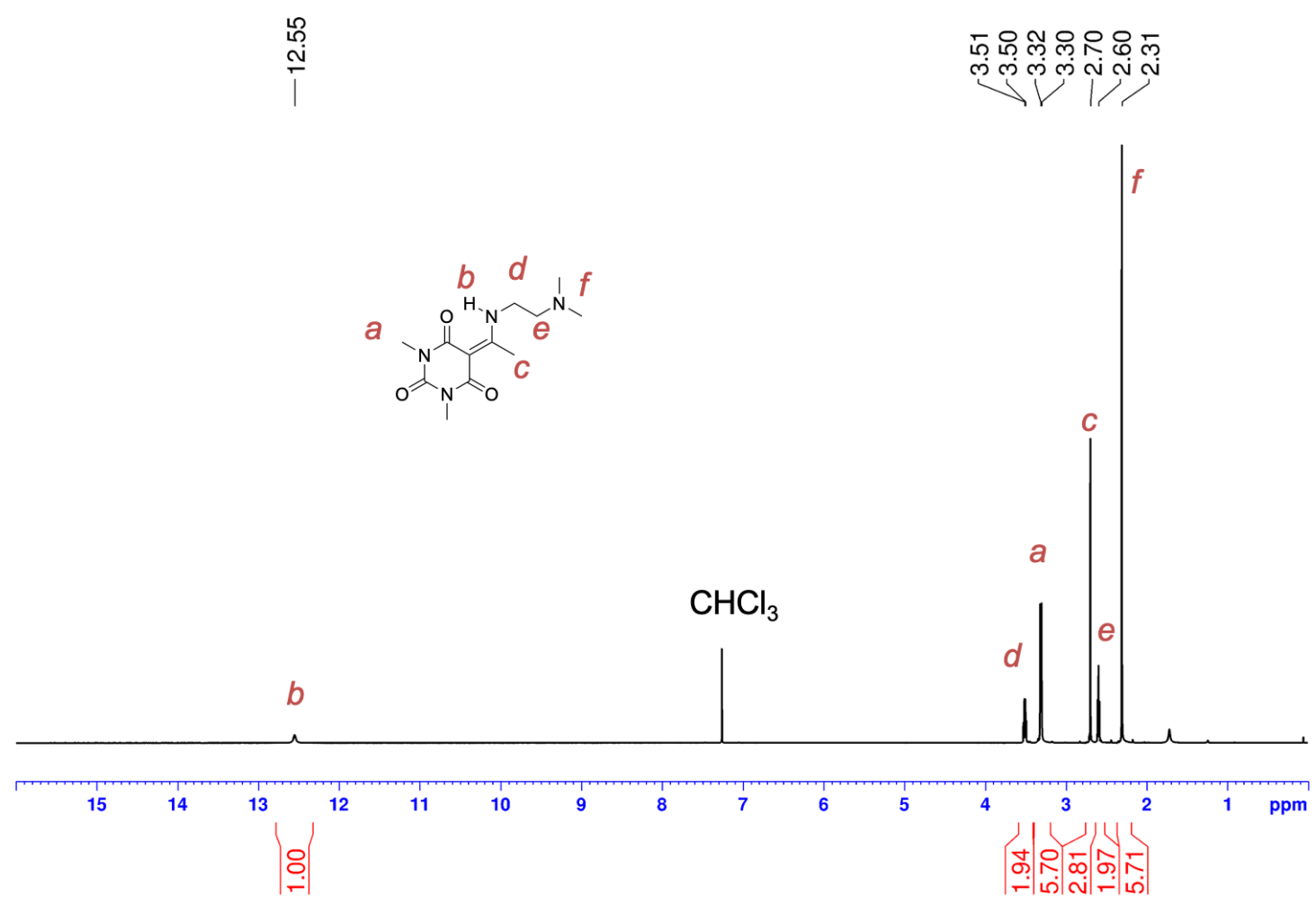

${ }^{1} \mathrm{H}$ NMR of DKE 4.

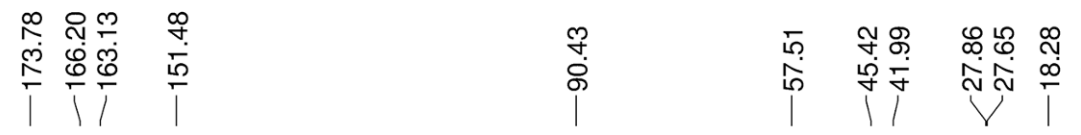

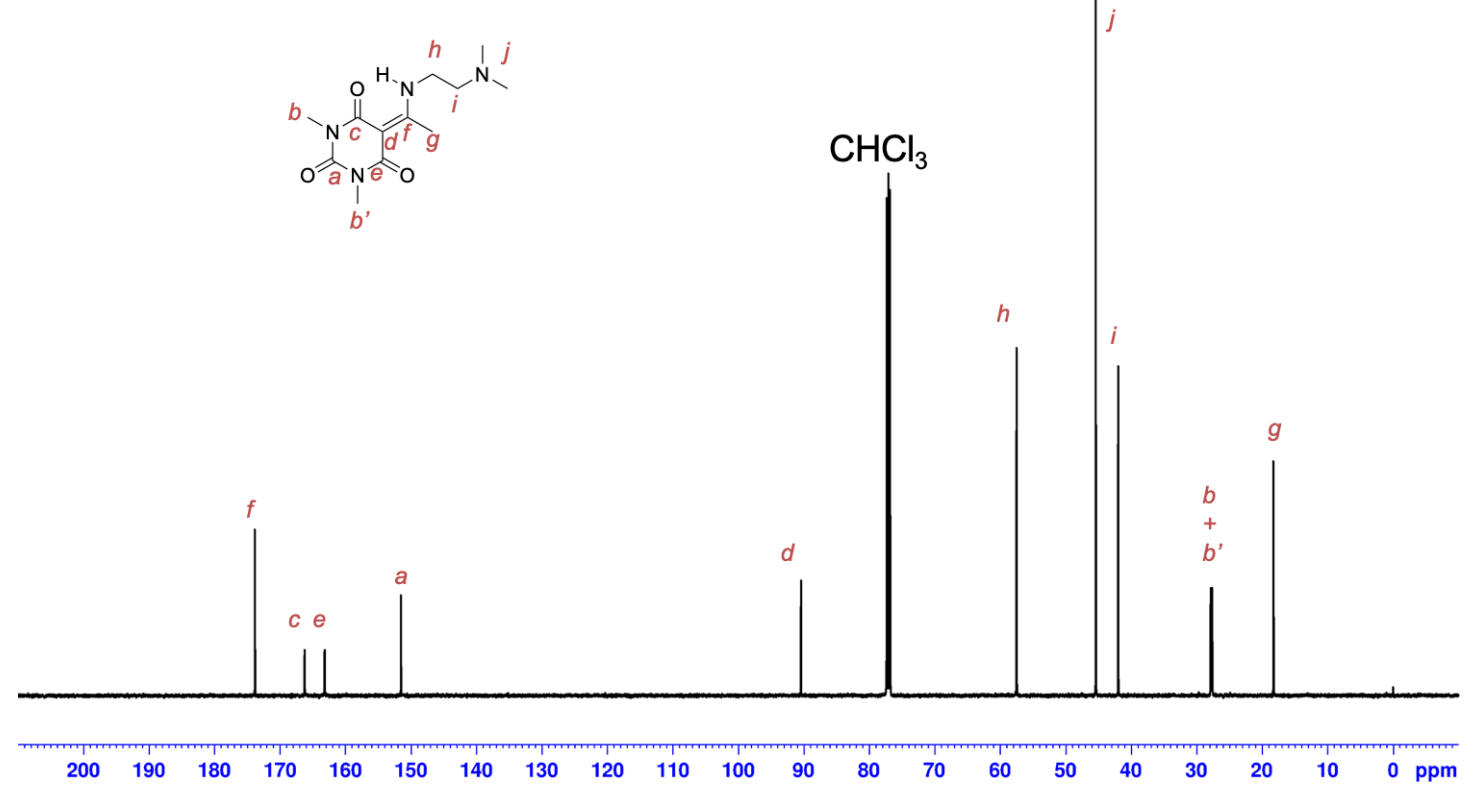

${ }^{13} \mathrm{C}$ NMR of DKE 4. 


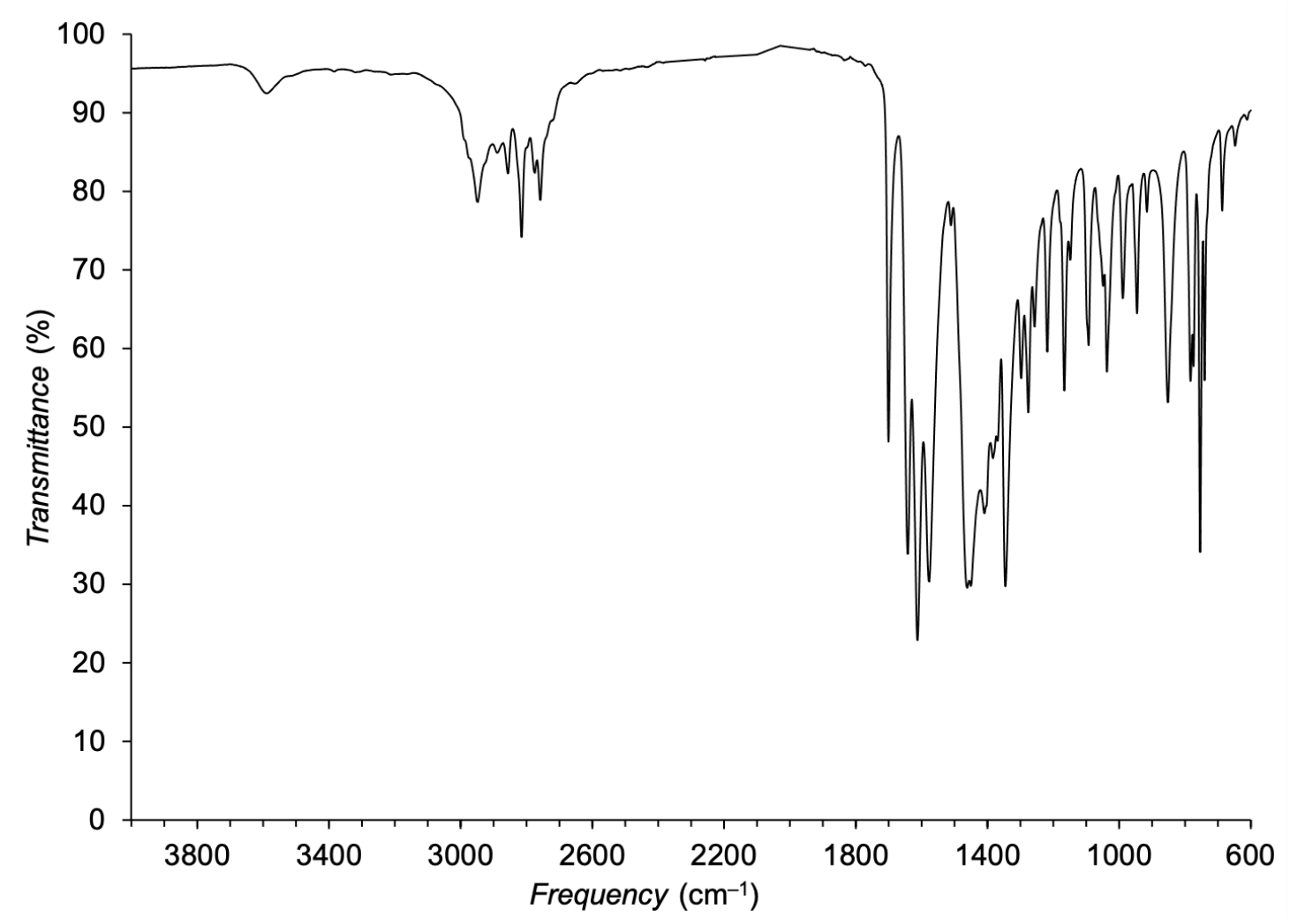

FT-IR of DKE 4.

PDK Polymerization by Ball-Milling. Ball-milling was performed using a Retsch Planetary BallMill PM100. The container in which the reactions were carried out was a zirconium-coated cylinder either with an inner diameter of $4.5 \mathrm{~cm}$ and a height of $3.5 \mathrm{~cm}$ (reactor volume $\sim 50 \mathrm{~mL}$ ) or with an inner diameter of $10 \mathrm{~cm}$ and a height of $7 \mathrm{~cm}$ (reactor volume $\sim 500 \mathrm{~mL}$ ). All experiments reported herein used the same weight of zirconium oxide ball bearings $(5 \mathrm{~mm}$ diameter) and triketone ratio, being 10 times the weight of triketone. The general procedure for all ball-milling reactions involved weighing out the appropriate amount of ditopic triketone monomer ( 2.0 or 10.0 g) and placing the powder at the bottom of the ball mill, along with the ball bearings (20 or 100 g). To the triketone monomer was added tris(2-aminoethyl)amine (TREN) using a pre-calibrated micropipette, which was immediately followed by ball-milling the contents of the closed container for $30 \mathrm{~min}$ at a rotation of $500 \mathrm{rpm}$. The reactor was opened to air and the reactor walls were scraped to bring together the reactants homogeneously. Ball-milling was resumed for an additional 30 min under the same rotation speed. The powder was recovered from the reactor and the residual water removed under vacuum. 


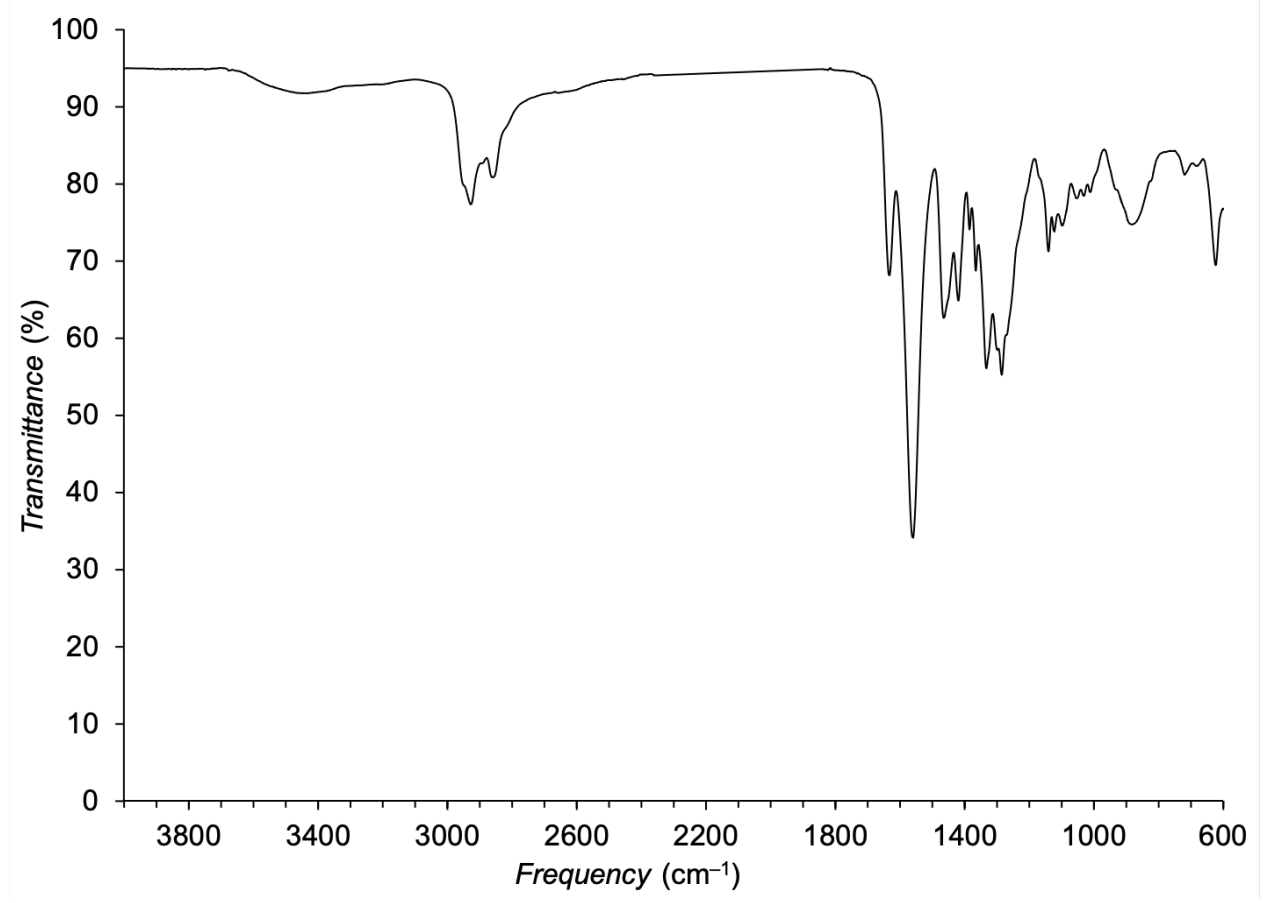

FT-IR of PDK 1.

FT-IR: 3450, 2927, 2861, 1633, 1561, 1465, 1420, 1385, 1366, 1333, 1286, 1141, 1123, 1098, $1054,1032,1012,883,720,681,624,570,521,464,418 \mathrm{~cm}^{-1}$.

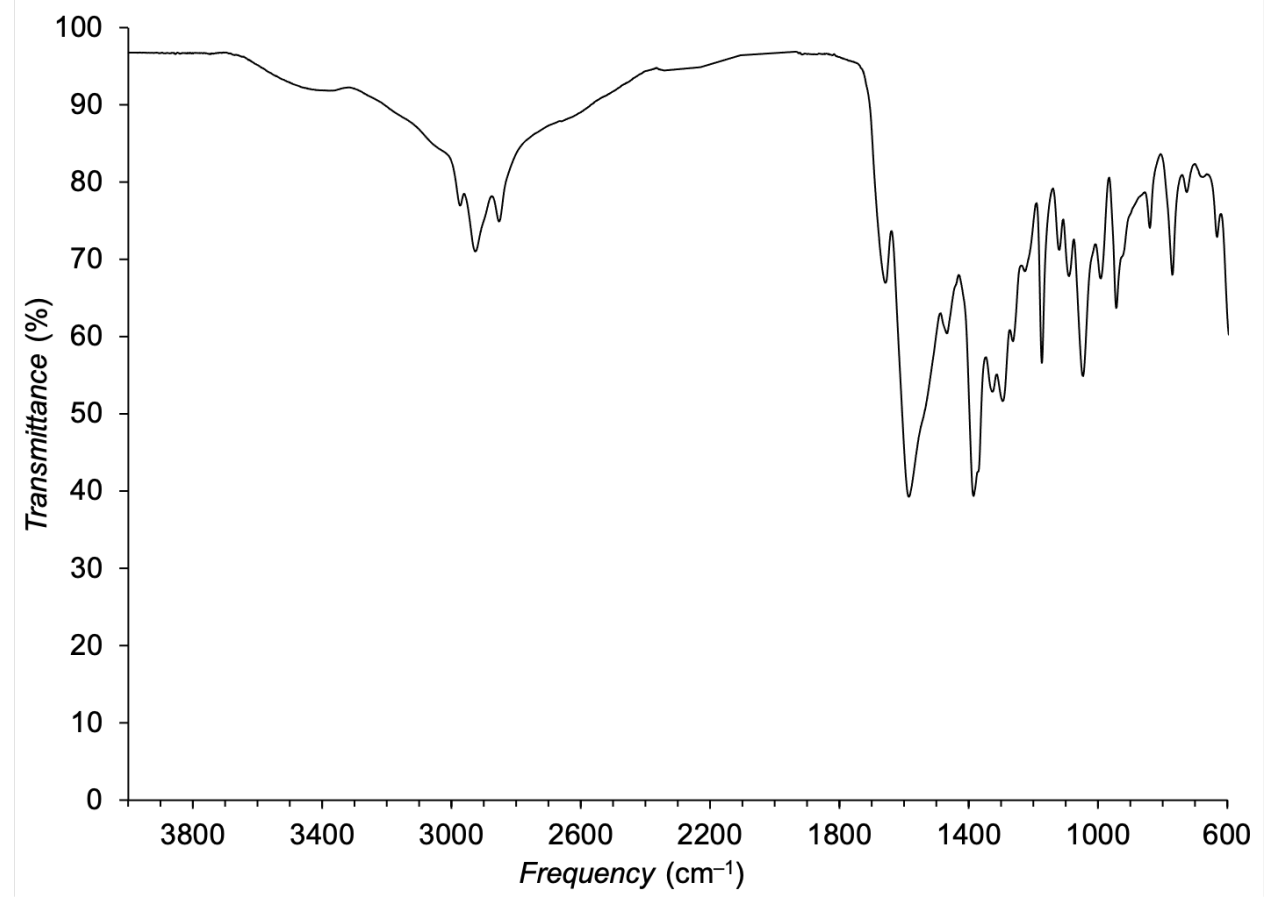

FT-IR of PDK 2.

FT-IR: 2973, 2926, 2853, 1658, 1585, 1467, 1385, 1326, 1295, 1263, 1226, 1174, 1120, 1090, $1047,992,943,840,770,726,676,632,595,542,484,430 \mathrm{~cm}^{-1}$. 


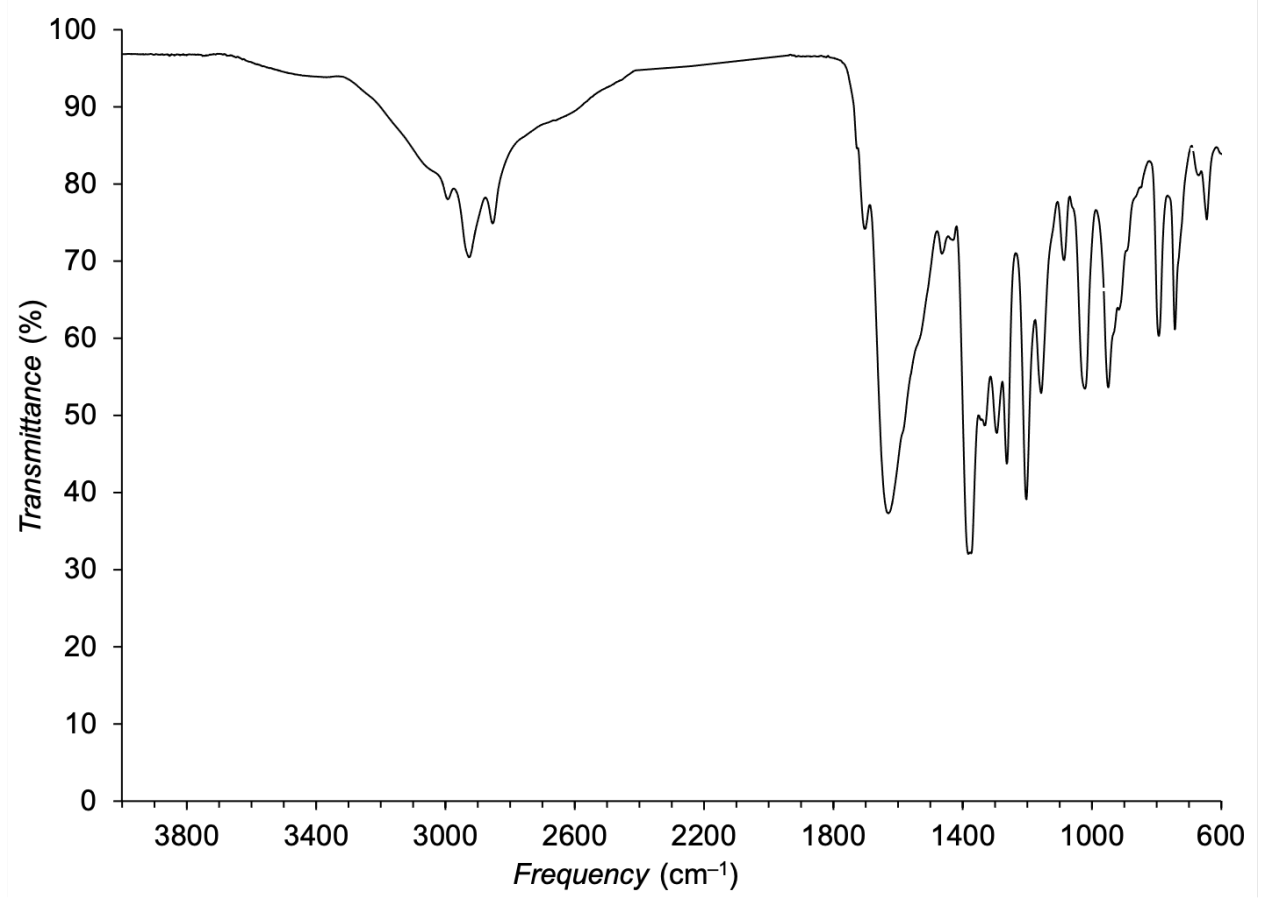

FT-IR of PDK 3.

FT-IR: 2992, 2926, 2854, 1702, 1629, 1464, 1430, 1382, 1332, 1295, 1263, 1203, 1157, 1087 , $1022,950,793,743,670,645,559,512,451,409 \mathrm{~cm}^{-1}$.

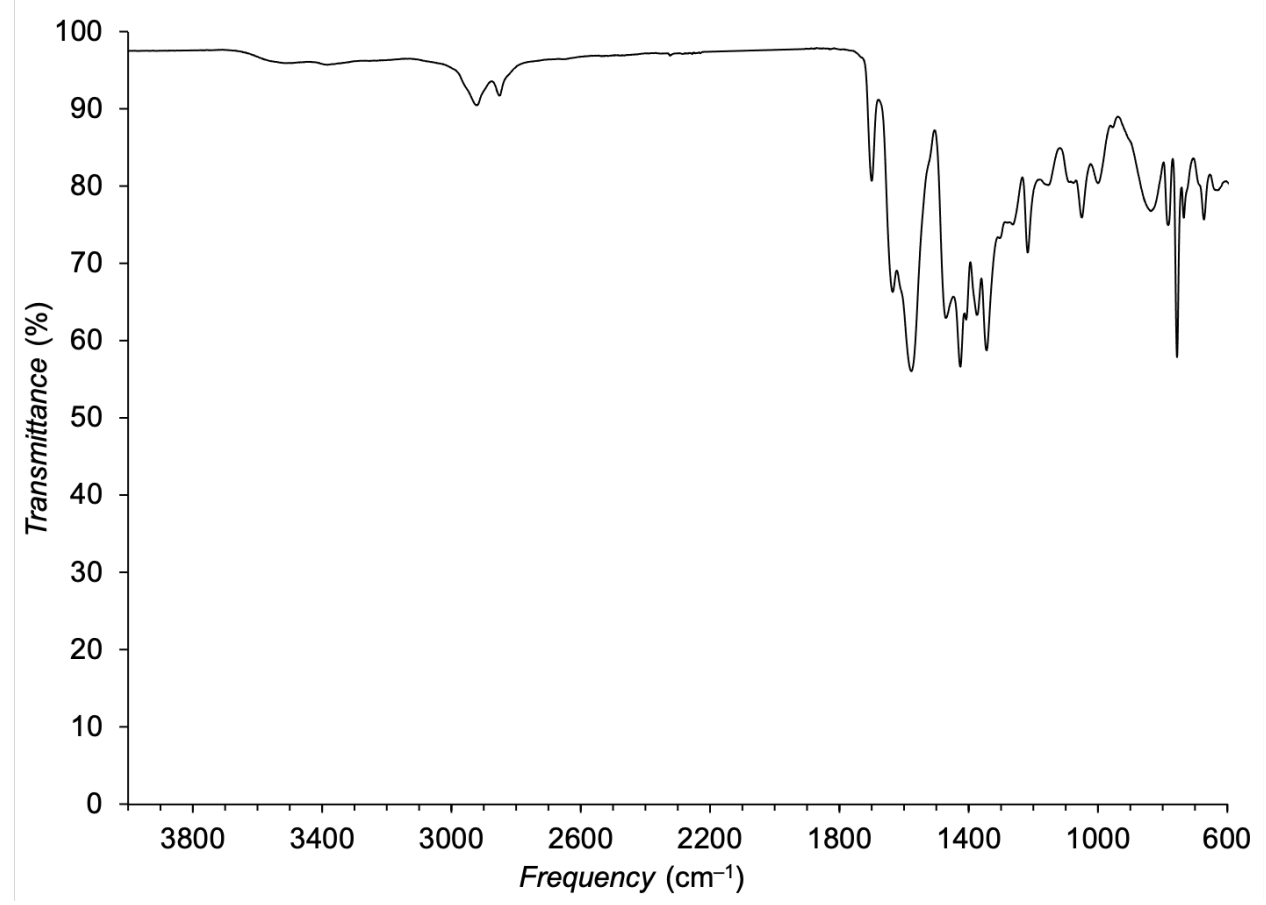

FT-IR of PDK 4.

FT-IR: 2924, 2852, 1692, 1588, 1409, 1379, 1232, 1086, 998, 866, 781, 757, 665, 511, 483, 415 $\mathrm{cm}^{-1}$. 
Compounding PDKs with Additives or Fillers. Composites were prepared by ball-milling for 1 min at a rotation of $500 \mathrm{rpm}$ PDK resin powders with $0-1 \% \mathrm{w} / \mathrm{w}$ filler (carbon black or Disperse Blue dye).

Preparation of solid samples for hydrolysis and DMA. Powdered materials obtained from the ball-mill were pressed into sheets of $\sim 1 \mathrm{~mm}$ in thickness using a thermal press operating at 100 ${ }^{\circ} \mathrm{C}$ for PDK 1 and PDK 2 and at $140{ }^{\circ} \mathrm{C}$ for PDK 4, at 20k psi for 20 min. Small rectangular samples both used for hydrolysis kinetics and DMA were shaped with dimensions of $l=20 \mathrm{~mm}$, $w=5 \mathrm{~mm}, t=1 \mathrm{~mm}$. Larger rectangular samples for multi-material hydrolysis experiments were shaped with dimensions of $l=35 \mathrm{~mm}, w=25 \mathrm{~mm}, t=1 \mathrm{~mm}$. Gel fractions for compression molded PDKs, after swelling the specimens for $24 \mathrm{~h}$ at $90{ }^{\circ} \mathrm{C}$ in DMF, were $90-100 \%$.

Acid-Catalyzed Hydrolytic Depolymerization of PDKs 1-4. PDK resin powders 1-4 ( 500 mg) were each placed in a $40 \mathrm{~mL}$ vial containing strong acid $(5.0 \mathrm{M} \mathrm{HCl}, 10 \mathrm{~mL})$ and a magnetic stirrer. Depolymerization reactions were conducted over a $24 \mathrm{~h}$ at either $0,20,40$, or $60{ }^{\circ} \mathrm{C}$.

Powdered PDK $1(500 \mathrm{mg})$ was completely depolymerized at $60{ }^{\circ} \mathrm{C}$ in aqueous $5.0 \mathrm{M} \mathrm{HCl}(10$ $\mathrm{mL}$ ) over $48 \mathrm{~h}$, yielding a white precipitate, which was isolated by centrifugation and rinsed with water. The solid was solubilized in $\mathrm{K}_{2} \mathrm{CO}_{3}(2.0 \mathrm{M}, 10 \mathrm{~mL})$, the filtrate was precipitated in $\mathrm{HCl}(2.0$ $\mathrm{M}, 30 \mathrm{~mL}$ ), and the TK 1 precipitate was filtrated and dried under vacuum (yield $371 \mathrm{mg}, 92 \%$ ).

Powdered PDK 2 (500 mg) was completely depolymerized at $20{ }^{\circ} \mathrm{C}$ in aqueous $5.0 \mathrm{M} \mathrm{HCl}(10$ $\mathrm{mL}$ ) over $24 \mathrm{~h}$, yielding a yellow precipitate, which was isolated by filtration. The solid was solubilized in aqueous $2.0 \mathrm{M} \mathrm{K}_{2} \mathrm{CO}_{3}(10 \mathrm{~mL})$, the yellow filtrate was precipitated in $\mathrm{HCl}(2.0 \mathrm{M}$, $30 \mathrm{~mL}$ ), and the TK 2 precipitate was recovered by filtration and dried under vacuum (yield 402 mg, 99\%).

Powdered PDK 3 (500 mg) was completely depolymerized at $40{ }^{\circ} \mathrm{C}$ in aqueous $5.0 \mathrm{M} \mathrm{HCl}(10$ $\mathrm{mL})$ over $24 \mathrm{~h}$, yielding a brown precipitate, which was extracted with DCM (2 x $10 \mathrm{~mL})$. The solvent was evaporated under vacuum and the brown powder was dried under vacuum. ${ }^{1} \mathrm{H}$ NMR analysis revealed a mixture of TK 3 (yield NMR $=51 \%$ ) and ß-keto acids.

Powdered PDK 4 (500 mg) was completely depolymerized at $60{ }^{\circ} \mathrm{C}$ in aqueous $5.0 \mathrm{M} \mathrm{HCl}(10$ $\mathrm{mL})$ over $24 \mathrm{~h}$, yielding a yellow precipitate, which was extracted with DCM (2 x $10 \mathrm{~mL})$. The solvent was evaporated under vacuum and the yellow-white powder was triturated with fresh portions of water $(2 \times 10 \mathrm{~mL})$. The mixture was centrifuged, the liquid was removed and the TK 4 monomer was dried under vacuum (yield $360 \mathrm{mg}, 88 \%$ ).

Tortoise Material Chemical Recycling of PDKs. Powdered PDK 1 was pressed using a stainless-steel mold at $100{ }^{\circ} \mathrm{C}$ at $20 \mathrm{kpsi}$ during $20 \mathrm{~min}$ to reach a homogeneous yellow rectangle. Small squares with dimensions of $l=5 \mathrm{~mm}$ and $w=5 \mathrm{~mm}$ were cut from this yellow PDK 1 rectangle. Similarly, powdered PDK 4 containing $1 \%$ of carbon black was pressed at $140{ }^{\circ} \mathrm{C}$ at 20 kpsi during $20 \mathrm{~min}$ to reach a homogeneous black rectangle. Small squares with dimensions of $l=$ $5 \mathrm{~mm}$ and $w=5 \mathrm{~mm}$ were cut from this black PDK 4 rectangle.

The mixed-PDK tortoise assembly was poured in aqueous $5.0 \mathrm{M} \mathrm{HCl}(15 \mathrm{~mL})$ and depolymerized during a $48 \mathrm{~h} 20^{\circ} \mathrm{C}$ isotherm into a white precipitate and untouched black PDK 4 squares. The 
white mixture was centrifuged and once the acid liquid removed, aqueous $2.0 \mathrm{M} \mathrm{K}_{2} \mathrm{CO}_{3}(10 \mathrm{~mL})$ was poured over the solid mixture to solubilize TK 1 monomer. Basic TK 1 solution was extracted and precipitated in $\mathrm{HCl}(2.0 \mathrm{M}, 30 \mathrm{~mL})$, the TK 1 precipitate was recovered by filtration and dried under vacuum for ${ }^{1} \mathrm{H}$ NMR analysis.
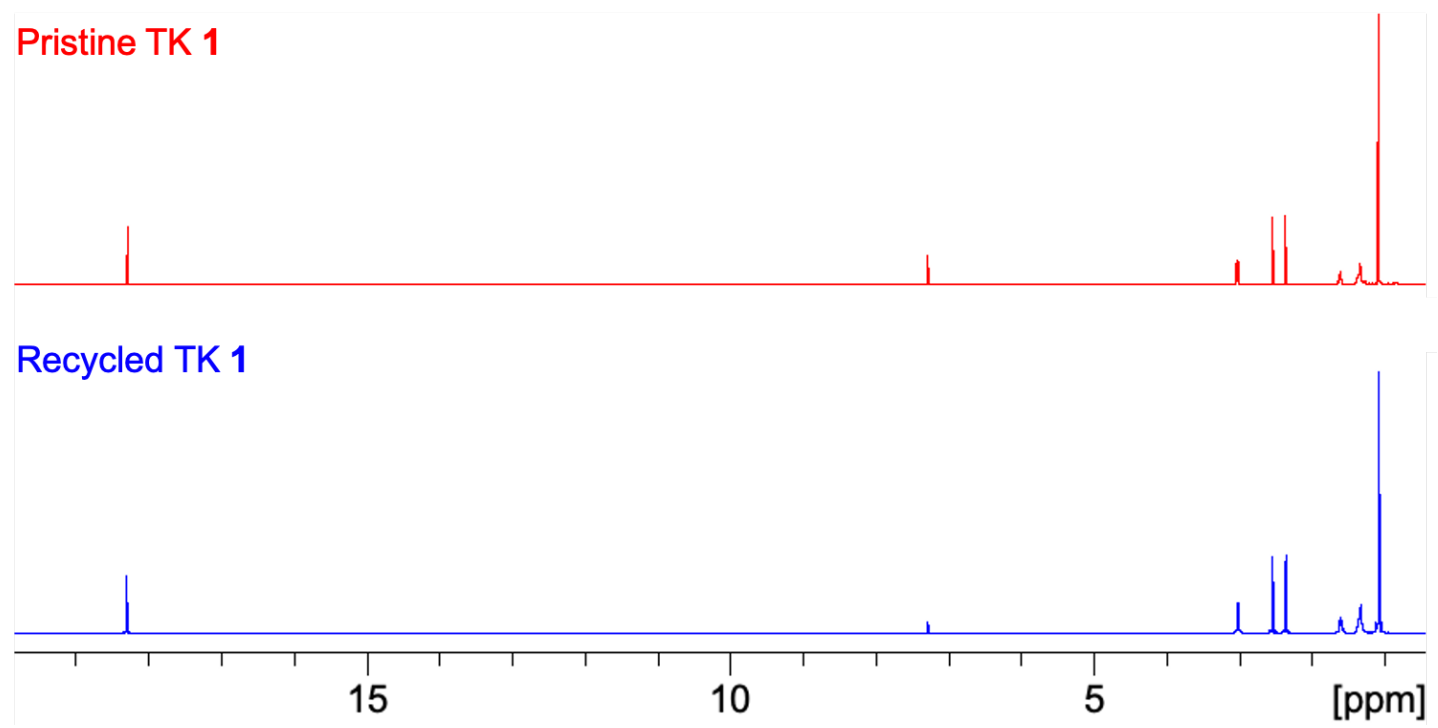

${ }^{1} \mathrm{H}$ NMR of pristine and recycled TK 1 from tortoise material.

The PDK 4 square-shaped chips were rinsed with water and transferred in a $20 \mathrm{~mL}$ vial containing $15 \mathrm{~mL}$ of fresh $5.0 \mathrm{M} \mathrm{HCl}$. The depolymerization was pursued $72 \mathrm{~h}$ at $60{ }^{\circ} \mathrm{C}$, after which, a fine black precipitate appeared. The TK 4 monomer was extracted from the aqueous mixture with DCM $(2 \times 10 \mathrm{~mL})$ and filtrated on paper to remove residual carbon black. The organic phase was isolated and the solvent evaporated under vacuum. The yellow precipitate was triturated with water (10 $\mathrm{mL}$ ), then centrifuged and dried under vacuum for ${ }^{1} \mathrm{H}$ NMR analysis.

Pristine TK 4

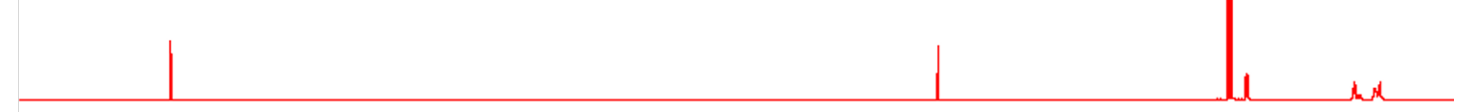

\section{Recycled TK 4}

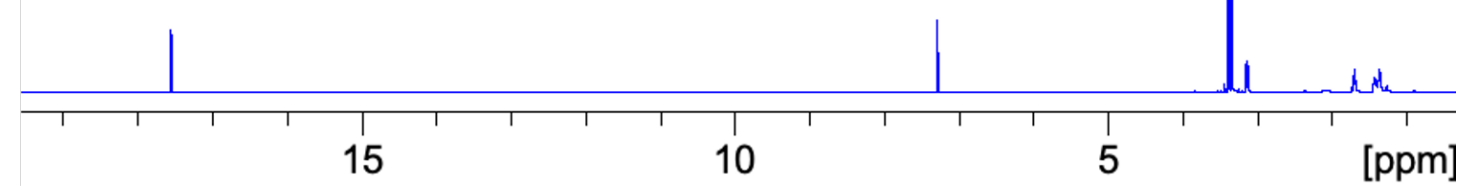

${ }^{1} \mathrm{H}$ NMR of pristine and recycled TK 4 from tortoise material. 
Molecular Blend Chemical Recycling of PDKs. Powdered PDK 1 (1000 mg) and PDK 4 (250 $\mathrm{mg}$ ) were mixed in a vial and were pressed at $140{ }^{\circ} \mathrm{C}$ at $20 \mathrm{kpsi}$ during 20 min to reach a homogeneous yellow rectangle. The PDK blend was shaped with dimensions of $l=35 \mathrm{~mm}, w=$ $10 \mathrm{~mm}, t=1 \mathrm{~mm}$. The solid PDK blend $(551 \mathrm{mg})$ was poured in aqueous $5.0 \mathrm{M} \mathrm{HCl}(15 \mathrm{~mL})$ and depolymerized during a $24 \mathrm{~h} 20{ }^{\circ} \mathrm{C}$ isotherm into a yellow precipitate that was isolated by centrifugation. Aqueous $2.0 \mathrm{M} \mathrm{K}_{2} \mathrm{CO}_{3}(10 \mathrm{~mL})$ was poured over the solid mixture to solubilize TK 1 monomer while white PDK 4 powder was centrifuged and isolated for further recycling. Basic TK 1 solution was extracted and precipitated in $\mathrm{HCl}(2.0 \mathrm{M}, 30 \mathrm{~mL})$, the TK 1 precipitate was recovered by filtration and dried under vacuum for ${ }^{1} \mathrm{H}$ NMR analysis.

Pristine TK 1

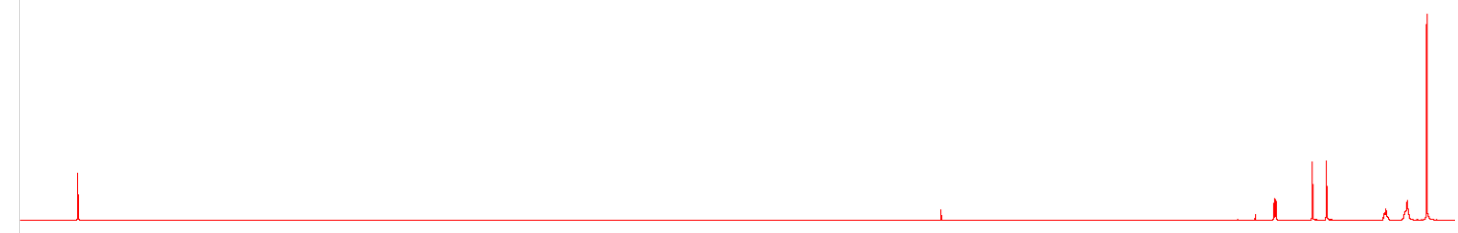

Recycled TK 1

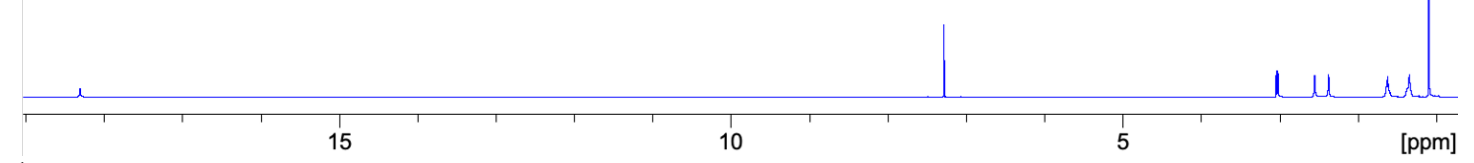

${ }^{1} \mathrm{H}$ NMR of pristine and recycled TK 1 from molecular blend material.

Centrifuged PDK 4 powder was poured in aqueous $5.0 \mathrm{M} \mathrm{HCl}(10 \mathrm{~mL})$ and depolymerized during a $72 \mathrm{~h} 60{ }^{\circ} \mathrm{C}$ isotherm into a yellow precipitate, which was extracted with DCM $(2 \times 10 \mathrm{~mL})$. The solvent was evaporated under vacuum and the yellow-white powder was triturated with fresh portions of water $(2 \times 10 \mathrm{~mL})$. The mixture was centrifuged, the liquid was removed and the TK 4 monomer was dried under vacuum for ${ }^{1} \mathrm{H}$ NMR analysis.

Pristine TK 4
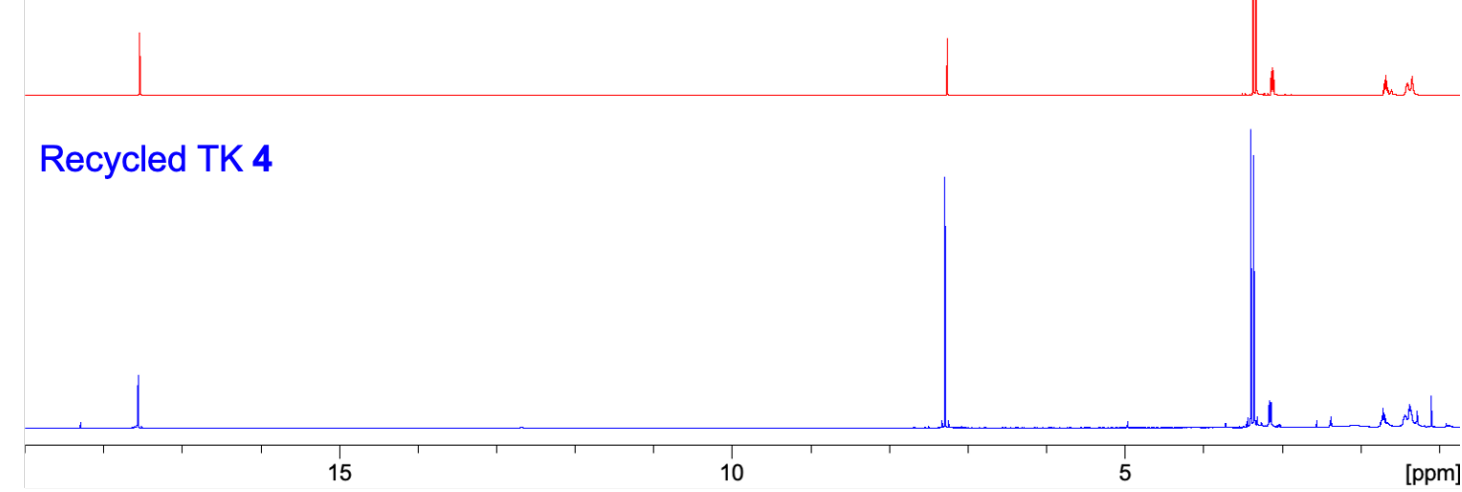

${ }^{1} \mathrm{H}$ NMR of pristine and recycled TK 4 from molecular blend material. 
Bilayer Laminate Chemical Recycling of PDKs. Powdered PDK 1 ( $700 \mathrm{mg})$ was pressed using a stainless-steel mold at $100^{\circ} \mathrm{C}$ at $20 \mathrm{kpsi}$ during 20 min to reach a homogeneous yellow rectangle. Powdered PDK 4 containing $1 \%$ of carbon black $(\sim 500 \mathrm{mg})$ was then added over the yellow rectangle and was pressed at $140{ }^{\circ} \mathrm{C}$ at $20 \mathrm{kpsi}$ during $20 \mathrm{~min}$ to reach a homogeneous bilayer black and yellow rectangle. The rectangle was shaped with dimensions of $l=35 \mathrm{~mm}, w=10 \mathrm{~mm}$, $t=1 \mathrm{~mm}$. The solid bilaminate PDK was poured in aqueous $5.0 \mathrm{M} \mathrm{HCl}(15 \mathrm{~mL})$ and depolymerized during a $24 \mathrm{~h} 20^{\circ} \mathrm{C}$ isotherm into a yellow precipitate that was isolated by centrifugation. Aqueous $2.0 \mathrm{M} \mathrm{K}_{2} \mathrm{CO}_{3}(10 \mathrm{~mL})$ was poured over the solid mixture to solubilize TK 1 monomer while black PDK 4 solid pieces were centrifuged, isolated and dried under vacuum. Basic TK 1 solution was extracted and precipitated in $\mathrm{HCl}(2.0 \mathrm{M}, 30 \mathrm{~mL})$, the TK 1 precipitate was recovered by filtration and dried under vacuum for ${ }^{1} \mathrm{H}$ NMR analysis.

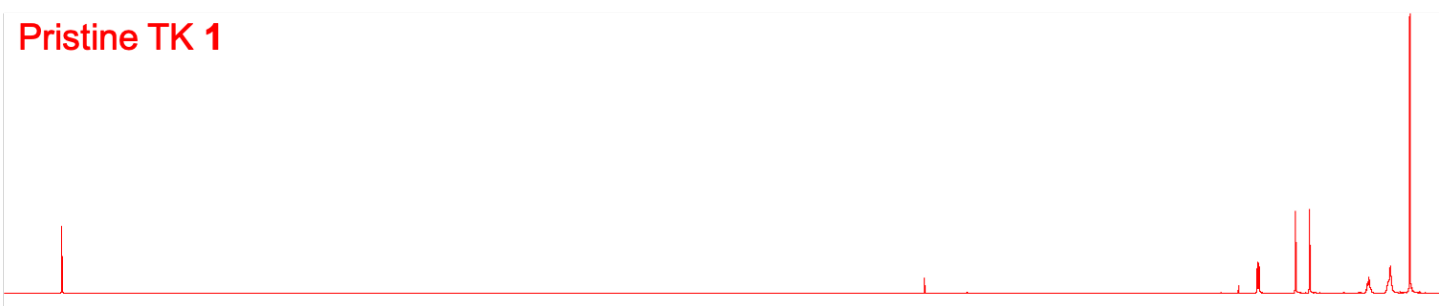

\section{Recycled TK 1}

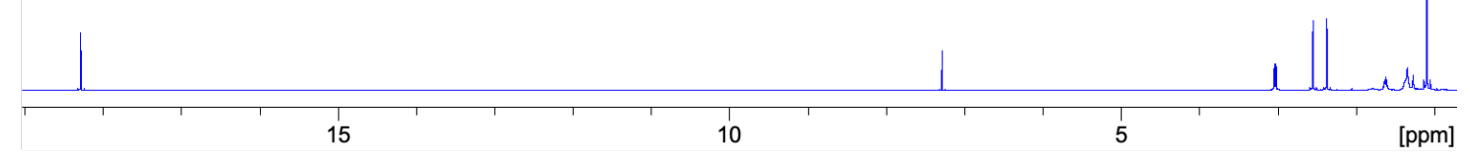

${ }^{1} \mathrm{H}$ NMR of pristine and recycled TK $\mathbf{1}$ from bilayer laminate material.

The carbon black-loaded PDK 4 sample was rinsed with water and transferred in a $20 \mathrm{~mL}$ vial containing $10 \mathrm{~mL}$ of fresh $5.0 \mathrm{M} \mathrm{HCl}$. Depolymerization was conducted over $72 \mathrm{~h}$ at $60{ }^{\circ} \mathrm{C}$, after which, a fine black precipitate appeared. The TK 4 monomer was extracted from the aqueous mixture with DCM $(2 \times 10 \mathrm{~mL})$ and filtrated on paper to remove residual carbon black. The organic phase was isolated and the solvent evaporated under vacuum. The yellow precipitate was triturated with water $(10 \mathrm{~mL})$, then centrifuged and dried under vacuum for ${ }^{1} \mathrm{H}$ NMR analysis. 

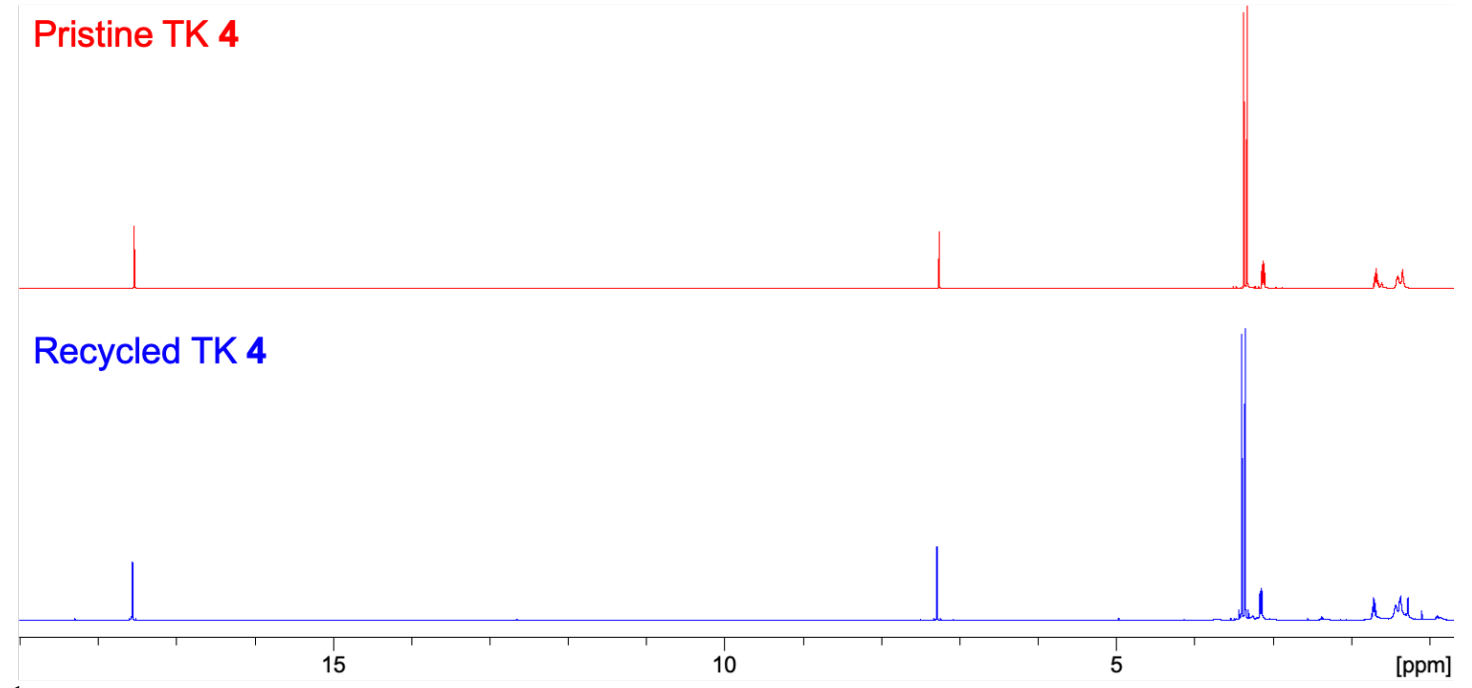

${ }^{1} \mathrm{H}$ NMR of pristine and recycled TK 4 from bilayer laminate material.

Acid-Catalyzed Hydrolytic Depolymerization of Laminate made of Biaxially-Oriented Poly(propylene) (BOPP)/PDK 1/Poly(ethylene terephthalate) (PET). Commercially available BOPP ( $0.05 \mathrm{~mm}$ thick) and PET (0.2 mm thick) were used as external layers of the laminate. PDK 1 powder was pressed at $140{ }^{\circ} \mathrm{C}$ at $20 \mathrm{kpsi}$ during $20 \mathrm{~min}$ to reach a homogeneous yellow transparent layer $(0.4 \mathrm{~mm}$ thick). Then, BOPP/PDK 1/PET layers were pressed into a unique laminate foil at $140{ }^{\circ} \mathrm{C}$ at 60 psi. The laminate was cut into a rectangle of $2 \mathrm{~cm}$ long and $1 \mathrm{~cm}$ large. The latter was transferred in a $20 \mathrm{~mL}$ vial containing $10 \mathrm{~mL}$ of $5.0 \mathrm{M} \mathrm{HCl}$. The depolymerization was conducted over $48 \mathrm{~h}$ at room temperature, after which, a fine precipitate remained in suspension, while colorless transparent BOPP and PET foils remained untouched. The precipitate was filtered, washed with water to remove residual acid and then solubilized in $2.0 \mathrm{M}$ $\mathrm{K}_{2} \mathrm{CO}_{3}(5 \mathrm{~mL})$ for $10 \mathrm{~min}$, followed filtering of residual solids and slowly precipitating a white solid out of excess $2.0 \mathrm{M} \mathrm{HCl}(10 \mathrm{~mL})$, maintaining a $\mathrm{pH}<3$. The yellow precipitate (TK 1) was collected by filtration, washed with water and dried under vacuum for ${ }^{1} \mathrm{H}$ NMR analysis.

Pristine TK 1
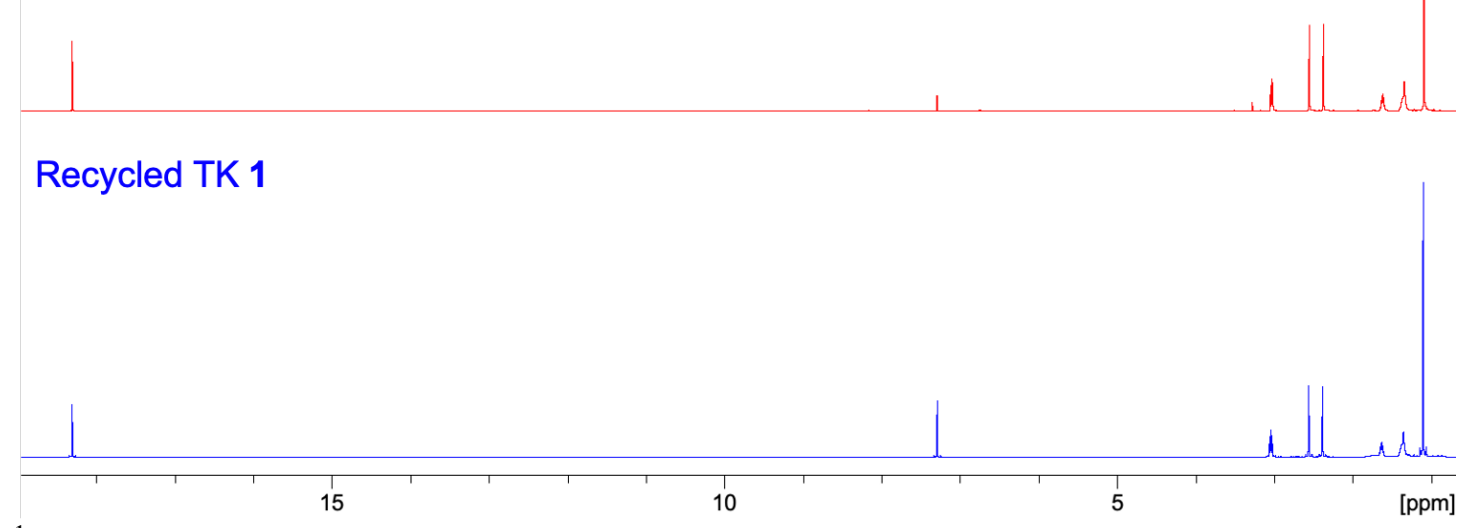

${ }^{1} \mathrm{H}$ NMR of pristine and recycled TK 1 from laminate packaging material. 
Multi-Polymer Recycling via Thermally Controlled Sequential Acid-Catalyzed Hydrolytic Depolymerization of PDKs 2 and 4 and Monomer Recovery from Additives and Fillers.

Powdered PDK $2(1.20 \mathrm{~g})$ and PDK $4(1.20 \mathrm{~g})$ were separately ball-milled with $0.1 \%(w / w)$ disperse blue 3 and $1 \%(w / w)$ carbon black respectively, using $10 \mathrm{~g}$ of zirconium oxide bearings in $50 \mathrm{~mL}$ reactor during 5 min to yield a green PDK 2 powder and a black PDK 4 powder. The powdered green and black polymer samples were pressed separately during $20 \mathrm{~min} 20 \mathrm{k}$ psi into two solid pieces at $100{ }^{\circ} \mathrm{C}$ for PDK 2 and $140{ }^{\circ} \mathrm{C}$ for PDK 4. Each sample was then cut to dimensions of $\sim 2 \mathrm{~cm}^{2}$ and $1 \mathrm{~mm}$ thick $\left(\right.$ PDDK $2_{2}=397 \mathrm{mg}$ and $\mathrm{mPDK}_{4}=503 \mathrm{mg}$ ) and placed in a unique $20 \mathrm{~mL}$ vial containing aqueous $5.0 \mathrm{M} \mathrm{HCl}(15 \mathrm{~mL})$. The depolymerization proceeded $24 \mathrm{~h}$ at room temperature, after which, a fine precipitate remained in suspension of a red mixture, while black PDK 4 sample remained untouched. The precipitate was filtered, washed with water to remove residual acid and then stirred in $2.0 \mathrm{M} \mathrm{K}_{2} \mathrm{CO}_{3}(10 \mathrm{~mL})$ for $10 \mathrm{~min}$, followed filtering of residual solids and slowly precipitating a white solid out of excess $2.0 \mathrm{M} \mathrm{HCl}(30 \mathrm{~mL})$, maintaining a $\mathrm{pH}<3$. The yellow precipitate (TK 2) was collected by filtration, washed with water, and dried under vacuum (yield $286 \mathrm{mg}, 90 \%$ ).

The carbon black-loaded PDK 4 sample was rinsed with water and transferred in a $20 \mathrm{~mL}$ vial containing $15 \mathrm{~mL}$ of fresh $5.0 \mathrm{M} \mathrm{HCl}$. The depolymerization was pursued $72 \mathrm{~h}$ at $60{ }^{\circ} \mathrm{C}$, after which, a fine black precipitate appeared. The TK 4 monomer was extracted from the aqueous mixture with DCM $(2 \times 10 \mathrm{~mL})$ and filtrated on paper to remove residual carbon black. The organic phase was isolated and the solvent evaporated under vacuum. The yellow precipitate was triturated with water $(10 \mathrm{~mL})$, then centrifuged and dried under vacuum (yield $307 \mathrm{mg}, 75 \%$ ).

Carbon black was recovered from the aqueous phase by centrifugation and filtration and was dried under vacuum.

Multi-Material Chemical Recycling of PDKs with Metal and Glass. Powdered PDK 1 was pressed using a stainless-steel mold at $100{ }^{\circ} \mathrm{C}$ at $20 \mathrm{kpsi}$ during $20 \mathrm{~min}$ to reach a homogeneous yellow rectangle. Similarly, powdered PDK 4 containing 1\% of Carbon Black was pressed at 140 ${ }^{\circ} \mathrm{C}$ at $20 \mathrm{kpsi}$ during $20 \mathrm{~min}$ to reach a homogeneous black rectangle. The multi-material was constructed using a metal blade and a rectangular-shaped glass with structural hybrid adhesive layers as binder: metal/adhesive/PDK 4/adhesive/glass/adhesive/PDK 1.

The multi-material assembly was poured in aqueous $5.0 \mathrm{M} \mathrm{HCl}(25 \mathrm{~mL})$ and depolymerized during a $24 \mathrm{~h} 20{ }^{\circ} \mathrm{C}$ isotherm into a white precipitate in light-green liquid. PDK 1 was selectively deconstructed under these conditions while the rest of the multi-material remained linked. The green mixture was centrifuged and once the acid liquid removed, aqueous $2.0 \mathrm{M} \mathrm{K}_{2} \mathrm{CO}_{3}(10 \mathrm{~mL})$ was poured over the solid mixture to solubilize TK 1 monomer. Basic TK 1 solution was extracted and precipitated in $\mathrm{HCl}(2.0 \mathrm{M}, 30 \mathrm{~mL})$, the TK 1 precipitate was recovered by filtration and dried under vacuum for ${ }^{1} \mathrm{H}$ NMR analysis.

The metal/adhesive/PDK 4/adhesive/glass/adhesive assembly was rinsed with water and transferred in a $40 \mathrm{~mL}$ vial containing $20 \mathrm{~mL}$ of fresh $5.0 \mathrm{M} \mathrm{HCl}$. The depolymerization was pursued $72 \mathrm{~h}$ at $60{ }^{\circ} \mathrm{C}$, after which, a fine black precipitate appeared in dark-green liquid. The TK 4 monomer was extracted from the aqueous mixture with DCM $(2 \times 10 \mathrm{~mL})$ and filtrated on paper to remove residual carbon black. The organic phase was isolated and the solvent evaporated under 
vacuum. The yellow precipitate was triturated with water $(10 \mathrm{~mL})$, then centrifuged and dried under vacuum for ${ }^{1} \mathrm{H}$ NMR analysis.

Hydrolysis Studies of Diketoenamines 1-4. At a determined temperature, preliminary lock, tune, shim and run of the initial DKE spectra were realized before the kinetics runs. The DKE (5 mg) was solubilized in $600 \mu \mathrm{L}$ of $5.0 \mathrm{M} \mathrm{D}_{2} \mathrm{O} / \mathrm{DCl}$ and transferred in a sealed-cap NMR tube. The NMR tube was introduced to the preheated NMR and spectra were subsequently acquired at different preset time intervals. Conversion values were calculated using the signal at $2.32 \mathrm{ppm}(\mathrm{t}, 2 \mathrm{H}$, $\left.\mathrm{NCH}_{2} \mathrm{CH}_{2}-\right)$ and the $2 \mathrm{CH}_{3}$ signal of the cyclic part of the DKE molecule. The procedure was repeated at different temperatures.

Integration of the enamine peak in the ${ }^{1} \mathrm{H}$ NMR spectrum was used to calculate the disappearance of the diketoenamine starting material. The first-order rate law,

was then used to calculate $k_{\text {obs. }}$

$$
\ln \left(\frac{[\text { diketoenamine }]_{0}}{\text { [diketoenamine }]}\right)=k_{\text {obs }} * t,
$$

Based on this equation, $k_{\text {obs }}$ could be calculated at $20^{\circ} \mathrm{C}$ for each DKE molecule, which enables the calculation of relative $k_{\text {obs. }}$.

$\Delta \mathrm{G}^{\ddagger}$ was determined using the Eyring equation (55):

$$
\ln \left(k_{\mathrm{obs}} / T\right)=\frac{\Delta H^{\ddagger}}{\mathrm{R} T}+\ln \frac{\mathrm{k}_{\mathrm{B}}}{\mathrm{h}}+\frac{\Delta S^{\ddagger}}{\mathrm{R}}
$$

From the extraction of $\Delta H^{\ddagger}$ and $\Delta S^{\ddagger}, \Delta G^{\ddagger}$ was calculated via the $\Delta G^{\ddagger}=\Delta H^{\ddagger}-T \Delta S^{\ddagger}$. 

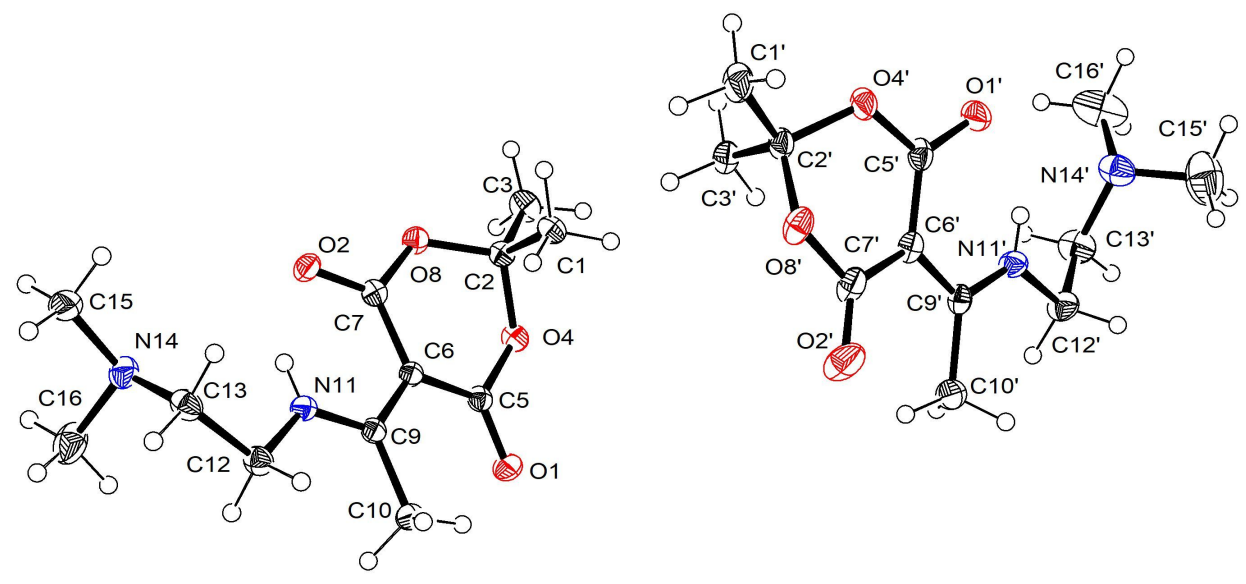

Figure S1. Single Crystal X-Ray structure for DKE 3. Legend: Carbon (black), Nitrogen (blue) Oxygen (red) and Hydrogen (open circles). 


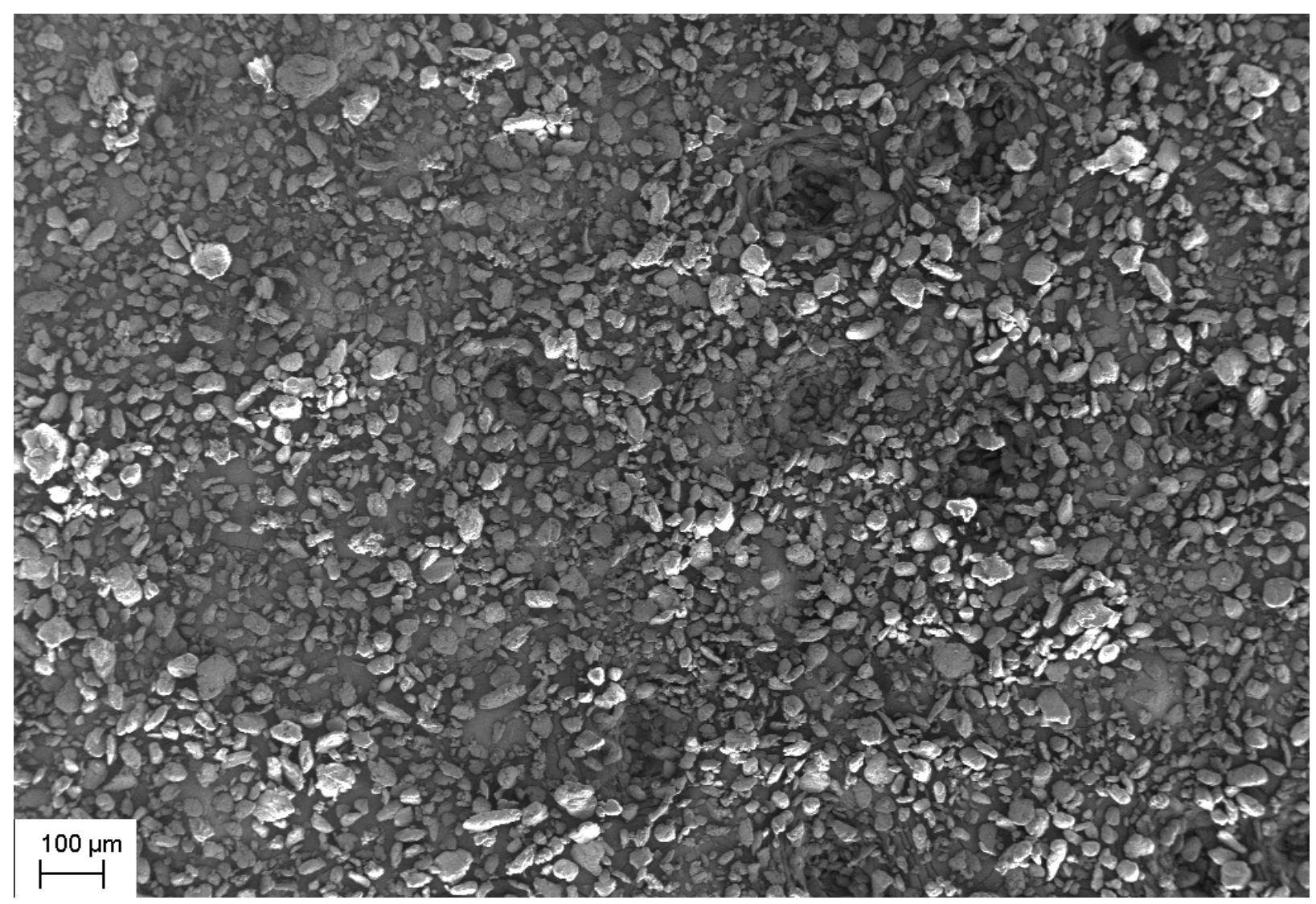

Figure S2. SEM image of PDK 1 resin powder. 


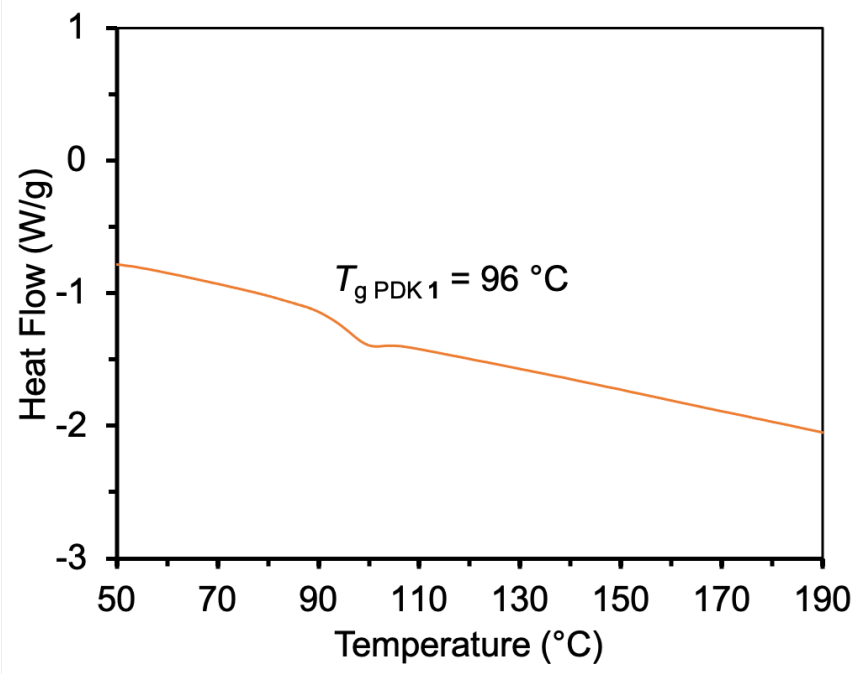

Figure S3. DSC of ball-milled PDK 1 resin powder. 


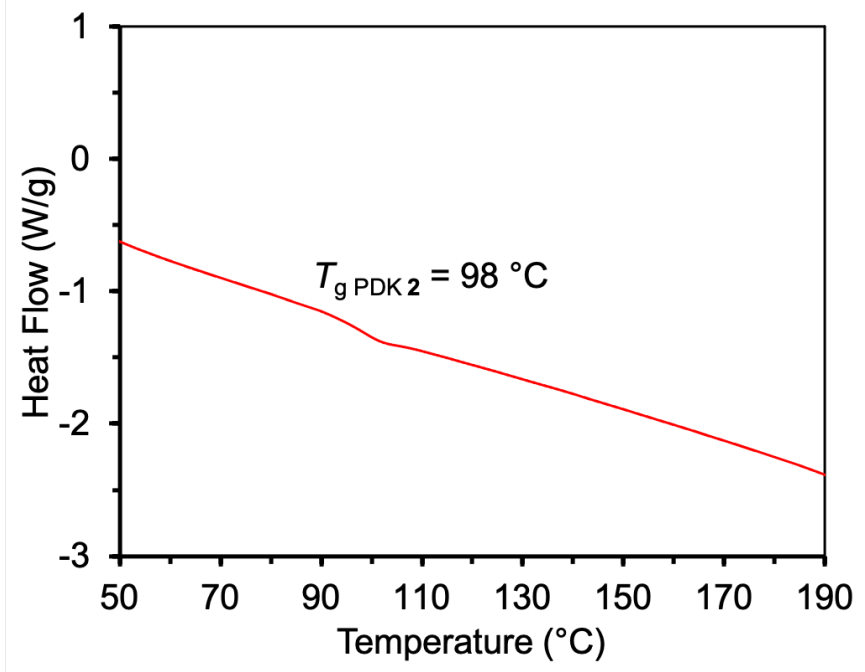

Figure S4. DSC of ball-milled PDK 2 resin powder. 


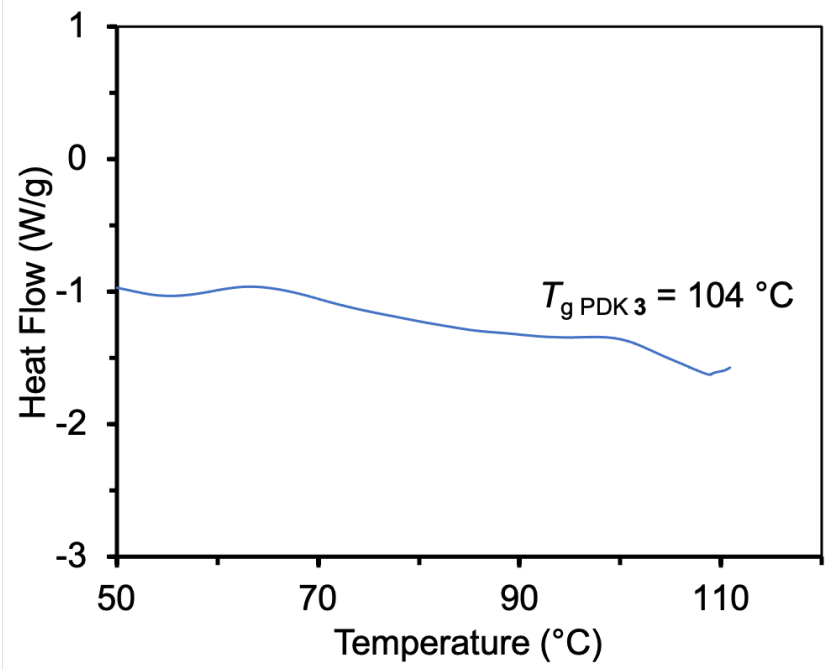

Figure S5. DSC of ball-milled PDK 3 resin powder. First heating curve shown, as this resin showed signs of thermal decomposition during the experiment. 


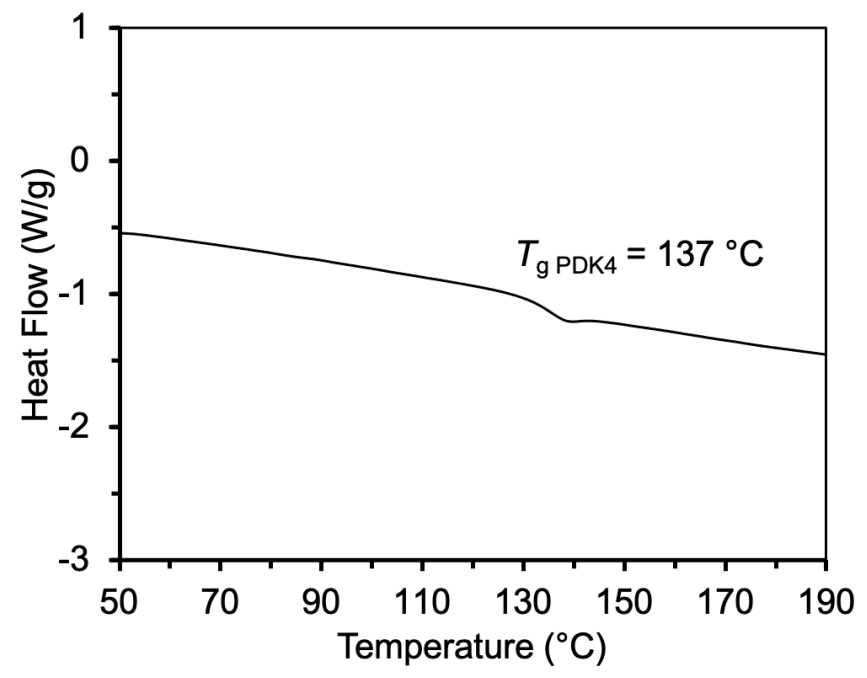

Figure S6. DSC of ball-milled PDK 4 resin powder. 
Pristine TK 1

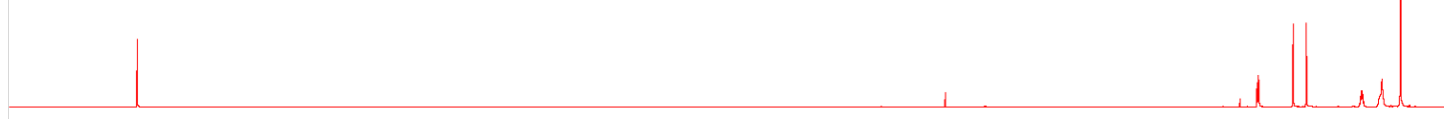

Recycled TK 1

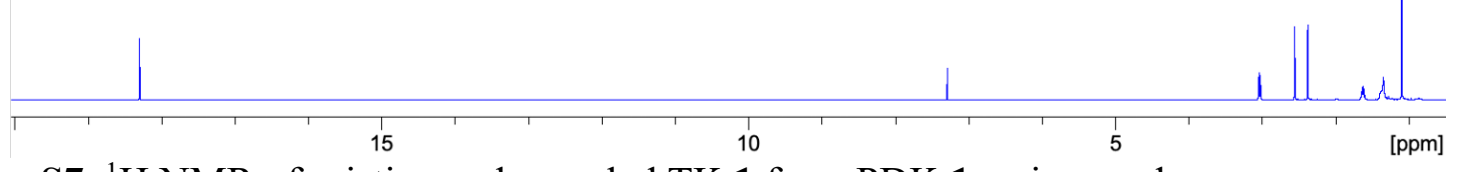

Figure S7. ${ }^{1} \mathrm{H}$ NMR of pristine and recycled TK 1 from PDK 1 resin powder. 

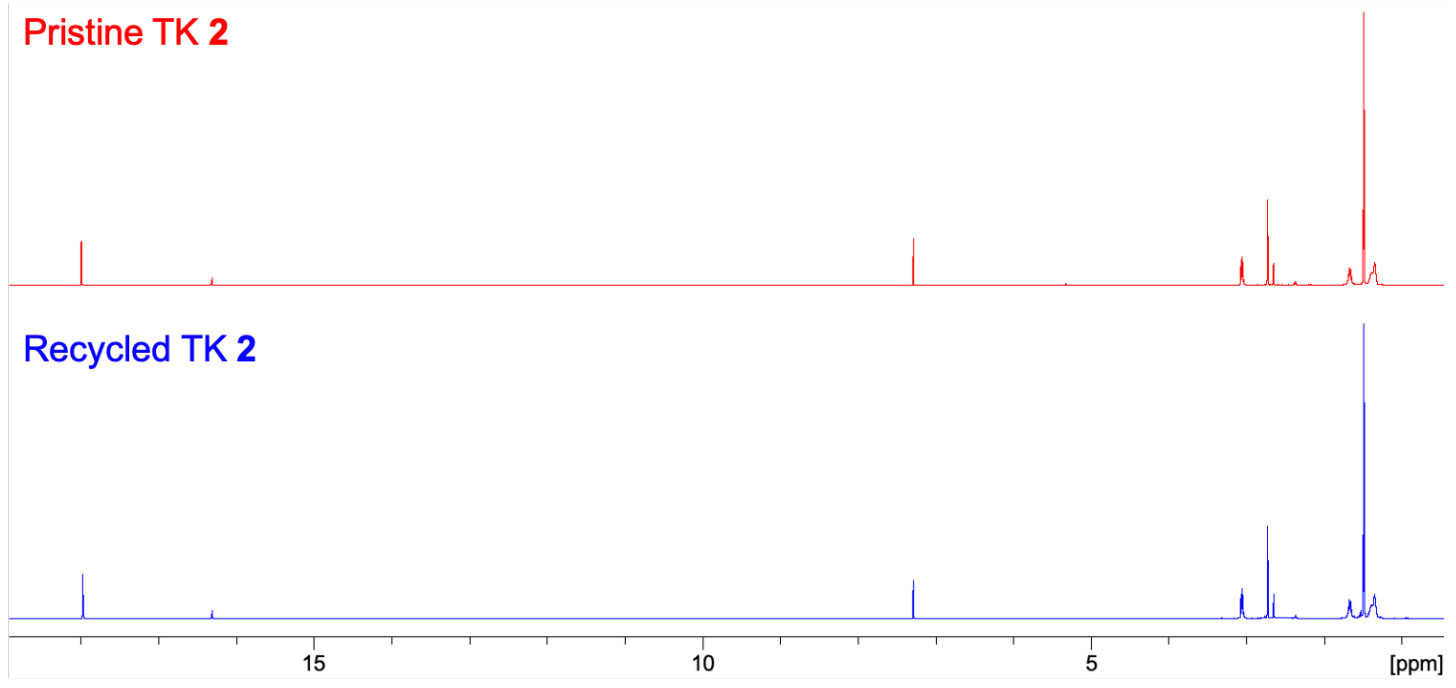

Figure S8. ${ }^{1} \mathrm{H}$ NMR of pristine and recycled TK 2 from PDK 2 resin powder. 


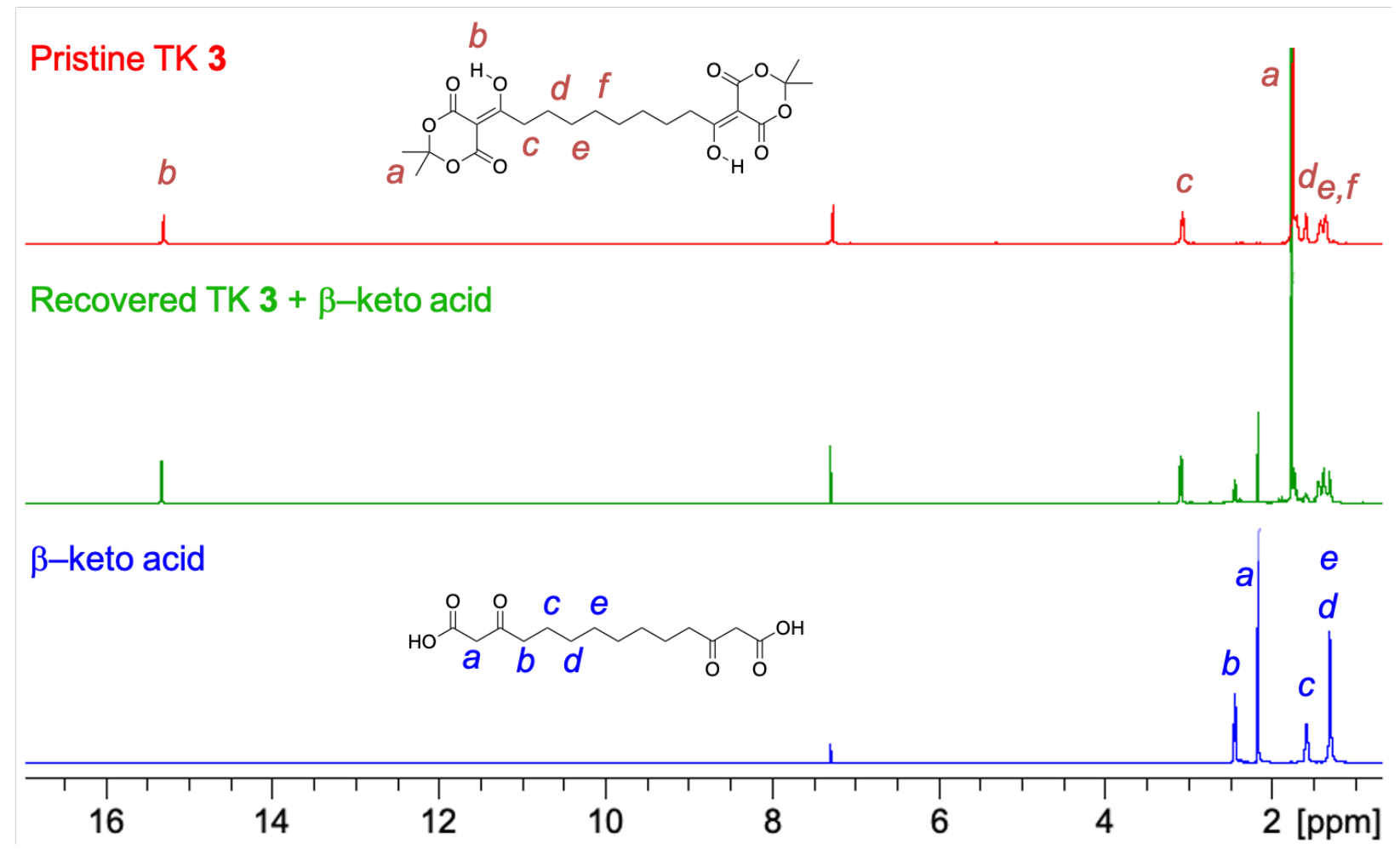

Figure S9. ${ }^{1} \mathrm{H}$ NMR of pristine TK $\mathbf{3}$, recycled TK 3 , and the bis( $\beta$-keto acid) byproduct isolated from depolymerizing PDK 3 resin powder. 

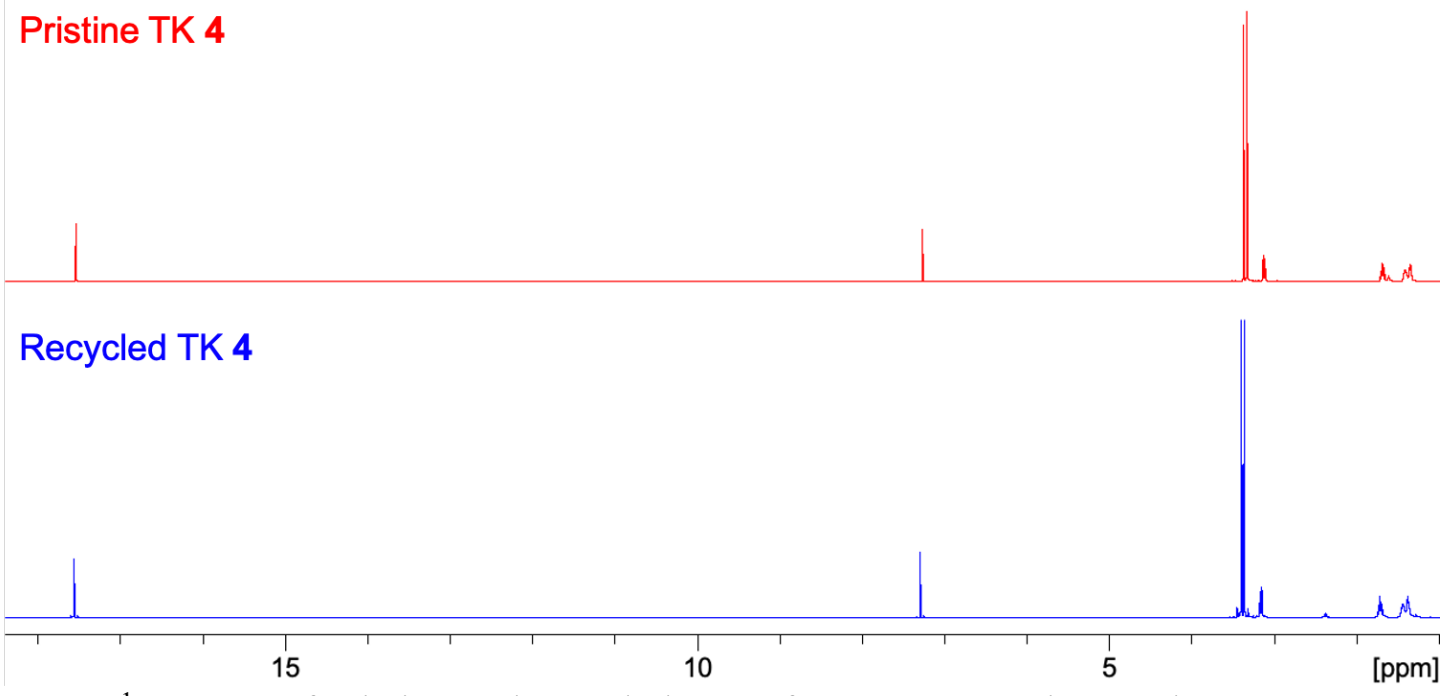

Figure S10. ${ }^{1} \mathrm{H}$ NMR of pristine and recycled TK 4 from PDK 4 resin powder. 

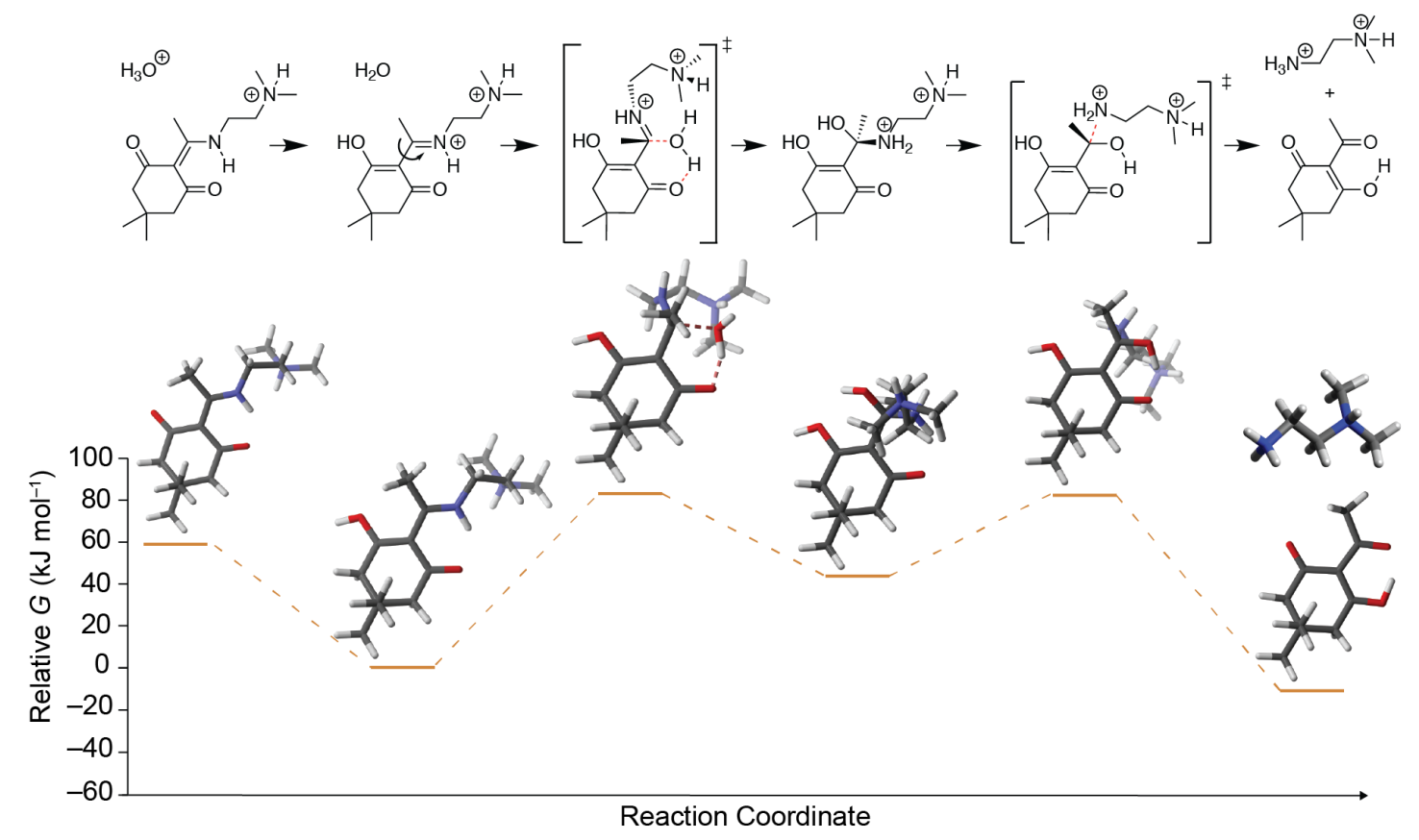

Figure S11. Computed free energy pathway of DKE 1 hydrolysis. 

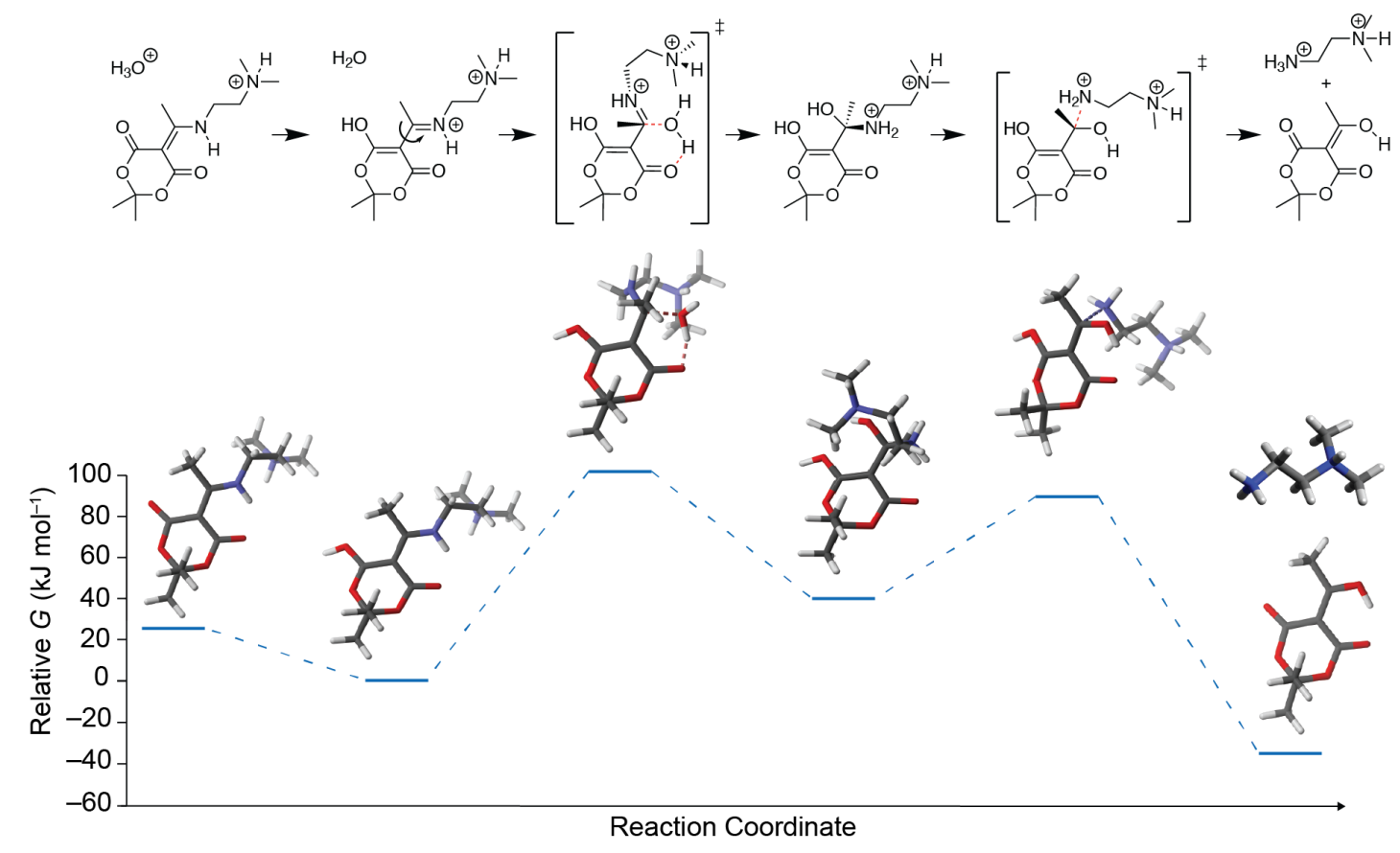

Figure S12. Computed free energy pathway of DKE 3 hydrolysis. 

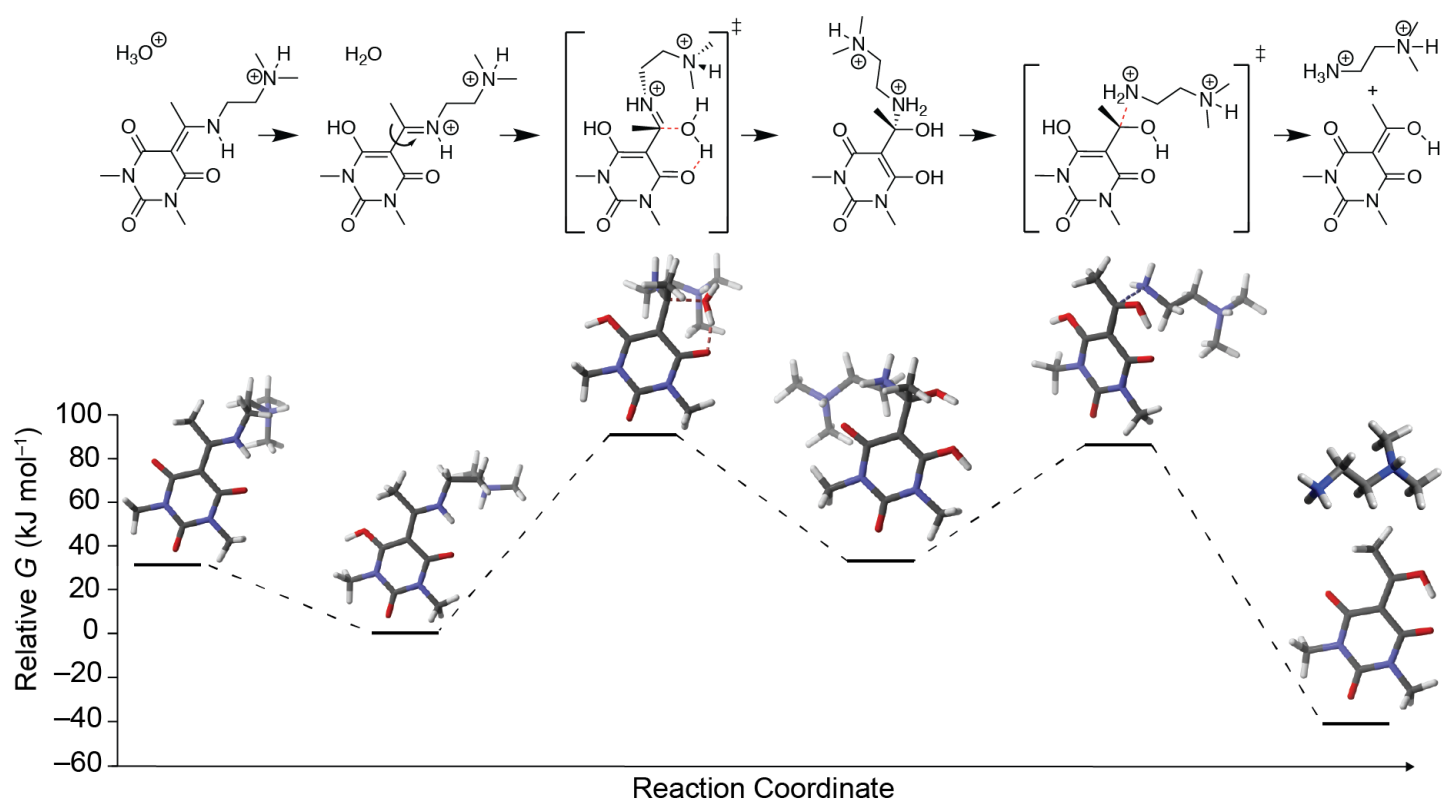

Figure S13. Computed free energy pathway of DKE 4 hydrolysis. 
A

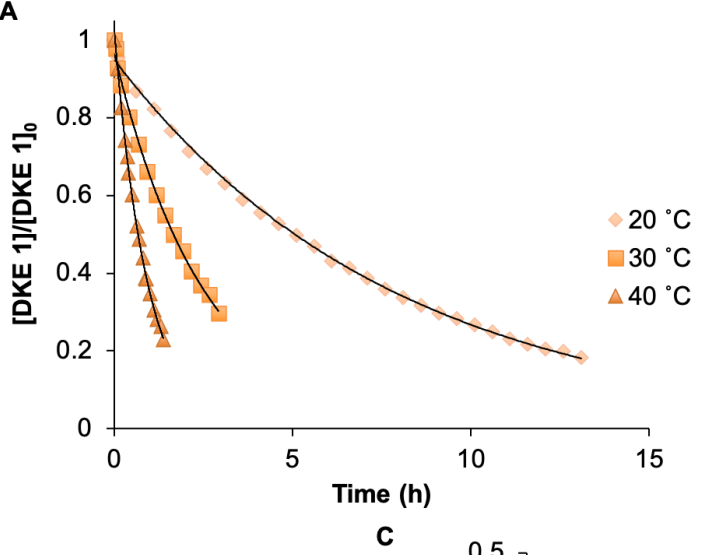

C
B

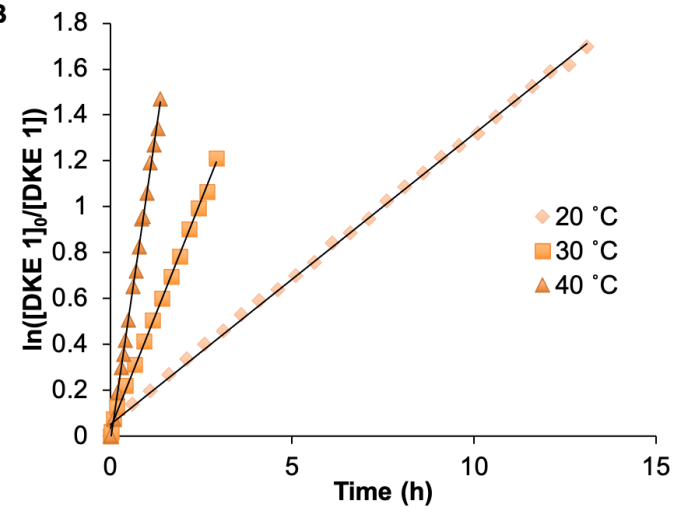

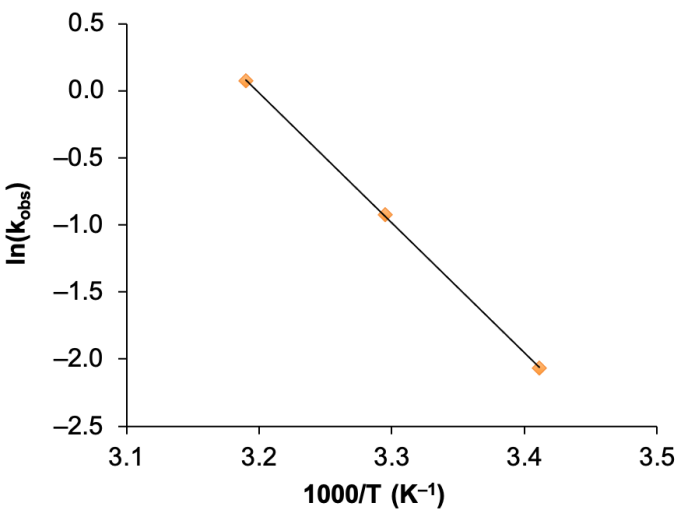

Figure S14. Hydrolysis kinetics of DKE 1 at 20,30 , and $40{ }^{\circ} \mathrm{C}$. 

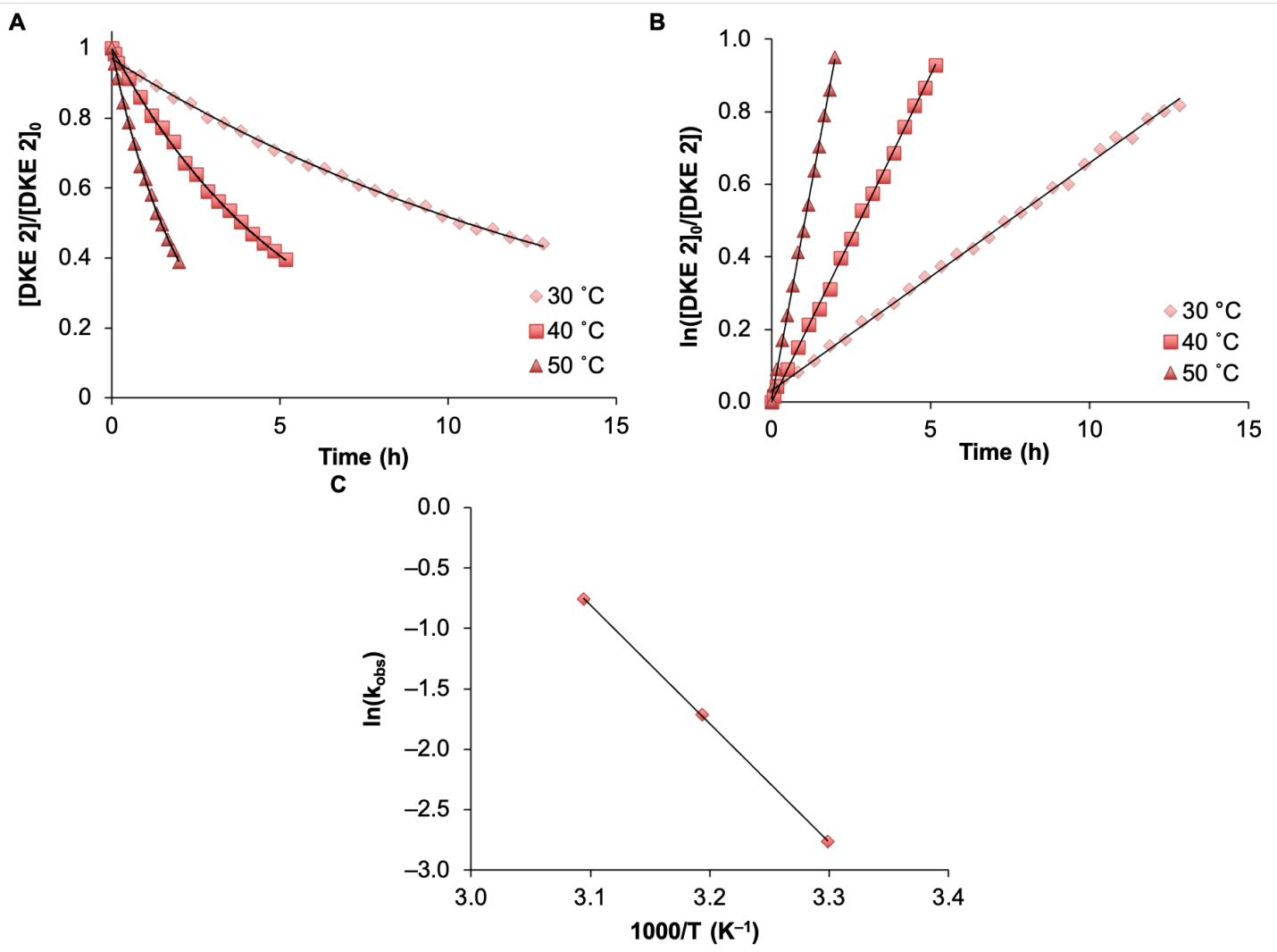

Figure S15. Hydrolysis kinetics of DKE 2 at 30,40 , and $50^{\circ} \mathrm{C}$. 
A

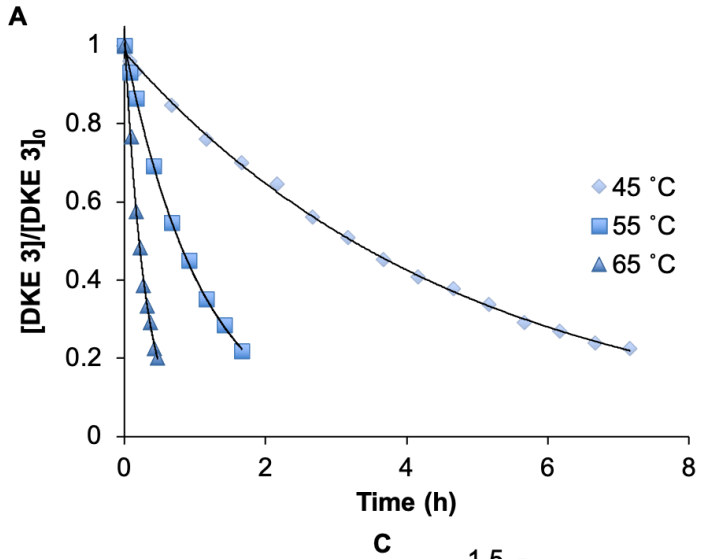

B

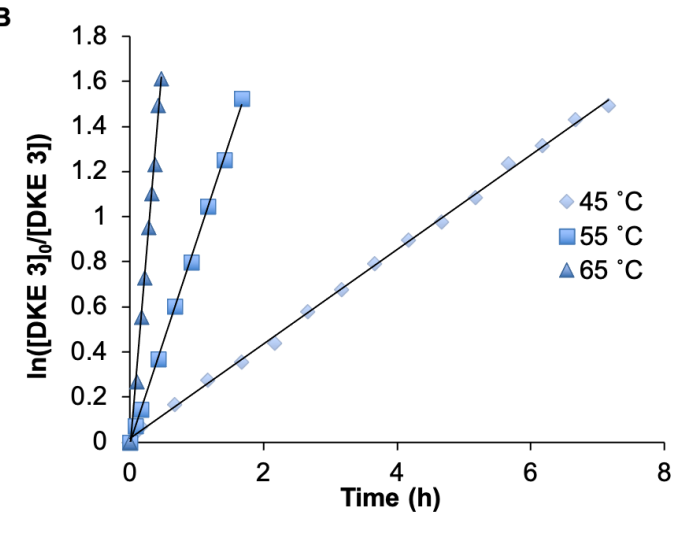

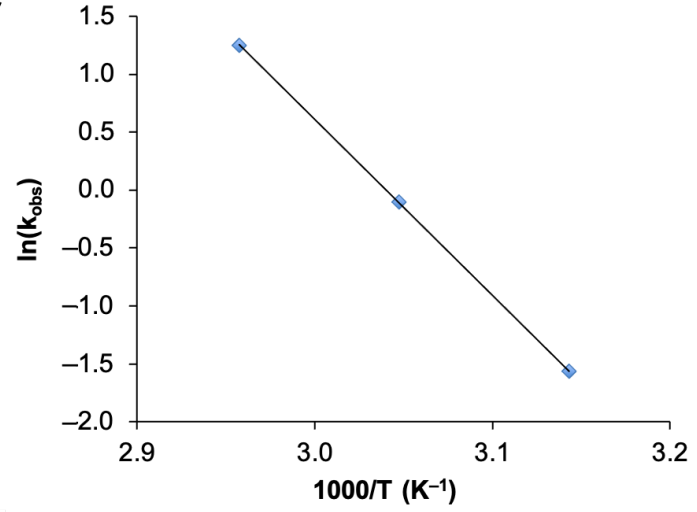

Figure S16. Hydrolysis kinetics of DKE 3 at 45,55 , and $65^{\circ} \mathrm{C}$. 

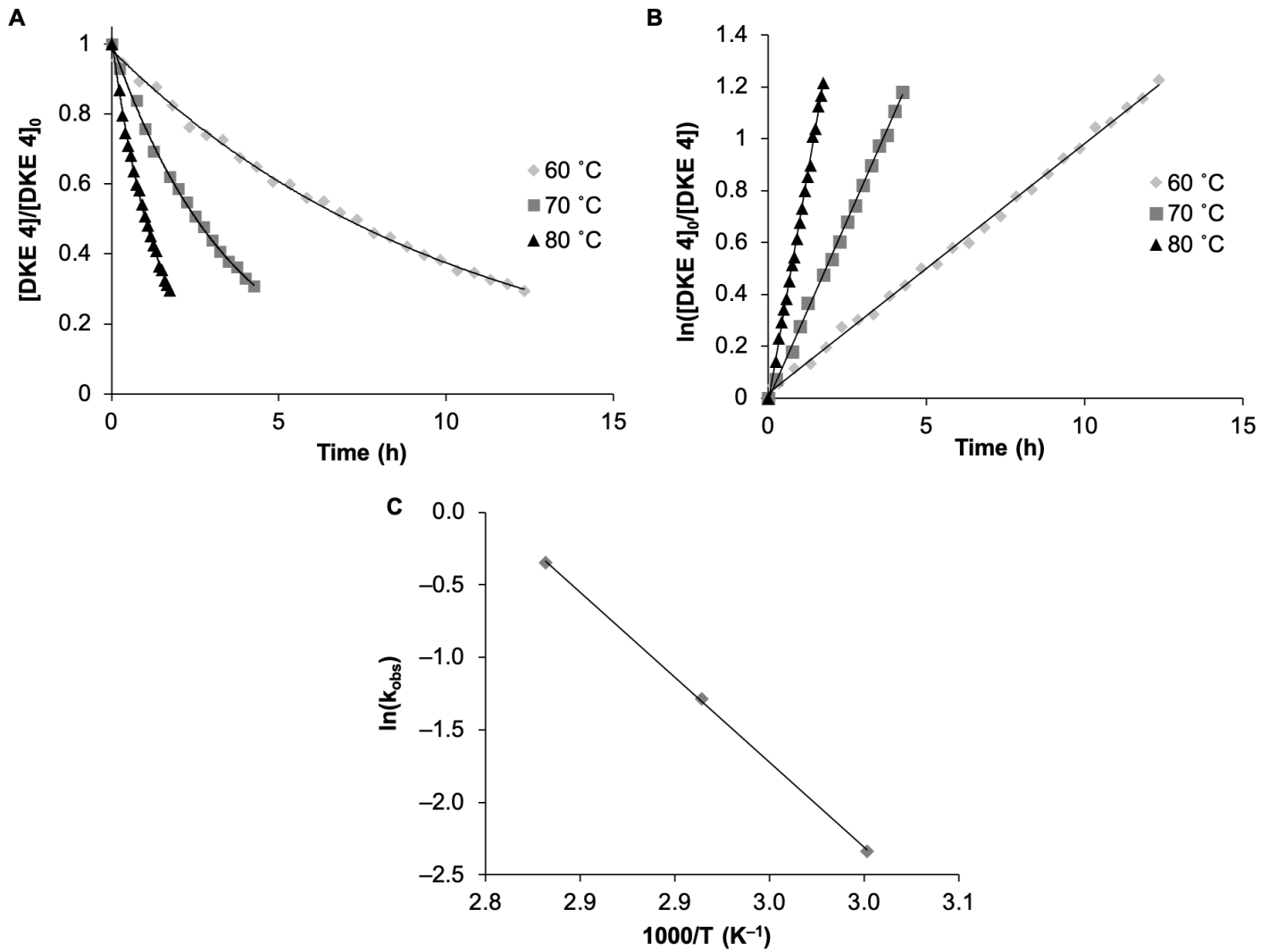

Figure S17. Hydrolysis kinetics of DKE 4 at 60,70 , and $80^{\circ} \mathrm{C}$. 


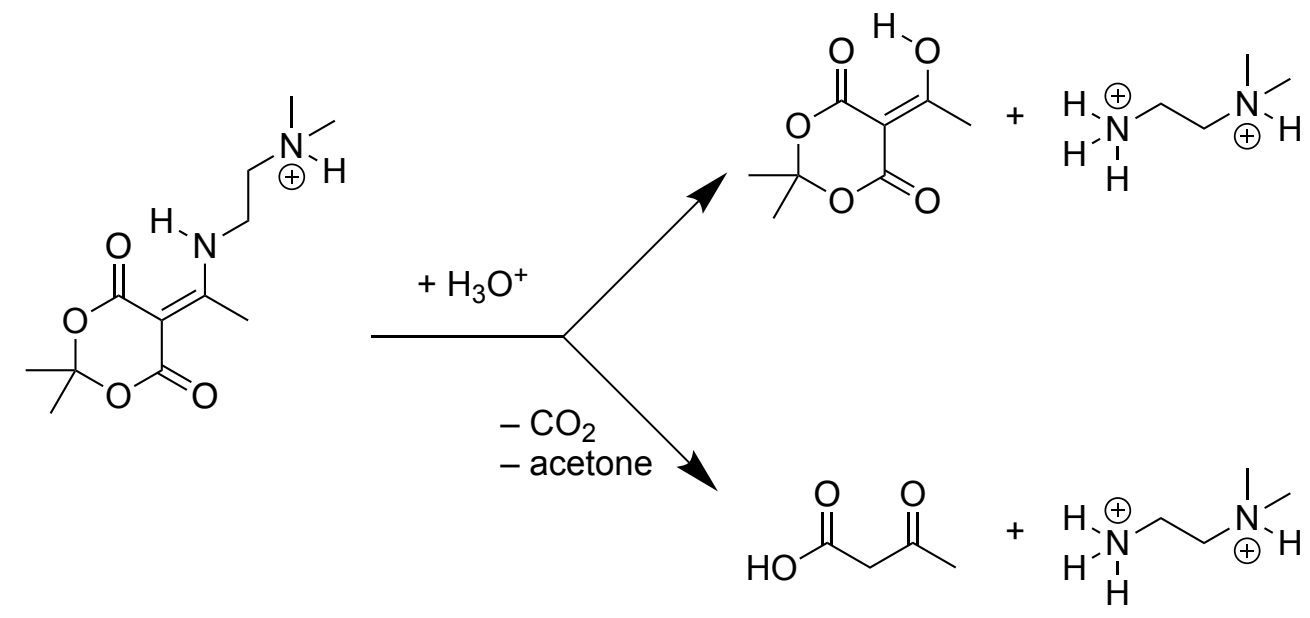

Figure S18. Competing pathways in the reactivity of DKE 3 at elevated temperature in strong acid, leading to an overestimation of the rate of hydrolysis when monitoring the rate of change in concentration of the starting material over time in small molecule kinetics studies. 

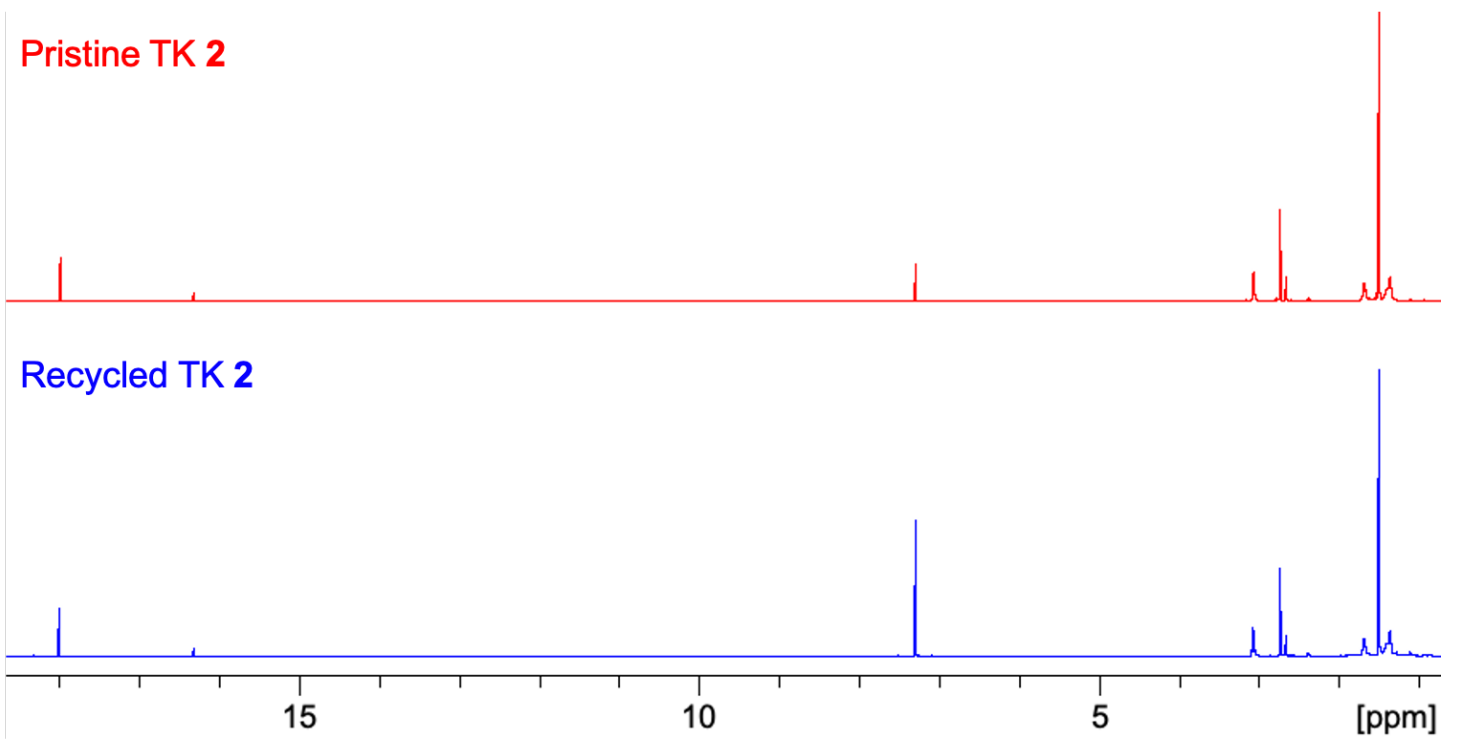

Figure S19. ${ }^{1} \mathrm{H}$ NMR of pristine and recycled TK 2 from PDK 2 that had been compounded with a blue dye prior to orthogonal mixed-PDK recycling with PDK 4. 


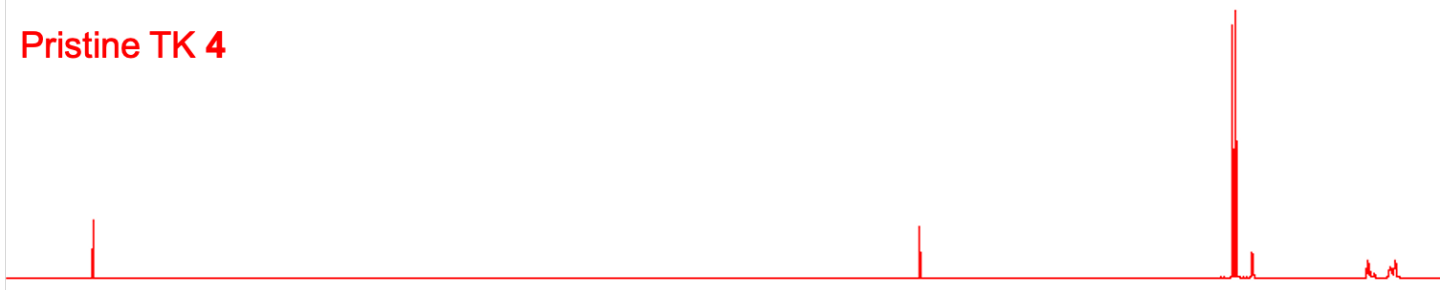

Recycled TK 4

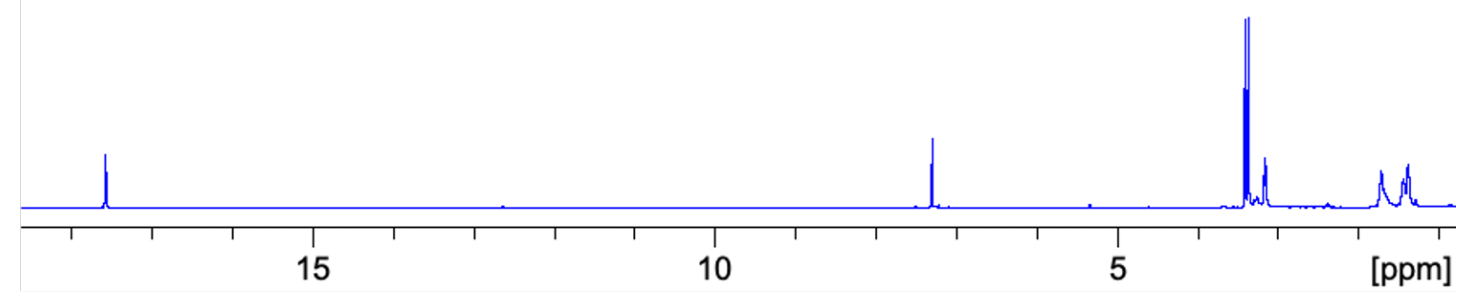

Figure S20. ${ }^{1} \mathrm{H}$ NMR of pristine and recycled TK 4 from PDK 4 that had been compounded with carbon black prior to orthogonal mixed-PDK recycling with PDK 2. 


\section{Pristine TK 1}

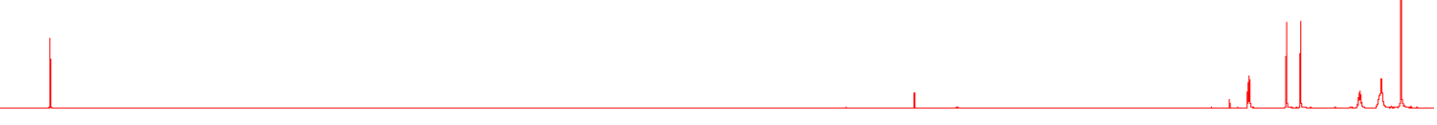

\section{Recycled TK 1}

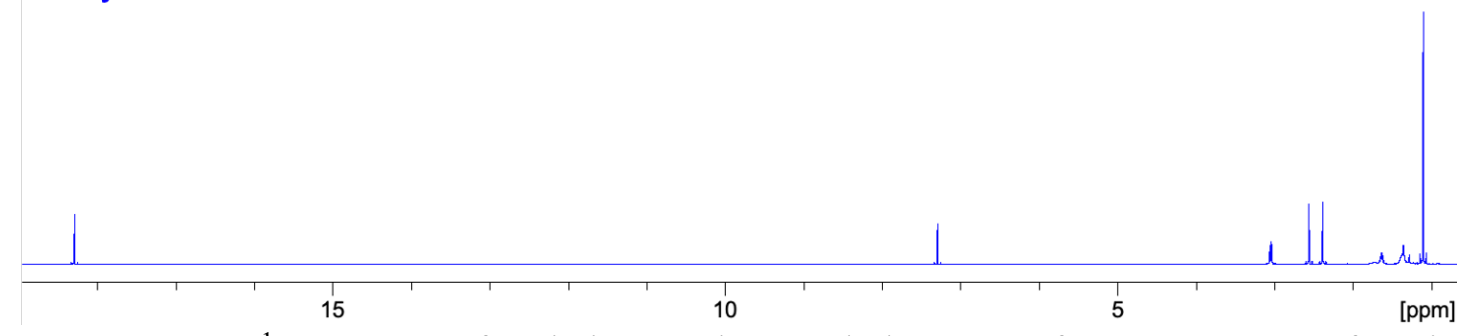

Figure S21. ${ }^{1} \mathrm{H}$ NMR of pristine and recycled TK 1 from PDK 1, after its selective depolymerization during mixed-material recycling with PDK 4, stainless steel, and glass. 

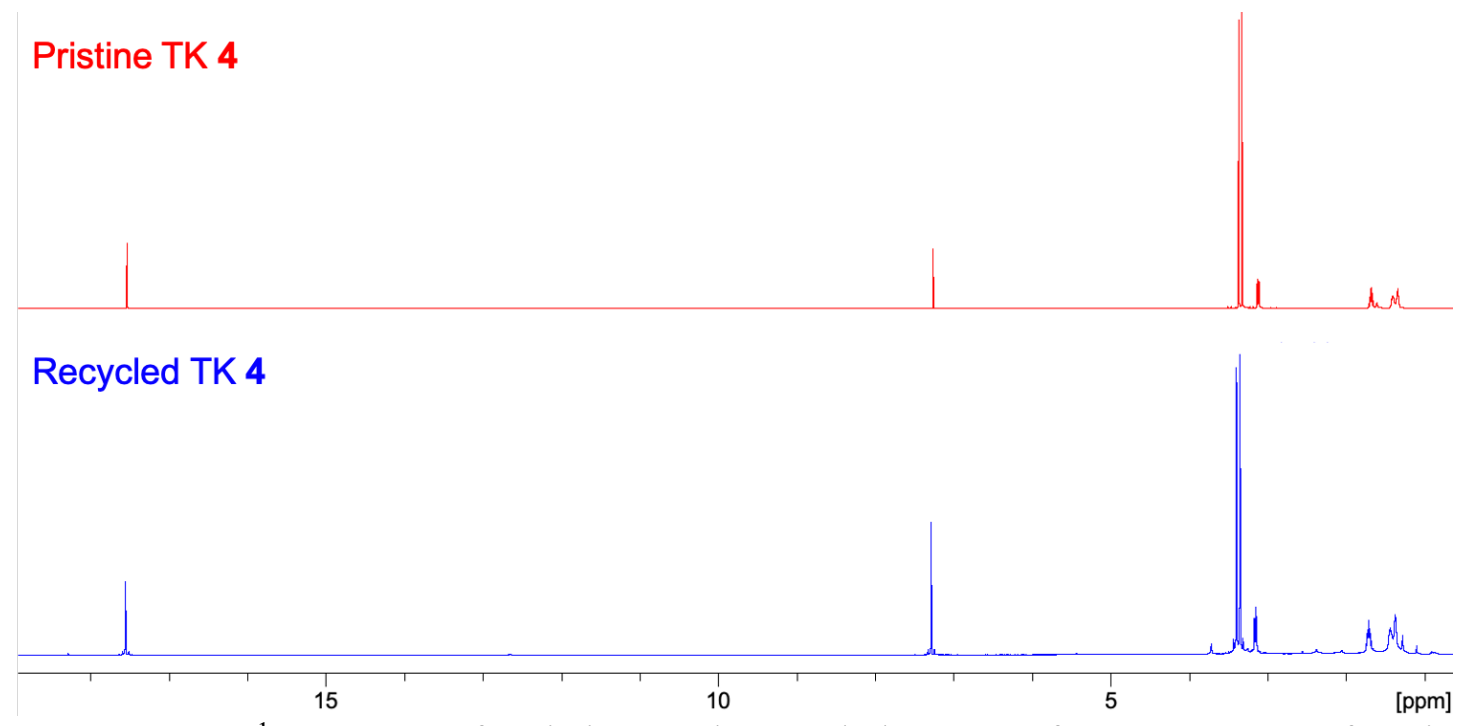

Figure S22. ${ }^{1} \mathrm{H}$ NMR of pristine and recycled TK 4 from PDK 4 , after its selective depolymerization during mixed-material recycling with PDK 1, stainless steel, and glass. 
Table S1.

Select $\mathrm{O}-\mathrm{H}$ bond distances extracted from X-ray crystallography data for TKs 1-4.

\begin{tabular}{lll} 
& \\
\hline
\end{tabular}




\section{Table S2.}

Crystal data and structure refinement for TK 1.

Identification code

Empirical formula

Formula weight

Temperature

Wavelength

Crystal system

Space group

Unit cell dimensions

Volume

Z

Density (calculated)

Absorption coefficient

$\mathrm{F}(000)$

Crystal size

Theta range for data collection

Index ranges

Reflections collected

Independent reflections

Completeness to theta $=25.930^{\circ}$

Absorption correction

Max. and min. transmission

Refinement method

Data / restraints / parameters

Goodness-of-fit on $\mathrm{F}^{2}$

Final $\mathrm{R}$ indices [I $>2 \operatorname{sigma}(\mathrm{I})]$

$\mathrm{R}$ indices (all data)

Extinction coefficient

Largest diff. peak and hole
TK 1

C26 H38 O6

446.56

$100(2) \mathrm{K}$

$0.7288 \AA$

Monoclinic

$\mathrm{P} 21 / \mathrm{n}$

$\mathrm{a}=7.3061(3) \AA$

$\mathrm{a}=90^{\circ}$.

$\mathrm{b}=8.7123(3) \AA$

$\mathrm{b}=98.5400(10)^{\circ}$.

$\mathrm{c}=18.5578(7) \AA$

$1168.16(8) \AA^{3}$

2

$1.270 \mathrm{Mg} / \mathrm{m}^{3}$

$0.093 \mathrm{~mm}^{-1}$

484

$0.200 \times 0.180 \times 0.100 \mathrm{~mm}^{3}$

2.276 to $31.386^{\circ}$.

$-10<=\mathrm{h}<=10,0<=\mathrm{k}<=12,0<=1<=26$

131132

$3575[\mathrm{R}(\mathrm{int})=0.0794]$

$100.0 \%$

Semi-empirical from equivalents

0.991 and 0.943

Full-matrix least-squares on $\mathrm{F}^{2}$

$3575 / 0 / 153$

1.082

$\mathrm{R} 1=0.0403, \mathrm{wR} 2=0.1125$

$\mathrm{R} 1=0.0447, \mathrm{wR} 2=0.1154$

$\mathrm{n} / \mathrm{a}$

0.486 and -0.220 e. $\AA^{-3}$ 


\section{Table S3.}

Crystal data and structure refinement for TK 2.

Identification code

Empirical formula

Formula weight

Temperature

Wavelength

Crystal system

Space group

Unit cell dimensions

Volume

Z

Density (calculated)

Absorption coefficient

$\mathrm{F}(000)$

Crystal size

Theta range for data collection

Index ranges

Reflections collected

Independent reflections

Completeness to theta $=25.930^{\circ}$

Absorption correction

Max. and min. transmission

Refinement method

Data / restraints / parameters

Goodness-of-fit on $\mathrm{F}^{2}$

Final $\mathrm{R}$ indices [I $>2 \operatorname{sigma}(\mathrm{I})]$

$\mathrm{R}$ indices (all data)

Extinction coefficient

Largest diff. peak and hole
TK 2

$\mathrm{C} 24 \mathrm{H} 34 \mathrm{O} 8$

450.51

$100(2) \mathrm{K}$

$0.7288 \AA$

Triclinic

P-1

$\mathrm{a}=7.0669(3) \AA$

$\mathrm{a}=113.8060(10)^{\circ}$.

$\mathrm{b}=9.7745(4) \AA$

$\mathrm{b}=103.456(2)^{\circ}$.

$\mathrm{c}=9.8331(4) \AA \quad \mathrm{g}=103.752(2)^{\circ}$.

560.83(4) $\AA^{3}$

1

$1.334 \mathrm{Mg} / \mathrm{m}^{3}$

$0.104 \mathrm{~mm}^{-1}$

242

$0.100 \times 0.060 \times 0.005 \mathrm{~mm}^{3}$

2.499 to $31.410^{\circ}$.

$-10<=\mathrm{h}<=10,-13<=\mathrm{k}<=13,-14<=\mathrm{l}<=14$

19224

$3423[\mathrm{R}(\mathrm{int})=0.0272]$

$100.0 \%$

Semi-empirical from equivalents

0.999 and 0.913

Full-matrix least-squares on $\mathrm{F}^{2}$

$3423 / 0 / 151$

1.058

$\mathrm{R} 1=0.0342, \mathrm{wR} 2=0.0972$

$\mathrm{R} 1=0.0381, \mathrm{wR} 2=0.1007$

$\mathrm{n} / \mathrm{a}$

0.419 and -0.221 e. $\AA^{-3}$ 


\section{Table S4.}

Crystal data and structure refinement for TK 3.

Identification code

Empirical formula

Formula weight

Temperature

Wavelength

Crystal system

Space group

Unit cell dimensions

Volume

Z

Density (calculated)

Absorption coefficient

$\mathrm{F}(000)$

Crystal size

Theta range for data collection

Index ranges

Reflections collected

Independent reflections

Completeness to theta $=25.930^{\circ}$

Absorption correction

Max. and min. transmission

Refinement method

Data / restraints / parameters

Goodness-of-fit on $\mathrm{F}^{2}$

Final $\mathrm{R}$ indices $[\mathrm{I}>2 \operatorname{sigma}(\mathrm{I})]$

$\mathrm{R}$ indices (all data)

Extinction coefficient

Largest diff. peak and hole
TK 3

C22 H30 O10

454.46

100(2) K

$0.7288 \AA$

Triclinic

P-1

$$
\begin{array}{ll}
\mathrm{a}=5.1711(3) \AA & \mathrm{a}=78.101(2)^{\circ} . \\
\mathrm{b}=7.1213(4) \AA & \mathrm{b}=81.767(2)^{\circ} . \\
\mathrm{c}=16.2442(10) \AA & \mathrm{g}=69.228(2)^{\circ} .
\end{array}
$$$$
\text { 545.68(6) } \AA^{3}
$$

1

$1.383 \mathrm{Mg} / \mathrm{m}^{3}$

$0.114 \mathrm{~mm}^{-1}$

242

$0.300 \times 0.160 \times 0.005 \mathrm{~mm}^{3}$

2.636 to $31.438^{\circ}$.

$-7<=\mathrm{h}<=7,-9<=\mathrm{k}<=10,0<=\mathrm{l}<=23$

20410

$3339[\mathrm{R}(\mathrm{int})=0.0421]$

$99.3 \%$

Semi-empirical from equivalents

0.999 and 0.852

Full-matrix least-squares on $\mathrm{F}^{2}$

3339 / 0 / 152

1.106

$\mathrm{R} 1=0.0356, \mathrm{wR} 2=0.0968$

$\mathrm{R} 1=0.0396, \mathrm{wR} 2=0.0992$

$\mathrm{n} / \mathrm{a}$

0.280 and -0.223 e. $\AA^{-3}$ 


\section{Table S5.}

Crystal data and structure refinement for TK 4.

Identification code

Empirical formula

Formula weight

Temperature

Wavelength

Crystal system

Space group

Unit cell dimensions

Volume

Z

Density (calculated)

Absorption coefficient

$\mathrm{F}(000)$

Crystal size

Theta range for data collection

Index ranges

Reflections collected

Independent reflections

Completeness to theta $=25.930^{\circ}$

Absorption correction

Max. and min. transmission

Refinement method

Data / restraints / parameters

Goodness-of-fit on $\mathrm{F}^{2}$

Final $\mathrm{R}$ indices [I $>2 \operatorname{sigma}(\mathrm{I})]$

$\mathrm{R}$ indices (all data)

Extinction coefficient

Largest diff. peak and hole
TK 4

C22 H30 N4 O8

478.50

100(2) K

$0.7288 \AA$

Monoclinic

$\mathrm{P} 21 / \mathrm{n}$

$\mathrm{a}=4.0129(2) \AA$

$\mathrm{b}=7.9565(3) \AA$

$\mathrm{c}=34.4436(14) \AA$

1098.93(8) $\AA^{3}$

2

$1.446 \mathrm{Mg} / \mathrm{m}^{3}$

$0.116 \mathrm{~mm}^{-1}$

508

$0.400 \times 0.020 \times 0.010 \mathrm{~mm}^{3}$

2.694 to $29.114^{\circ}$.

$-5<=\mathrm{h}<=5,0<=\mathrm{k}<=10,0<=\mathrm{l}<=45$

22549

$2746[\mathrm{R}(\mathrm{int})=0.0777]$

$99.6 \%$

Semi-empirical from equivalents

0.999 and 0.376

Full-matrix least-squares on $\mathrm{F}^{2}$

$2746 / 0$ / 161

1.087

$\mathrm{R} 1=0.0511, \mathrm{wR} 2=0.1362$

$\mathrm{R} 1=0.0536, \mathrm{wR} 2=0.1395$

$\mathrm{n} / \mathrm{a}$

0.569 and -0.343 e. $\AA^{-3}$ 


\section{Table S6.}

Crystal data and structure refinement for DKE 3.

Identification code

Empirical formula

Formula weight

Temperature

Wavelength

Crystal system

Space group

Unit cell dimensions

Volume

Z

Density (calculated)

Absorption coefficient

$\mathrm{F}(000)$

Crystal size

Theta range for data collection

Index ranges

Reflections collected

Independent reflections

Completeness to theta $=25.930^{\circ}$

Absorption correction

Max. and min. transmission

Refinement method

Data / restraints / parameters

Goodness-of-fit on $\mathrm{F}^{2}$

Final $\mathrm{R}$ indices $[\mathrm{I}>2 \operatorname{sigma}(\mathrm{I})]$

$\mathrm{R}$ indices (all data)

Extinction coefficient

Largest diff. peak and hole
DKE 3

C12 H20 N2 O4

256.30

$100(2) \mathrm{K}$

$0.7288 \AA$

Monoclinic

$\mathrm{P} 21 / \mathrm{c}$

$\mathrm{a}=22.2450(10) \AA$

$\mathrm{b}=12.2739(6) \AA$

$\mathrm{c}=10.0926(5) \AA$

2740.5(2) $\AA^{3}$

8

$1.242 \mathrm{Mg} / \mathrm{m}^{3}$

$0.098 \mathrm{~mm}^{-1}$

1104

$0.050 \times 0.020 \times 0.005 \mathrm{~mm}^{3}$

2.542 to $26.131^{\circ}$.

$-26<=\mathrm{h}<=26,-14<=\mathrm{k}<=14,-12<=\mathrm{l}<=12$

60504

$5034[\mathrm{R}(\mathrm{int})=0.0743]$

$99.8 \%$

Semi-empirical from equivalents

1.000 and 0.860

Full-matrix least-squares on $\mathrm{F}^{2}$

5034 / 62 / 356

1.067

$\mathrm{R} 1=0.0447, \mathrm{wR} 2=0.1167$

$\mathrm{R} 1=0.0549, \mathrm{wR} 2=0.1232$

$\mathrm{n} / \mathrm{a}$

0.343 and -0.311 e. $\AA^{-3}$

$$
\begin{aligned}
& \mathrm{a}=90^{\circ} . \\
& \mathrm{b}=95.997(2)^{\circ} . \\
& \mathrm{g}=90^{\circ} .
\end{aligned}
$$




\section{Table S7.}

Summary of thermomechanical characterization data for PDKs 1, 2 and $\mathbf{4}$ by dynamic mechanical analysis (DMA).

\begin{tabular}{lcc} 
& Storage Modulus $(\mathrm{GPa})$ & Elastic Modulus $(\mathrm{MPa})$ \\
\hline PDK 1 & 1.81 & 5.33 \\
PDK 2 & 2.03 & 5.67 \\
PDK 4 & 2.12 & 6.86
\end{tabular}




\section{Table S8.}

Calculated concentration-corrected Quasi-RRHO free energies for DKEs 1-4.

$$
\boldsymbol{G} \text { (Ha) }
$$

\begin{tabular}{|c|c|c|c|c|c|}
\hline & & DKE 1 & DKE 2 & DKE 3 & DKE 4 \\
\hline \multirow{2}{*}{ Step 1} & DKE & -807.9513 & -843.91132 & -879.86946 & -914.16442 \\
\hline & $\mathrm{H}_{3} \mathrm{O}^{+}$ & -76.427354 & -76.828115 & -76.828115 & -76.828115 \\
\hline \multirow{2}{*}{ Step 2} & DKE & -808.37459 & -844.32997 & -880.27989 & -914.57758 \\
\hline & $\mathrm{H}_{2} \mathrm{O}$ & -76.427354 & -76.427354 & -76.427354 & -76.427354 \\
\hline Step 3 & DKE & -884.77008 & -920.7224 & -956.66857 & -990.96997 \\
\hline Step 4 & DKE & -884.78517 & -920.74423 & -956.66857 & -990.99176 \\
\hline Step 5 & DKE & -884.77007 & -920.72422 & -956.6725 & -990.97172 \\
\hline \multirow{2}{*}{ Step 6} & $\mathrm{TK}$ & -614.95734 & -650.91452 & -686.87091 & -721.17064 \\
\hline & Amine & -269.85009 & -269.85009 & -269.85009 & -269.85009 \\
\hline
\end{tabular}


Table S9.

Eyring analyses for the hydrolysis of DKEs $\mathbf{1}-\mathbf{4}$ in $5.0 \mathrm{M} \mathrm{DCl}$ in $\mathrm{D}_{2} \mathrm{O}$.

\begin{tabular}{|c|c|c|c|}
\hline & $\begin{array}{c}\Delta H \\
\left(\mathrm{~kJ} \mathrm{~mol}^{-1}\right)\end{array}$ & $\begin{array}{c}\Delta S \\
\left(\mathrm{~J} \mathrm{~mol}^{-1} K^{-1}\right)\end{array}$ & $\begin{array}{c}\Delta G \text { at } 298 \mathrm{~K} \\
\left(\mathrm{~kJ} \mathrm{~mol}^{-1}\right)\end{array}$ \\
\hline DKE 1 & 77.9 & 3.9 & 76.8 \\
\hline DKE 2 & 79.2 & -6.7 & 81.2 \\
\hline DKE 3 & 123.2 & 128.9 & 84.8 \\
\hline DKE 4 & 94.4 & 18.2 & 89.0 \\
\hline
\end{tabular}




\section{References:}

43. X. Xu, X. Xu, P. Y. Zavalij, M. P. Doyle, Dirhodium(II)-catalyzed formal [3+2+1]-annulation of azomethine imines with two molecules of a diazo ketone. Chem. Commun. 49, 2762-2764 (2013).

44. S. Gelin, B. Chantegrel, C. Deshayes, Synthesis of some 4-carboxy-3- and 5-(2hydroxyalkyl)pyrazole lactone derivatives. J. Heterocycl. Chem. 19, 989-991 (1982).

45. J. H. Sahner, H. Sucipto, S. C. Wenzel, M. Groh, R. W. Hartmann, R. Mueller, Advanced Mutasynthesis Studies on the Natural $\alpha$-Pyrone Antibiotic Myxopyronin from Myxococcus fulvus. ChemBioChem. 16, 946-953 (2015).

46. J. Figueiredo, J. L. Serrano, M. Soares, S. Ferreira, F. C. Domingues, P. Almeida, S. Silvestre, 5-Hydrazinylethylidenepyrimidines effective against multidrug-resistant Acinetobacter baumannii: Synthesis and in vitro biological evaluation of antibacterial, radical scavenging and cytotoxic activities. Eur. J. Pharm. Sci. 137, 104964 (2019).

47. SAINT Software for CCD Diffractometers, Bruker AXS Inc., Madison, WI. (2014).

48. G. M. Sheldrick, TWINABS, Bruker Analytical X-ray Systems, Inc., Madison, WI. (2000).

49. G. M. Sheldrick, SADABS, Bruker Analytical X-ray Systems, Inc., Madison, WI. (2000).

50. G. M. Sheldrick, A short history of SHELX. Acta Crystallogr. A. 64, 112-122 (2008).

51. G. M. Sheldrick, Crystal structure refinement with SHELXL. Acta Crystallogr. Sect. C Struct. Chem. 71, 3-8 (2015).

52. M. J. Frisch, G. W. Trucks, H. B. Schlegel, G. E. Scuseria, M. A. Robb, J. R. Cheeseman, G. Scalmani, V. Barone, G. A. Petersson, H. Nakatsuji, X. Li, M. Caricato, A. V. Marenich, J. Bloino, B. G. Janesko, R. Gomperts, B. Mennucci, H. P. Hratchian, J. V. Ortiz, A. F. Izmaylov, J. L. Sonnenberg, D. Williams-Young, F. Ding, F. Lipparini, F. Egidi, J. Goings, B. Peng, A. Petrone, T. Henderson, D. Ranasinghe, V. G. Zakrzewski, J. Gao, N. Rega, G. Zheng, W. Liang, M. Hada, M. Ehara, K. Toyota, R. Fukuda, J. Hasegawa, M. Ishida, T. Nakajima, Y. Honda, O. Kitao, H. Nakai, T. Vreven, K. Throssell, J. A. Montgomery, Jr., J. E. Peralta, F. Ogliaro, M. J. Bearpark, J. J. Heyd, E. N. Brothers, K. N. Kudin, V. N. Staroverov, T. A. Keith, R. Kobayashi, J. Normand, K. Raghavachari, A. P. Rendell, J. C. Burant, S. S. Iyengar, J. Tomasi, M. Cossi, J.M. Millam, M. Klene, C. Adamo, R. Cammi, J. W. Ochterski, R. L. Martin, K. Morokuma, O. Farkas, J. B. Foresman, and D. J. Fox, Gaussian 16, Revision A.03, Gaussian, Inc., Wallingford CT, (2016).

53. A. V. Marenich, C. J. Cramer, D. G. Truhlar, Universal solvation model based on solute electron density and on a continuum model of the solvent defined by the bulk dielectric constant and atomic surface tensions. J. Phys. Chem. B. 113, 6378-6396 (2009).

54. S. Grimme, Supramolecular Binding Thermodynamics by Dispersion-Corrected Density Functional Theory. Chem. Eur. J. 18, 9955-9964 (2012).

55. H. Eyring, Statistical Mechanical Treatment of the Activated Complex in Chemical Reactions. J. Chem. Phys. 3, 107-115 (1935). 